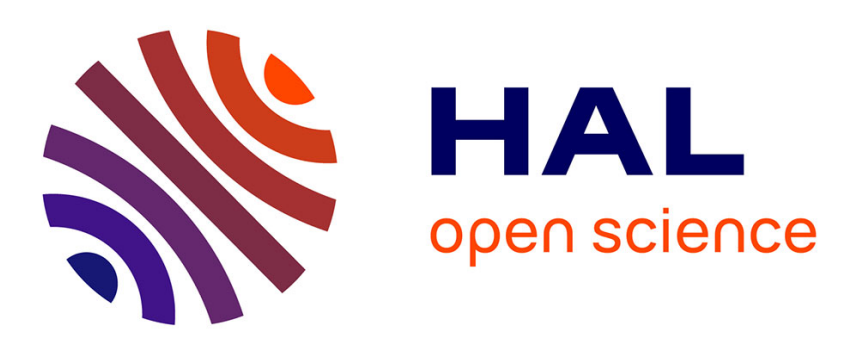

\title{
Who Lives Where in the City? Amenities, Commuting and Income Sorting
}

\author{
Carl Gaigné, Hans R A Koster, Fabien Moizeau, Jacques-François Thisse
}

\section{To cite this version:}

Carl Gaigné, Hans R A Koster, Fabien Moizeau, Jacques-François Thisse. Who Lives Where in the City? Amenities, Commuting and Income Sorting. Journal of Urban Economics, 2022, 128, pp.103394. 10.1016/j.jue.2021.103394 . halshs-03379541

\section{HAL Id: halshs-03379541 https://shs.hal.science/halshs-03379541}

Submitted on 15 Oct 2021

HAL is a multi-disciplinary open access archive for the deposit and dissemination of scientific research documents, whether they are published or not. The documents may come from teaching and research institutions in France or abroad, or from public or private research centers.
L'archive ouverte pluridisciplinaire HAL, est destinée au dépôt et à la diffusion de documents scientifiques de niveau recherche, publiés ou non, émanant des établissements d'enseignement et de recherche français ou étrangers, des laboratoires publics ou privés. 


\title{
Who Lives Where in the City? Amenities, Commuting and Income Sorting*
}

\author{
Carl Gaigné ${ }^{\dagger} \quad$ Hans R.A. Koster ${ }^{\ddagger} \quad$ Fabien Moizeau ${ }^{\S}$ \\ Jacques-François Thisse
}

August 30, 2021

\begin{abstract}
We develop a new model of a "featureful" city in which locations are differentiated by two attributes, that is, the distance to employment centers and the accessibility to given amenities. The residential equilibrium involves the spatial separation of households sharing similar incomes. Under Stone-Geary preferences, amenities and commuting are subsumed into a location-quality index. Hence, the assignment of households to locations becomes one-dimensional. Since residential choices are driven by the location-quality index, the income mapping may be fully characterized. Using a rich micro-dataset on the Netherlands, we show that household income sorting is indeed driven by amenities and commuting times.
\end{abstract}

Keywords: cities, social stratification, income, amenities, commuting

JEL classification: R14, R23, R53, Z13.

${ }^{*}$ We are grateful to K. Behrens and two referees for a wealth of useful comments. We also thank N. BaumSnow, J. Brinkman, P.-P. Combes, M.S. Delgado, R.J.G.M. Florax (†), M. Fujita, J.V. Henderson, K. Matsuyama, F. Mayneries, M. Miyake, Y. Murata, H.G. Overman, P. Picard, G. Ponzetto, S. Riou, F. RobertNicoud, S.L. Ross, K. Schmidheiny, H. Takatsuka, P. Ushchev, and J.N. van Ommeren for insightful suggestions. We further thank participants to seminars at the LSE, the Higher School of Economics in Moscow, Purdue, AMSE, the Workshop on Public Policies, Cities and Regions, the Utrecht School of Economics, Laval University, the Université de Genève, the summer school "Sustainable Cities", the 2018 SMU Conference on Urban and Regional Economics, 64th AFSE Congress, 32d EEA Congress, the Federal Reserve Bank in Philadelphia, and the 7th North American Meeting of the Urban Economics Association, for their comments. The authors acknowledge, respectively, financial supports from the Agence Nationale de la Recherche (ANR-12-INEG-0002), the Institut Universitaire de France, and the HSE University Basic Research Program.

${ }^{\dagger}$ INRA, UMR1302, SMART-LERECO Rennes (France) and CREATE, Laval University, Quebec (Canada).

${ }_{\ddagger}^{\ddagger}$ Department of Spatial Economics, Vrije Universiteit Amsterdam (The Netherlands), HSE University (Russia), Tinbergen Institute (The Netherlands) and CEPR.

$\S$ CREM (Condorcet Center), Université de Rennes 1.

^CORE-UCLouvain (Belgium), HSE University (Russia) and CEPR. 


\section{Introduction}

Residential segregation by income is a prominent and growing feature of many metropolitan areas. While residential segregation generates negative and persistent effects on economic development and social cohesion, it both reflects and reinforces interpersonal and social inequalities. For these reasons, we find it important to study the spatial sorting of heterogeneous consumers. We also believe that such an effort is warranted if policy actions against spatial segregation are taken to favor more social cohesion.

The canonical monocentric city model leads to a fairly extreme prediction: households are sorted by increasing income order as the distance to the central business district rises. This result contradicts empirical evidence (Glaeser et al., 2008; Rosenthal and Ross, 2015). One missing key explanation is the existence of amenity endowments, such as historic buildings and architecture, scenic landscapes, river and sea proximity. That such amenities matter in residential choices has been well documented (Brueckner et al., 1999; Glaeser et al., 2001; Koster and Rouwendal, 2017; Lee and Lin, 2018; Cuberes et al., 2019). Other facilities that appeal to people, such as restaurants and shops, are often located together with households (Glaeser et al., 2001; Couture, 2016; Hoelzlein, 2020). Such endogenous consumption amenities are ignored in this paper because they are likely to be the consequence and not the cause of residential choices, and thus the result of spatial income sorting.

This paper proposes a new approach that combines housing consumption and heterogeneity in incomes and locations. To be precise, we propose a new approach in which cities are "featureful" in that locations are distinguished by two vertically differentiated attributes, that is, commuting costs and the accessibility of given and dispersed amenities. While the demand for amenities has a tendency to rise with income, high-income commuters bear higher costs than low-income commuters. Our aim is then to study how local amenity endowments and commuting costs interact to determine the spatial sorting of income-heterogeneous households. To check the relevance of our approach, we estimate the so-obtained income mapping by using rich datasets from the Netherlands.

The study of income sorting when locations are differentiated by more than one attribute brings about new and difficult issues. The determination of a residential equilibrium has the nature of a matching problem between landlords and households in which land at specific locations is differentiated by two characteristics and households by one characteristic. Multidimensional matching problems typically assume quasi-linear preferences and indivisible choices (Chiappori, 2017). By contrast, each household chooses a single location but her housing consumption is variable and income-dependent. The bid-rent approach offers a way to square the circle, as this function gives the maximum price a household is willing to pay for one unit of housing at 
each location at a given utility level when housing consumption is variable. This function thus represents the Pareto frontier between a household and the owner of land at each location. The key point is then to find conditions for the existence of a unique positive assortative matching between households and landowners.

What are our main contributions? First, we model space as a topological network. Attempts made to move away from the standard one-dimensional framework of urban economics typically use the Euclidean plane (see, e.g. Lucas and Rossi-Hansberg, 2002). Such an approach neglects one the most fundamental features of a space-economy, that is, the shape and density of its transportation networks. Residences and jobs are thus distributed over the topological network.

Second, recent surveys, such as Duranton and Puga (2015) and Behrens and Robert-Nicoud (2015), express some skepticism about the ability of the bid-rent approach to deal with a continuum of heterogeneous households to be mapped on a continuum of locations. We first demonstrate that the bid-rent approach is still applicable to such settings. We then show that the interaction between amenities and commuting gives rise to turning points in the spatial income distribution. In other words, provided that amenities are distributed unevenly across space, a greater geographical distance between households does not necessarily implies a wider income gap.

Third, when commuting costs vary with income, characterizing the equilibrium income mapping requires non-homothetic preferences. Indeed, empirical evidence suggests that housing expenditure shares decline with income (Albouy et al., 2016). Furthermore, we show that in our setting homothetic preferences such as the Cobb-Douglas or the CES generate a continuum of equilibria. In this case, the standard approach is to select an equilibrium via stability. However, doing this is especially hard here because we work with a continuum of heterogeneous households and a continuum of locations (de Palma et al., 2019). We therefore prefer to use non-homothetic preferences. More specifically, we consider Stone-Geary preferences - but we could equally assume a generalized CES - and establish the following two main results. In the first place, there exists a unique spatial equilibrium. Households with different incomes always choose locations with different characteristics, but households sharing the same income may live in separated neighborhoods. Second, we find a location-quality index (LQI) whose behavior reflects the properties of the equilibrium income mapping. This index is built from the primitives of the model, as its value at any particular location is pinned down by the amenity endowments and households' commuting behavior. It is worth stressing that these results are not specific to Stone-Geary preferences. They hold true for other non-homothetic preferences; what changes is the functional form of the LQI.

The upshot is that households' bliss point is the global maximizer of the LQI over space, thus implying that the affluent flock to this location because they propose the highest bid. As 
one moves away from this location along all admissible directions, households are sorted by decreasing incomes until a local minimizer of the LQI is reached where poorest households are located. Around this minimizer, household income starts rising. Hence, households are more exposed to other social groups when the number of turning points of the LQI rises.

Fourth, our model is flexible enough to determine analytically the equilibrium outcome when incomes and the location-quality index are Fréchet-distributed. The so-obtained mapping between the location-quality index and income can be straightforwardly estimated using real-life data.

We then aim to empirically investigate whether the two main forces in our theoretical model - amenities and commuting costs - also drive income sorting in practice. We estimate a reduced-form version of the income mapping for the Netherlands. The choice of the Netherlands is motivated by (i) the availability of large disaggregated data sets and (ii) the fact that the public services that underpin social cohesion (e.g., education and health) are centrally financed and/or administered (Ritzen et al., 1997). First, we have access to rich microdata for more than 10 million households covering the years 2010 to 2015 on incomes, residential and job locations at the household level, commuting time, as well as land values and amenities at each location. Second, the central provision of education implies that the quality of schools, which is a major determinant of residential choices in many U.S. metropolitan areas, is much less of an issue in the Netherlands.

Dutch cities, which were established long ago, are known to offer a high quality of life, which is at least partly due to the presence of amenity endowments. Despite being a small country, the Netherlands hosts no less than 10 UNESCO world heritage sites, which is more than London and Paris together, while it hosts 61,908 listed buildings, which is more than three times the number of listed buildings in Greater London. With a population density of 407.4 pop/sq km, the Netherlands is almost as dense as the San Francisco Bay area whose area is similar to that of the Netherlands. By focusing on the whole country rather than a subset of metropolitan areas, we are able to capture relationships that are deployed within the entire Dutch urban system, from the large cities to the small villages.

It is well known that measuring the quality of amenities is a hard task. In this paper, we use a proxy suggested by Ahlfeldt (2013) and Saiz et al. (2018): the number of outside geocoded pictures taken by residents at a certain location. One key advantage of this LQI is that it lets consumers choose the aesthetic quality of buildings and locations they like best by "voting with their clicks" (Carlino and Saiz, 2019). This allows us to move beyond the approach of defining amenities implicitly, as in Ahlfeldt et al. (2015) and Albouy (2016). We show the robustness of our results by using a completely different proxy for amenities based on a hedonic price approach developed by Lee and Lin (2018), who use variation in housing prices. 
Since there is no proxy that perfectly captures the full amenity potential at a certain location, amenities are measured with error. Commuting time is also likely to be endogenous due to correlation with unobservable household characteristics and agglomeration economies - the latter being more prevalent in dense areas where commutes are shorter. We address the endogenous nature of amenities and commuting time in our econometric analysis in several ways, e.g., by obtaining Oster's (2019) bias-adjusted estimates and by constructing historic instruments. Since the strategy of using instruments based on historic data raises several issues, we devote considerable attention to the validity of such an identification strategy.

In a first step, we show that picture density is strongly correlated to the presence of amenity endowments, such as the density of historic listed buildings and the presence of water bodies. We then show that both amenities and commuting costs are important in determining the spatial income mapping. More specifically, we find that doubling the amenity level attracts households whose incomes are $2.6 \%$ higher, while doubling commuting time leads to households whose incomes are $15 \%$ lower. Hence, the impact of commuting time seems to be somewhat stronger than the impact of amenities. We also find a strong impact on land prices: doubling amenities leads to an increase in land prices of $13 \%$, which is sizable. We further estimate the key parameters of the model, which enables us to predict the LQI and income mapping at each location. Because of historic amenities that are prevalent in Dutch cities, we show that higher incomes are clustered in city centers.

Thus, our results unambiguously suggest that both amenities and commuting costs are important in determining the spatial income distribution. Nevertheless, commuting costs seem to be a more important driver of income sorting than amenities. Hence, our results support the emphasis put on commuting costs in standard models of urban economics. However, our results also show that the featureless model of urban economics is far too restrictive to explain the city's social structure. Yet, focusing on amenities only is unwarranted because commuting costs are too important to be disregarded. A relevant theory of the space-economy must account explicitly for both amenities and commuting costs.

Related literature. Suggesting the complexity of the issue, only a handful of papers in urban economics have studied the social stratification of cities. Beckmann (1969) was the first attempt to take into account a continuum of heterogeneous households in the monocentric city. Unfortunately, the assignment approach used by Beckmann was flawed (Montesano, 1972). Hartwick et al. (1976) and Fujita (1989) proposed a rigorous analysis of the residential pattern for a finite number of income classes of otherwise identical households in a featureless monocentric city.

Our work is related to two different strands of literature. First, there is a huge number 
of contributions on the sorting of heterogeneous households across jurisdictions that supply local public goods (see, e.g., Epple and Nechyba, 2004, for a survey). This literature relies on a particular geography in which jurisdictions are small enough for commuting within jurisdictions to be costless while jurisdictions are far enough for households to consume only public goods provided in their own jurisdictions. The attempt made by Epple et al. (2010) shows how difficult it is to introduce commuting in those models. Interestingly, Gravel and Oddou (2014) have obtained a necessary condition for perfect income sorting across jurisdictions: the Marshallian demand for the public good must be a monotone function of the price index of housing and a tradable consumption good. To obtain this necessary condition, Gravel and Oddou assume that households's preferences are separable between public goods and private goods, very much like us, and homothetic between consumption goods and housing, unlike us. We do not use their preferences because they are akin to homothetic preferences and would generate a continuum of equilibria in our set-up. What is more, unlike these authors, we focus on the trade-off between amenities, commuting and land in a setting that involves a continuum of locations. Even though perfect sorting may emerge in our set-up, there is no contradiction between results because the two analytical frameworks are too different for the results to be directly comparable.

Second, quantitative spatial models are also related to us because they involve amenities and commuting (Ahlfeldt et al., 2015; Diamond, 2016; Monte et al., 2018; Tsivanidis, 2019; Couture et al., 2019). Their main purpose is to calibrate the impact of various shocks or policies, such as new transportation infrastructure, on the spatial equilibrium. Moreover, these models do not provide properties of the spatial equilibrium because doing so is often hard under a finite location set. We differ from this literature in that our primary aim is to characterize the residential equilibrium in a setting with a continuum of locations distributed along a transportation network. Stated differently, our model is in the tradition of urban economics à la Alonso-Fujita.

The remainder of the paper is organized as follows. We provide a detailed description of our model in Section 2. In Section 3, we show how the bid-rent function may be used to determine the social stratification of the city. In Section 4, we study the properties of the residential pattern for preferences that generate a LQI. Since the equilibrium is undetermined under homothetic preferences, we illustrate our results for Stone-Geary preferences. Section 5 presents data, the identification strategy and reduced-form empirical results on the impact of amenities and commuting time on income sorting. We further provide a simple strategy to obtain structural parameters of the income mapping in order to be able to undertake counterfactual analyses. In Section 6, we summarize our main results and discuss the role of endogenous amenities. 


\section{The model}

\subsection{The spatial economy}

The economy involves a unit mass of income-heterogeneous households. A household's gross income is given by $\omega$ units of the numéraire, with $\omega \in[\underline{\omega}, \bar{\omega}]$ and $0<\underline{\omega} \leq \bar{\omega}$. The income c.d.f. $F(\omega)$ and the density $f(\omega)$ are continuous over $[\underline{\omega}, \bar{\omega}]$. We are agnostic about the reasons that explain inequality in earnings. ${ }^{1}$ The economy involves two normal consumption goods: (i) land $h$, which is a proxy for housing, and (ii) a homogeneous final consumption good $q$. Shipping the final good within the economy is costless, so that its price is the same across locations. This good is used as the numéraire.

Our spatial setting differs from the standard linear (sometimes planar) space used in urban economics. The map formed by streets, roads, highways, and railway junctions (in a city, region or country) is modeled by means of a topological network. A topological arc, denoted $a_{\tau}$, is the image in $\mathbb{R}^{2}$ of the interval $[0,1]$ by a continuous one-to-one mapping (Kuratowski, 1968). The endpoints of arcs are called vertices. Clearly, an arc contains a continuum of locations. A topological network $N=\cup_{\tau=1}^{T} a_{\tau}$ is defined as the union of a finite number of topological arcs that have a finite length. Here, $N$ is the location set. Households can travel on arcs in both directions. One unit of land is available at each location $x \in N$ and the network is supposed to be large enough for the total supply of land to accommodate the whole population of households.

The set $N$ is connected, that is, for any two points $x_{1}$ and $x_{2}$ belonging to $N$ there is at least one concatenation of arcs and subarcs that links these two points. The distance $d\left(x_{1}, x_{2}\right)$ between $x_{1}$ and $x_{2}$ is given by the length of the shortest path that connects these locations. Clearly, $d(\cdot)$ is a metric defined on $N$. We assume that vertices are not colinear, so that $(N, d)$ is not a one-dimensional metric space. An example of transportation networks similar to ours can be found in Allen and Arkolakis (2014). In what follows, we assume that functions are almost everywhere (a.e.) differentiable along each $\operatorname{arc}$ of the network $N$; at the vertices of $N$, differentiability is defined by the directional derivatives along the corresponding arcs.

\subsection{Consumption}

Household preferences are separable between amenities $b$, on the one hand, and the two private goods $(q, h)$, on the other:

$$
U(q, h ; b)=b \cdot u(q, h),
$$

\footnotetext{
${ }^{1}$ In Gaigné et al. (2020), we discuss how incomes can be determined from the interaction between individual skills and local productivity factors.
} 
where $q$ is the numéraire, $h$ is land consumption, $u$ is a well-behaved utility function. The function $b(x)>0$ captures the common attributes, such as those discussed in the introduction, that make location $x$ a more or less attractive place to live ${ }^{2}$ this function is continuously differentiable function over each arc of $N$ and may display flat portions $\left(b_{x}=0\right){ }^{3}$ Preferences (1) are used in a wide range of models where goods are vertically differentiated because they capture in a simple way the fundamental idea that high-income households are willing to pay more than low-income households to enjoy a given amenity. In other words, the single-crossing condition between incomes and amenities holds.

There is a finite number of employment locations $i \in N$ with $i=1, \ldots, n$. Each household works in a single employment location and earns the same gross income $\omega$ for all $i$. However, her income net of commuting costs changes with her residential location and workplace. Since there is ample evidence that the opportunity cost of time varies significantly when households are heterogeneous in incomes (Small, 2012; Koster and Koster, 2015), we assume that commuting costs are income-dependent. More specifically, we model commuting as an income loss, not as a utility loss. Ahlfeldt et al. (2015) and others show that the two approaches are equivalent when preferences are homothetic, but this ceases to hold under non-homothetic preferences.

We also assume that commuting costs lead to a household's net income given by $\omega t_{i}(x)$ where the function $t_{i}(x)$ decreases with the distance $d(x, i)$ between the residential location $x$ and the employment location $i$. Since the function $t_{i}$ is specific to the employment location, it may capture production fundamentals of this location. Hence, the commuting cost increases with income and distance as it amounts to $\omega\left(1-t_{i}(x)\right)$. We now show that the above specification displays enough flexibility to encompass the two types of income-dependent commuting costs used in urban economics. Let $\tau_{i}(x)$ be the commuting time between locations $x$ and $i$. We have (i) an iceberg cost when the effective labor supply of a worker living at $x$ decreases with the length of the commute, so that $t_{i}(x)=\left[\tau_{i}(x)\right]^{-\theta}$ where $\theta>0$ and (ii) an additive cost when the labor supply is perfectly inelastic while the net income is given by $t_{i}(x)=1-\theta \tau_{i}(x)$.

The household's budget constraint is as follows:

$$
\omega t(x)=q+R(x) h
$$

where $R(x)$ is the land rent at $x$. In line with the literature, we assume that the land rent is paid to absentee landowners (Fujita, 1989).

The function $t(x)$ used in (2) may be obtained from $t_{1}(x), \ldots, t_{n}(x)$ according to different specifications. First, when a household is free to choose where to work, she chooses the em-

\footnotetext{
${ }^{2}$ Note that $b(x)$ may also include local disamenities as long as $b(x)>0$.

${ }^{3}$ For any function $f(y, z)$, let $f_{y}$ (resp., $f_{y z}$ ) be the partial (cross-) derivative of $f$ with respect to $y$ (resp., $y$ and $z$ ).
} 
ployment centers that maximize her net income, that is, $t(x) \equiv \max _{i} t_{i}(x) \cdot{ }^{4}$ In this case, all households located at $x$ work in the same employment center. Second, a household knows her employment location $j$ before choosing her residential location $x$, so that $t(x)=t_{j}(x)$ holds for all $x \in N$. In this event, households sharing the same residential location $x$ may work in different working places but the model does not explain how households choose their workplace.

In the spirit of quantitative spatial models, one may want households to have idiosyncratic reasons for residing and working in different location pairs $(x, i)$. In this case, each location $x$ is characterized by the share of households who work at $i$ (Ahlfeldt et al., 2015; Monte et al., 2018; Thisse et al., 2021). This approach suits well empirical settings with a finite number of locations where a location represents a block or neighborhood occupied by households whose commuting behavior may be described by a gravity-like equation. Accounting for this type of heterogeneity requires here solving a matching problem between two multi-dimensional continuous spaces (income-and-taste on the consumer side, amenities-and-commuting in space), a problem that remains unsolved when housing consumption is endogenous. However, we do not see that as a major weakness of our approach. As we work with a continuum of locations, households separated by a positive but small distance may work in different employment locations, which meets the empirical requirement that people living close to each other need not work at the same place. In addition, we will see that households who share the same income need not live at the same place. Therefore, such households typically work in different employment locations. In sum, people may have the same income while working and living in different workplace-residence pairs.

In what follows, we are agnostic about how $t(x)$ is obtained. We assume only that $t(x)$ is a.e. differentiable over $N$ and such that $t$ is never constant on a subarc of $N$ because commuting costs increase with the distance $d(x, i)$.

Maximizing the utility $U$ of a $\omega$-household residing at $x$ and working at $e_{i}$ with respect to $q$ and $h$ subject to $(2)$ yields the numéraire demand

$$
q^{*}(x, \omega) \equiv q(R(x), \omega t(x))=\omega t(x)-R(x) h^{*}(R(x), \omega t(x))
$$

and the housing demand $h^{*}(x, \omega) \equiv h(R(x), \omega t(x))$, which is the unique solution to the equation:

$$
u_{h}\left[\omega t(x)-R(x) h^{*}, h^{*}\right]-R(x) u_{q}\left[\omega t(x)-R(x) h^{*}, h^{*}\right]=0 .
$$

\subsection{The residential equilibrium}

Given an amenity function $b(x)$, a given mass of heterogeneous households choose where to live, how much land and how much of the composite good to consume. For the moment, we

\footnotetext{
${ }^{4}$ Note that the function $t$ is not differentiable at the intersection points between any two functions $t_{i}$ and $t_{j}$. Since we assume that $t$ is never flat over a positive measure set, $t$ is a.e. differentiable.
} 
assume that households who reside at $x$ have the same income $\omega$. In other words, there is an income mapping $\omega(x)$ from $N$ to $[\underline{\omega}, \bar{\omega}]$ that specifies which $\omega$-households are located at $x$. In other words, households endowed with different incomes reside in different locations. We will show in Section 4 that this property holds true for different non-homothetic preferences.

By contrast, the $\omega$-households may be distributed over several locations, so that $\omega(x)$ need not be monotone. Let $s(x, \omega) \in[0,1]$ is the share of the $\omega$-households who reside at $x$. The land market clearing condition holds if the mapping $\omega(x)$ satisfies the following condition (Montesano, 1972):

$$
s(x, \omega(x)) f(\omega(x)) h^{*}(x, \omega(x))|\mathrm{d} \omega|=|\mathrm{d} x|,
$$

where the left-hand and right-hand derivatives of the income mapping are not the same over a finite set of locations. This condition states that the amount of land available between any $x$ and $x+\mathrm{d} x>x$ along a topological arc while the subarc occupied by the households whose income varies from $\omega$ to $\omega+\mathrm{d} \omega$ are the same. Since $d \omega$ need not be positive, the land market clearing condition is expressed in absolute value.

Last, the network is supposed to be large enough to accommodate the whole population of households:

$$
\int_{N} s(x, \omega(x)) f(\omega(x)) h^{*}(x, \omega(x)) \mathrm{d} x<\int_{N} \mathrm{~d} x,
$$

where the second integral stands for the total supply of land.

A residential equilibrium is such that no household has an incentive to move, all households sharing the same income have the same maximum utility level, and the land market clears. Formally, a residential equilibrium is defined by the following vector:

$$
\left(\omega^{*}(x), s^{*}\left(x, \omega^{*}(x)\right), R^{*}(x), h^{*}\left(x, s^{*}(x)\right), q^{*}\left(x, s^{*}(x)\right)\right)
$$

with $x \in N$, such that

$$
b(x) \cdot u\left[q^{*}\left(x, \omega^{*}(x)\right), h^{*}\left(x, \omega^{*}(x)\right)\right] \geq b(y) \cdot u\left[q^{*}\left(y, \omega^{*}(x)\right), h^{*}\left(y, \omega^{*}(x)\right)\right] \quad \text { for all } x, y \in N
$$

holds under the budget constraint (2) and the land market clearing condition (4).

If the above inequality is strict for all $y \neq x$, then all $\omega^{*}(x)$-households are located at $x$ (i.e. $s^{*}\left(x, \omega^{*}(x)\right)=1$ ). Otherwise, there exist at least two locations $x_{1}$ and $x_{2}$ such that the $\omega^{*}(x)$-households are indifferent between the locations $x_{1}$ and $x_{2}$. In this case, we have $0<s^{*}\left(\cdot, s^{*}(x)\right)<1$ at $x_{1}$ and $x_{2}$, while the sum of the shares is equal to 1 . Hence, there is spatial splitting of identical households.

\section{The residential equilibrium with amenities}

Since $u$ is strictly increasing in $q$, the equation $u(q, h)=U / b(x)$ has a single solution $Q(h, U / b(x))$, which describes the consumption of the numéraire when the utility level is $U / b(x)$ and the land 
consumption $h$. The bid rent $\Phi(x, \omega, U)$ of a $\omega$-household is the highest amount it is willing to pay for one unit of land at $x$ when its utility level is equal to $U$. Formally, the bid-rent function is defined as follows:

$$
\begin{aligned}
\Phi(x, \omega, U) & \equiv \max _{q, h}\left\{\frac{\omega t(x)-q}{h} \mid \text { s.t. } b(x) \cdot u(q, h)=U\right\} \\
& =\max _{h} \frac{\omega t(x)-Q(h, U / b(x))}{h} .
\end{aligned}
$$

Since each household treats the utility level parametrically, differentiating (6) with respect to $h$ yields the equation:

$$
Q(h, U / b(x))-h Q_{h}(h, U / b(x))-\omega t(x)=0
$$

whose solution, denoted $H(\omega t(x), U / b(x))$, is the quantity of land consumed at $x$ when the household pays its bid rent $\Phi(\cdot)$; it is called the bid-max lot size (Fujita, 1989). Hence, the budget constraint implies that the bid-rent function may be rewritten as follows:

$$
\Phi(x, \omega, U) \equiv \frac{\omega t(x)-Q(\omega t(x), U / b(x))}{H(\omega t(x), U / b(x))} .
$$

This shows that a household's bid rent at $x$ depends on both $b(x)$ and $t(x)$ while its housing consumption $H$ also varies with these two attributes of $x$.

Since we consider a mapping that assigns a specific income to a location, the bid-rent function has a unique maximizer $\omega^{*}(x)$ at each location $x$. Consequently, $\omega^{*}(x)$ solves the first-order condition:

$$
\frac{\left.\partial \Phi\left(x, \omega, U^{*}(\omega)\right)\right)}{\partial \omega}=0,
$$

while the second-order condition $\partial^{2} \Phi / \partial \omega^{2}<0$ holds at $\omega^{*}(x)$.

Totally differentiating (9) with respect to $x$ yields:

$$
\frac{\mathrm{d} \omega^{*}}{\mathrm{~d} x}=-\left[\frac{\partial^{2} \Phi\left(x, \omega, U^{*}(\omega)\right)}{\partial \omega^{2}}\right]^{-1} \cdot \frac{\partial^{2} \Phi\left(x, \omega, U^{*}(\omega)\right)}{\partial \omega \partial x} \text { a.e., }
$$

which implies that $\Phi_{x \omega}\left(x, \omega, U^{*}(\omega)\right)$ and $\mathrm{d} \omega^{*}(x) / \mathrm{d} x$ have a.e. the same sign.

Set

$$
B(x) \equiv \frac{b_{x}(x)}{b(x)}, \quad T(x) \equiv-\frac{t_{x}(x)}{t(x)},
$$

and let $\mathcal{E}_{U, \omega} \equiv\left(\omega / U^{*}\right) U_{\omega}^{*}$, the income elasticity of indirect utility, $\mathcal{E}_{H, \omega} \equiv(\omega / H)\left(H_{\omega}+H_{U} U_{\omega}^{*}\right)$ the income elasticity of housing demand/bid-max lot size while $\mathcal{E}_{u_{q}, \omega} \equiv\left(\omega / u_{q}\right)\left(\partial u_{q} / \partial \omega\right)$ is the income elasticity of the marginal utility of the numéraire consumption. ${ }^{5}$

We may now characterize the slope of the equilibrium income mapping.

\footnotetext{
${ }^{5}$ When no ambiguity may arise, we do not specify the independent variables.
} 
Proposition 1. The equilibrium mapping $\omega^{*}(x)$ is a.e. strictly increasing (decreasing) at $x$ if

$\Phi_{x \omega}\left(x, \omega, U^{*}(\omega)\right)=\frac{t}{H} \phi(x, \omega) \quad$ with $\quad \phi(x, \omega) \equiv\left(1-\frac{\mathcal{E}_{H, \omega}+\mathcal{E}_{u_{q}, \omega}}{\mathcal{E}_{U, \omega}}\right) B(x)-\left(1-\mathcal{E}_{H, \omega}\right) T(x)$

is strictly positive (negative) at this location.

Proof. The proof is given in Appendix A.1.

The expression (11) shows that for any given utility function $u$ the interaction between the amenity and commuting cost functions determines the social stratification of the city through the behavior of the function $\phi$. It also shows that the sign of $\phi$, whence the slope of the spatial income distribution, changes at any solution $\omega^{*}(x)$ to the equation $\phi(x, \omega)=0$ if $\phi_{x}(x, \omega) \neq 0$. Hence, (11) emphasizes that preferences play a key role in explaining the pattern of social stratification.

To illustrate, consider the benchmark case of a monocentric, linear and featureless city $[0, L]$ where $b(x)=1$ and $t_{x}(x)<0$ for all $x$ since there is a single employment center whose location is at $x=0$. We know from Fujita (1989) that household locations are determined by ranking the bid-rent slopes with respect to income. It then follows from (11) that the sign of $\phi(x, \omega)$ depends on whether the income elasticity $\mathcal{E}_{H, \omega}$ of the bid-max lot size is positive because land is a normal good; it is not constant and may be smaller or larger than 1 (Wheaton, 1977). Since the empirical evidence shows that the expenditure share allocated to housing declines as income rises, the income elasticity of housing is smaller than 1 (Glaeser et al., 2008, Albouy et al., 2016). Therefore, when income increases, the slope of the bid-rent function gets steeper. A longer commute shifts the utility of a high-income household downward more than that of a low-income household because the former has a higher opportunity cost of time than the latter. However, this effect is not offset by the higher housing consumption because the income elasticity of housing is smaller than 1. By implication, at the residential equilibrium, households are sorted by decreasing order of income as the distance to the CBD increases.

Consider now the case of a featureful monocentric and linear city $(B(x) \neq 0)$. Owing to the existence of amenities, even when the bid-rent functions are downward sloping, the equation $\phi(x, \omega)=0$ may have several solutions. In this case, there is imperfect sorting, that is, greater income differences are not mapped into more spatial separation. The following three cases may arise. The first two cases are straightforward as we assume that $\phi(x, \omega)$ keeps the same sign for all $x$, even though the elasticities $\mathcal{E}_{H, \omega}, \mathcal{E}_{u_{q}, \omega}$ and $\mathcal{E}_{U, \omega}$, as well as $B(x)$ and $T(x)$, could change sign.

(i) Assume that $\phi(x, \omega)>0$ for all $x$, which implies that $\omega^{*}(x)$ increases. As $\omega$ rises, the bid-rent curve becomes flatter. Since the bid rent of a high-income household is always flatter than that of a low-income household, individuals are sorted out by increasing income. In other 
words, the richer is the household, the closer to the city limit is its location. Consumers are willing to pay more to reside at a distant location because the corresponding hike in amenity consumption is sufficient to compensate them for their longer commute (Fujita, 1989).

(ii) If $\phi(x, \omega)<0$ for all $x$, which implies that $\omega^{*}(x)$ decreases. Indeed, as the income $\omega$ rises, the bid-rent curve becomes steeper. Therefore, the bid-rent curves associated with any two different incomes intersect once and, for each $\omega$, there exists a unique $x(\omega)$ such that $s(x(\omega), \omega)=1$. In this case, $x=0$ is the most-preferred city location. To put it differently, the utility loss incurred by an increase in distance to the workplace is exacerbated by a drop in the consumption of central amenities (Brueckner et al., 1999).

(iii) The most interesting case arises when $\phi(x, \omega)$ changes its sign over $[0, L]$, so that the bid-rent functions may intersect several times. In this case, there is imperfect sorting: household income rises over some range of sites and falls over others. We develop this argument in more detail in the next section.

The expression (11) highlights the fact that the impact of the amenity and commuting cost functions on the sign of $\phi(x, \omega)$ depends on the elasticities $\mathcal{E}_{H, \omega}, \mathcal{E}_{u_{q}, \omega}$ and $\mathcal{E}_{U, \omega}$. When the utility $u(q, h)$ is specified, the condition (11) may be used to determine how households are distributed according to the behavior of $B(x)$ and $T(x)$ by calculating those elasticities. Even when these elasticities are constant, $B(x)$ and $T(x)$ are monotone, imperfect income sorting may arise because the signs of the coefficients of $B(x)$ and $T(x)$ in (11) are undetermined. ${ }^{6}$

\section{The social structure of cities}

\subsection{Non-homothetic preferences}

In this section, we characterize the equilibrium mapping $\omega^{*}(x)$ and the equilibrium land rent $R^{*}(x)$ for preferences $u(q, h)$ that reduce the dimensionality of the matching problem.

It is common place to work with homothetic preferences, as they include the CES, CobbDouglas and translog. Here, there are at least two reasons to rule out such preferences. First, using homothetic preferences implies that the elasticity of the housing demand is constant in price and income, which contradicts its variability across heterogeneous consumers (Albouy et al., 2016). Second, when the utility $u$ is homogeneous linear, we show in Appendix A.2 that

\footnotetext{
${ }^{6}$ We recognize that our modelling of commuting cost has an impact on the resulting sorting patterns. To illustrate, consider an income-independent commuting cost $c(x) \geq 0$. When $B(x)=0$, the expression (11) must be replaced by $\Phi_{x \omega}=\left[t_{x}\left(1-\mathcal{E}_{H, \omega}\right)+\left(c_{x} / \omega\right) \mathcal{E}_{H, \omega}\right] / H$ (see Appendix A.1). Thus, income-dependent and income-independent commuting costs have opposite impacts on sorting when $\mathcal{E}_{H, \omega}<1$. Our empirical study supports the evidence that income is decreasing in distance from the nearest employment center, thus suggesting that the effect of $c(x)$ is offset by the impact of $t(x)$.
} 
$\mathcal{E}_{U, \omega}=\mathcal{E}_{H, \omega}=1$ and $\mathcal{E}_{u_{q}, \omega}=0$, so that (11) yields $\phi(x, \omega)=0$ for all $x$. In other words, there exists a continuum of residential equilibria under homothetic preferences.

For these reasons, we consider Stone-Geary preferences which obviate the multiplicity of equilibria. ${ }^{7}$ They also account for the plausible assumption of a minimum lot size $\bar{h}>0^{8}$ :

$$
u(q, h)=q^{1-\mu}(h-\bar{h})^{\mu},
$$

where $0<\mu<1$. Maximizing (12) with respect to $q$ and $h$ subject to (2) leads to the following demands for the numéraire:

$$
q^{*}(x, \omega)=(1-\mu)[\omega t(x)-R(x) \bar{h}]
$$

and for housing:

$$
h^{*}(x, \omega)=(1-\mu) \bar{h}+\mu \frac{\omega t(x)}{R(x)} .
$$

Thus, the demand for housing at any location $x$ increases less than proportionally with income (Albouy et al., 2016). Note that the housing demand is perfectly inelastic when $\mu=0$, which corresponds to the assumption of a fixed lot size.

We show in Appendix A.3 that $\phi(x, \omega)$ is given by

$$
\phi(x, \omega)=\phi(x) \equiv B(x)-(1-\mu) T(x),
$$

which is independent of $\omega$. Set

$$
\Delta(x) \equiv b(x)[t(x)]^{1-\mu} .
$$

Differentiating (16) shows that $\Delta_{x}(x)$ and $\phi(x)$ have the same sign. Hence, $\phi(x)$ changes sign at any extrema of $\Delta(x)$.

The function $\Delta(x)$ subsumes the amount of time devoted to work and the amenity level at $x$ into a single scalar, which has the nature of a location-quality index (LQI), which is defined over the interval $[\underline{\Delta}, \bar{\Delta}]$ where $\underline{\Delta}(\bar{\Delta})$ is the minimum (maximum) value of $\Delta(x)$ over $N$. Note that the LQI depends on location $x$ but not on income $\omega^{*}(x)$. The higher $\mu$, the stronger the preference for housing. In other words, as the intensity of preference for housing increases, commuting matters less than the accessibility of amenities. Since the commuting cost function is never constant over a subarc of the network $N, \Delta(x)$ is never flat on a positive measure interval.

\footnotetext{
${ }^{7}$ Schmidheiny (2006) also uses Stone-Geary preferences to show income segregation in a set-up where a finite number of jurisdictions/locations are differentiated by their sole provision of local public goods to households heterogeneous in taste and income.

${ }^{8}$ A minimum housing threshold will be especially relevant if working from home becomes widespread (Behrens et al., 2021).
} 


\subsection{The spatial income distribution}

Our objective is now to determine the equilibrium income mapping $\omega^{*}(x)$. Since housing consumption is chosen optimally at each $x$, what makes a site attractive to households is both its amenity level and the corresponding working time. The next proposition shows that incomes are distributed over the location set $N$ according to the values of the LQI.

For a given value $\Delta>0$, we define the function $g(\Delta)$ by the number of locations $x \in N$ such that $\Delta(x)=\Delta$. Since $\Delta(x)$ is a.e. continuously differentiable, $g(x)$ is a step function. Let $G(\Delta)$ be the c.d.f. whose density is equal to $g(\Delta)$ except at the values of $\Delta$ where $g(\Delta)$ is not continuous. Hence, $G(\Delta)$ is piecewise linear and strictly increasing over $[\underline{\Delta}, \bar{\Delta}]$.

We are now equipped to characterize the equilibrium income mapping.

Proposition 2. Assume that preferences are given by (12). Then, (i) each location hosts at most one household type; (ii) there exists a unique residential equilibrium; (iii) the equilibrium income mapping $\omega^{*}(x)$ and the $L Q I \Delta(x)$ vary together with $x$; and (iv) the equilibrium income mapping is given by

$$
\omega^{*}(x)=F^{-1}[G(\Delta(x))],
$$

Proof. The proof is given in Appendix A.4.

Note that (17) implies:

$$
\frac{\mathrm{d} \omega^{*}}{\mathrm{~d} x}=\frac{g(\Delta(x))}{f\left(\omega^{*}(x)\right)} \frac{\mathrm{d} \Delta}{\mathrm{d} x} \quad \text { a.e. }
$$

Since the bid-rent function allows describing the Pareto frontier between households and locations, it is sufficient to show that the equilibrium utility level $U^{*}(\omega)$ satisfies the SpenceMirrlees condition with respect to $\omega$ and $\Delta$, and hence the bid-rent function is supermodular. This in turn implies the existence of a unique positive assortative matching between incomes and the values of the LQI (Chiappori, 2017). Furthermore, the expression (17) tells us that the equilibrium income mapping is determined by the income distribution $F(\cdot)$ and the distribution function $G(\cdot)$ associated with the LQI function $\Delta(\cdot)$.

Equally important, Proposition 2 shows that it is sufficient to study how $\Delta(x)$ varies with $x$ to determine how households are distributed over $N$. In other words, the initial two-to-one matching is reduced to a one-to-one matching $\omega^{*}(\Delta)$, which is unique and strictly increasing in $\Delta$. Consequently, the highest income households locate where the LQI reaches its global maximum. As $\Delta(x)$ starts decreasing with $x$, the income level of the corresponding residents also decreases. The lowest income households reside at a global minimizer of the LQI. Around this location, the income level rises together with $\Delta$. As a result, a wider income gap is no longer matched with a greater distance between two households because the function $\Delta(x)$ is in 
general not monotonic in $x$. In other words, we have:

$$
\frac{\partial}{\partial x} \frac{\mathrm{d} U^{*}}{\mathrm{~d} \omega} \gtrless 0 .
$$

To illustrate, consider a linear city where $\Delta(x)$ is $\backsim$-shaped over $[0, L]$ with two maximizers at $x=0$ and $x_{2}<L$ and two minimizers at $x_{1}<x_{2}$ and $x=L$. Proposition 2 implies that households are sorted by decreasing income over $\left[0, x_{1}\right)$. As $x$ increases, $\Delta(x)$ increases and households are sorted by increasing income until $x_{2}$, while households' income decreases over $\left(x_{2}, L\right]$. Since $\Delta(y)=\Delta(z)$ for some $y \in\left(0, x_{1}\right)$ and $z \in\left(x_{1}, x_{2}\right)$, households who reside at $y$ and $z$ have the same income $\omega^{*}$. In other words, households sharing the same income do not live in the same place. Although these consumers enjoy the same equilibrium utility level and consume the same lot size (see Appendix 4(i)), they do not have the same net income, do not pay the same land rent and do not consume the same amount of the numéraire because amenities and commuting costs are not the same at $y$ and $z$.

It remains to determine the equilibrium values of the shares $s\left(x, \omega^{*}(x)\right)$. If $x_{1} \neq x_{2} \ldots \neq x_{n}$ exist such that $\Delta\left(x_{1}\right)=\Delta\left(x_{j}\right)$ for $j=2, \ldots, n$, it follows from Proposition 2 that $\omega^{*}\left(x_{1}\right)=\omega^{*}\left(x_{j}\right)$ for $j=2, \ldots, n$. Under Stone-Geary preferences, the bid-max lot size $H(\cdot)$ depends on $b(x)$ and $t(x)$ only through the LQI, $\Delta(x)$. As $H[\omega t(x), U / b(x)] \equiv H(\omega, \Delta(x), U)$, it must be that $H\left(\omega, \Delta\left(x_{1}\right), U\right)=H\left(\omega, \Delta\left(x_{j}\right), U\right)$ for $j=2, \ldots, n$. Since $f\left(\omega^{*}\left(x_{1}\right)\right)=f\left(\omega^{*}\left(x_{j}\right)\right)$ for $j=2, \ldots, n$, using (4) and (18) leads to

$$
s\left(x_{1}, \omega^{*}\left(x_{1}\right)\right)\left|\frac{\mathrm{d} \Delta\left(x_{1}\right)}{\mathrm{d} x_{1}}\right|=s\left(x_{j}, \omega^{*}\left(x_{j}\right)\right)\left|\frac{\mathrm{d} \Delta\left(x_{j}\right)}{\mathrm{d} x_{j}}\right|, \quad j=2, \ldots, n .
$$

Since

$$
\sum_{i=1}^{n} s\left(x_{i}, \omega^{*}\left(x_{i}\right)\right)=1
$$

the unique solution to these $n$ linear equations is given by

$$
s\left(x_{i}, \omega^{*}\left(x_{i}\right)\right)=\frac{1}{\sum_{k=1}^{n} \frac{1}{\mathrm{~d} \Delta\left(x_{k}\right) / \mathrm{d} x_{k} \mid}} \cdot \frac{1}{\left|\mathrm{~d} \Delta\left(x_{i}\right) / \mathrm{d} x_{i}\right|}, \quad i=1, \ldots, n .
$$

In words, households who have the same income $\omega^{*}\left(x_{1}\right)$ are split across locations whose LQI is equal to $\Delta\left(x_{1}\right)$ according to location-specific shares $s\left(x_{i}, \omega^{*}\left(x_{i}\right)\right)$ because the LQI gradients need not be the same across locations $x_{1}, \ldots, x_{n}$ (see Appendix A.4.(iv) for a detailed proof). Note also that in a linear city where $\Delta(x)$ is monotone increasing or decreasing over $[0, L]$ would lead to $s=1$.

It is worth stressing that Proposition 2 holds true for non-homothetic preferences other than Stone-Geary. In other words, our results hold for a substantial variety of preferences. First, consider the generalized CES given by $u(q, h)=q^{\rho_{1}}+h^{\rho_{2}}$ with $0<\rho_{i}<1$ and $\rho_{1} \neq \rho_{2}$ 
(Mukerji, 1963). The elasticity of substitution between land and the numéraire is variable and equal to $1 /\left(1-\delta_{1} \rho_{1}-\delta_{2} \rho_{2}\right)$ where $\delta_{i}$ is the expenditure share on good $i=1,2$. When $\rho_{1}>\rho_{2}$, i.e., the composite good matters more than land, it can be shown that the above preferences generate the index $\Delta(x) \equiv[b(x)]^{1 / \rho_{1}} t(x)$. This index plays the same role as (16) and may be substituted in (17) to obtain the corresponding income mapping. Second, under Price-Independent-Generalized-Linear (PIGL) preferences (Boppart, 2014), the indirect utility function has the following form: $V(\omega, x)=b(x)\left\{[\omega t(x)]^{\epsilon} / \epsilon-\mu[R(x)]^{\gamma} / \gamma\right\}$ where $0 \leq \epsilon \leq$ $\gamma<1$. When $\epsilon=0$, we have homothetic preferences while $V$ becomes an indirect (logtransformed) Cobb-Douglas utility function when $\gamma=\epsilon=0$. For any given location $x$, we have $V_{\omega}=\Delta(x) \omega^{\epsilon-1}$, so that $\Delta(x) \equiv b(x) t(x)^{\epsilon}$ is the new LQI. Last, if preferences are quasi-linear

preferences $u(q, h)=v(h)+q$ where $v$ is strictly increasing and concave, we have $\mathcal{E}_{H, \omega}=\mathcal{E}_{u_{q}, \omega}=$ 0 , so that the bracketed term of (11) yields $\Delta(x)=b(x) t(x)$.

Note also that our setting displays enough flexibility to account for a special, but empirically relevant, type of heterogeneity across households. To be precise, assume that a household is characterized by her type $(\omega, \nu)$ where $\nu$ may represent, e.g., households are heterogeneous in their attitudes toward leisure. In this case, a household's income is given by $\omega \nu$ where $\nu$ is an inverse measure of her demand for leisure. This is accomplished by considering the following indirect utility:

$$
V(x, \omega, \nu) \propto \Delta(x)\left[\omega \nu-\frac{R(x)}{t(x)} \bar{h}\right]\left[\frac{R(x)}{t(x)}\right]^{-\mu} .
$$

In this case, it can be shown that (15) becomes

$$
\phi(x, \omega \nu)=\frac{\bar{h}}{h(x, \omega \nu)}[A(x)-(1-\mu) T(x)] .
$$

Repeating the argument of Proposition 2 implies that the exists a unique PAM between $\omega \nu$ and $\Delta$. In other words, the sorting of households is based on the trade-off between income and leisure, so that households who live at $x$ may enjoy different incomes and different demands for leisure that satisfy the condition $\omega \nu=\omega^{\prime} \nu^{\prime}$. This approach can be extended to deal with differences in family structure.

\subsection{Land rent}

The land market clearing condition (4) may be rewritten as follows:

$$
h^{*}(x, \omega(x))=\frac{1}{s(x, \omega(x)) f(\omega(x))} \frac{1}{|\mathrm{~d} \omega / \mathrm{d} x|}, \quad \text { a.e. }
$$

From (18), using $\mathrm{d} \Delta / \mathrm{d} x \equiv \phi(x) \Delta(x)$, we get:

$$
h^{*}\left(x, \omega^{*}(x)\right)=\frac{1}{s\left(x, \omega^{*}(x)\right) g(\Delta(x))} \frac{1}{|\phi(x)| \Delta(x)}, \quad \text { a.e. }
$$


Hence, a higher LQI gradient at $x$ is associated with a higher mass of households located at $x$, which in turn leads to a lower housing consumption.

When land at $x$ is occupied by households, (14) then implies that the equilibrium land rent at $x$ must solve the following equation:

$$
(1-\mu) \bar{h}+\mu \frac{\omega^{*}(x) t(x)}{R(x)}=\Omega(x) \text { with } \Omega(x) \equiv \frac{1}{s\left(x, \omega^{*}(x)\right) g(\Delta(x))} \frac{1}{|\phi(x)| \Delta(x)}, \quad \text { a.e. }
$$

so that

$$
R^{*}(x)=\mu \frac{1}{\Omega(x)-(1-\mu) \bar{h}} \omega^{*}(x) t(x), \quad \text { a.e. }
$$

which increases with the minimum lot size $\bar{h}$.

To illustrate, consider the case where $x_{1} \neq x_{2} \ldots \neq x_{n}$ exist such that $\Delta\left(x_{1}\right)=\Delta\left(x_{j}\right)$ for $j=2, \ldots, n$. According to Proposition 2, households with income $\omega^{*}\left(x_{1}\right)$ are indifferent between locations $x_{1} \neq x_{2} \ldots \neq x_{n}$. However, the land rents at these locations differ. Indeed, it follows from (20) that

$$
\frac{R^{*}\left(x_{1}\right)}{t\left(x_{1}\right)}=\frac{R^{*}\left(x_{2}\right)}{t\left(x_{2}\right)}=\ldots=\frac{R^{*}\left(x_{n}\right)}{t\left(x_{n}\right)},
$$

which implies that variations of the rent $R^{*}(x)$ are exactly balanced by variations of commuting $t(x)$ within the location set $\left\{x_{1}, x_{2}, \ldots, x_{n}\right\}$. Stated differently, the land rent at locations hosting households with a higher disposable income t $\omega^{*}$ is also higher.

We show in Appendix A.5 that the land gradient is given by

$$
R_{x}^{*}(x)=\frac{\omega^{*}(x) t(x)}{\Omega(x)}\left[\frac{1}{\Omega(x)-(1-\mu) \bar{h}} B(x)-T(x)\right], \quad \text { a.e. }
$$

Since the coefficient of $B(x)$ in (21) is positive and smaller than 1, the above expression implies that the land rent gradient is negative when $B(x)-T(x)<0$ for all $x$. As $x$ rises, the decreasing land rent compensates the households $\omega^{*}(x)$ located at $x$ for bearing higher commuting costs and being farther away from places endowed with more amenities. For example, in the standard monocentric city model in which $B(x)=0$ and $T(x)>0$ the land rent gradient is always negative. When $B(x)-T(x)>0$ over some interval $\left[x_{1}, x_{2}\right]$, the land rent gradient can be positive or negative according to the value of the coefficient of $B(x)$ in (21). Since household income increases over $\left[x_{1}, x_{2}\right]$, commuting costs also increase over this interval. Therefore, the land rent is a priori neither monotonic nor the mirror image of the spatial income distribution. In short, the interaction between amenities, commuting and income sorting may give rise to a wealth of land rent profiles, which generally differ from that of the LQI.

\subsection{From theory to data}

To derive testable predictions about the effects of amenities and commuting costs on the spatial income distribution, we have to determine the explicit form of the income mapping $\omega^{*}(x)=$ 
$F^{-1}[G(\Delta(x))]$. For this, we must specify the distributions $F$ and $G$. Earning distributions are skewed to the right so that the Fréchet distribution is a good candidate to capture this. More specifically, we assume that incomes are drawn from a Fréchet distribution with the shape parameter $v>0$ and the scale parameter $\Upsilon>0: F(\omega)=\exp \left[-(\omega / \Upsilon)^{-v}\right]$ over $[0, \infty)$. An increase in $v$ leads to less income inequality.

The case of $G$ is more delicate. By definition, the density $g(\Delta)$ is equal to integer values over a finite number of intervals of $[\underline{\Delta}, \bar{\Delta}]$. Each interval is determined by the $\Delta$-images of some subarcs of $N$. As $\Delta$ increases from $\Delta$ to $\bar{\Delta}$, we assume that the number of subarcs in $N$ where $\Delta(x)$ takes low (i.e., close to $\underline{\Delta}$ ) or high (i.e., close to $\bar{\Delta}$ ) values is small, while $\Delta(x)$ has intermediate values over a large number of subarcs. This amounts to assuming that $g(\Delta)$ is a quasi-concave step function over $[\underline{\underline{\Delta}}, \bar{\Delta}]$. In other words, good and bad areas are few whereas there are many decent and pretty good areas where to live in, which seems a reasonable description of Dutch cities. In what follows, we assume that the values of $\Delta(x)$ are drawn from a Fréchet distribution $G(\Delta)=\exp \left[-(\Delta / \Psi)^{-\psi}\right]$, where $\psi>0$ are the shape parameter and $\Psi>0$ the scale parameter. By playing with $\psi$, it is possible to describe a fairly wide array of amenity and commuting cost distributions. Furthermore, this specification allows us to determine an analytical expression for $\omega^{*}(x)$ that is amenable to the data. In Section 5.3 we provide empirical evidence that $\Delta(x)$ is well approximated by a Fréchet distribution.

Using (17), the mapping $\omega^{*}(x)$ can be retrieved from the condition:

$$
\int_{\omega^{*}}^{\infty} f(y) \mathrm{d} y=1-\exp \left(-\left(\omega^{*} / \Upsilon\right)^{-v}\right)=\int_{\Delta}^{\infty} g(\delta) \mathrm{d} \delta=1-\exp \left(-(\Delta / \Psi)^{-\psi}\right),
$$

which is the counterpart in the $\Delta$-space of the land market clearing condition (4). Solving the above equation yields the equilibrium income mapping:

$$
\omega^{*}(x)=\Upsilon\left[\frac{\Delta(x)}{\Psi}\right]^{\psi / v} .
$$

Alternatively, we could assume that $\Delta(x)$ takes high (low) values on a small (large) number of subarcs of $N$ while there is an intermediate number of subarcs where $\Delta(x)$ takes intermediate values. In this case, $g(\Delta)$ is a weakly decreasing step function over $[\underline{\Delta}, \bar{\Delta}]$. It is readily verified that we obtain an expression similar to $(22)$ for $\omega^{*}(x)$ when $G(\Delta)$ is a Pareto distribution that approximates continuously $g(\Delta)$.

\section{Empirical analysis}

In this section, we first describe our data in order to provide reduced-form evidence in support of the model's qualitative predictions that amenities and commuting time affect the income 
distribution in and between cities; and hence that exogenous amenities are an important determinant of sorting of households. The analysis is complemented by a wide range of controls that provide evidence against alternative possible explanations. We close this section by using the estimated parameters to calculate the LQI and income mapping $\omega^{*}(x)$ over space.

\subsection{Datasets}

We have gained access to various nationwide non-public microdata from Statistics Netherlands between 2010 and 2015. Unlike the United States or the United Kingdom, the Netherlands does not undertake censuses to register their population, but the register is constantly updated when people move or when there are changes in the household composition. The first dataset we use is the Sociaal Statistisch Bestand $(S S B)$, which provides basic information on demographic characteristics, such as age, country of birth, marital status, and gender. We only keep people that could be part of the working population, that is, those between 18 and 65 years and aggregate these data to the household level. Importantly, the $S S B$ data enable us to determine where households reside, up to the postcode level. Hence, space is discrete in the plane.

The data on yearly income of households are obtained from the Integraal Huishoudens Inkomen panel dataset. These data are based on the tax register, which provides information on taxable income, tax paid, as well as payments to or benefits from property rents or dividends. The income data also provide information on whether households are homeowners or renters. More than $65 \%$ of the rental sector applies to public housing. Public housing is rent controlled and there are often long waiting lists for public housing. So, households are not entirely free to choose their utility-maximizing location. Therefore, we will focus on owner-occupied housing, which means that we keep about $70 \%$ of the data. ${ }^{9}$

To estimate the commuting time for each household, we use the tax register information, which provides information on individual jobs and the number of hours worked in each firm for each year. Using data on location information on each establishment from $A B R$ Regio and network travel time from SpinLab, we calculate for each household the average commuting time. More information on how we calculate the commuting time between locations is provided in Appendix B.1.

A location is given by a neighborhood (which is a postcode 4-digit location) as defined by Statistics Netherlands. There are 4,033 neighborhoods; the median size of a neighborhood is only 528ha while the average population is about 4,000. Information on land values and lot sizes is not directly available. As is common practice, we infer them from data on housing

\footnotetext{
${ }^{9}$ We furthermore obtain information on the educational level of adults in the household. This is available for only $75 \%$ of the population, but our main specifications will not use these data so this does not appear to be an issue.
} 
transactions, provided by the Dutch Association of Real Estate Agents (NVM). The methodology used to calculate land values and lot sizes is described in Appendix B.2. The NVM data contain information on the large majority (about 75\%) of owner-occupied house transactions between 2000 and 2015. We know the transaction price, the lot size, inside floor space size (both in $\mathrm{m}^{2}$ ), the exact address, and a wide range of housing attributes such as house type, number of rooms, construction year, garden, state of maintenance, and whether a house is equipped with central heating. ${ }^{10}$ We also know whether the house is a listed building.

We are interested in the impact of amenities on income sorting and land prices. We proxy the amenity level by the picture density in a neighborhood. More specifically, we gather data from Eric Fisher's Geotagger's World Atlas, which contain all geocoded pictures on the website Flickr. The idea is that locations with an abundant supply of aesthetic amenities will have a high picture density. We show in Appendix B.3 that there is a strong positive correlation between picture density and historic amenities or geographical variables, such as access to open water or open space. There are, however, several issues with using geocoded pictures as a proxy for amenities. ${ }^{11}$

First, to avoid the possibility of inaccurate geocoding, we keep only one geocoded picture per location defined by its geographical coordinates. ${ }^{12}$ This reduces the number of pictures by about $50 \%$. Second, one may argue that the patterns of pictures taken by tourists and residents may be very different. Since we have information on users' identifiers, we can distinguish between residents' and tourists' pictures by keeping users who take pictures for at least 6 consecutive months between 2004 and 2015 in the Randstad. It seems unlikely that tourists stay for 6 consecutive months in the area. Note that the correlation between residents' and tourists' pictures is 0.653 , which is rather low.

Third, many recorded pictures may not be related to amenities but to ordinary events in daily life occurring inside the house. Hence, we only keep pictures that are taken outside buildings, using information on all the buildings in the Netherlands from the $G K N$ dataset, which comprises information on the universe of buildings. Furthermore, if pictures are not related to amenities, one would expect almost a one-to-one relationship with population density. However, if we calculate the population density in the same way as we calculate the amenity

\footnotetext{
${ }^{10}$ We exclude transactions with prices that are above $€ 1$ million or below $€ 25,000$ and have a price per square meter which is above $€ 5,000$ or below $€ 500$. We furthermore leave out transactions that refer to properties that are larger than $250 \mathrm{~m}^{2}$ of inside floor space, are smaller than $25 \mathrm{~m}^{2}$, or have lot sizes above $5000 \mathrm{~m}^{2}$. These selections consist of less than one percent of the data and do not influence our results.

${ }^{11}$ Ahlfeldt (2013) shows that in Berlin and London the picture density is strongly correlated to the number of restaurants, music nodes, historic amenities and architectural sites, as well as parks and water bodies.

${ }^{12}$ The location of most pictures is determined through the GPS of cameras. Hence, in a continuous space, the probability that several pictures are taken at exactly the same location is zero. Observing multiple pictures at the same location is therefore likely caused by inaccurate geocoding.
} 
level, the correlation is only 0.223 . Last, we recognize that people who take pictures may belong to a specific socio-demographic group (e.g., young people with a smartphone) by including demographic controls and using instrumental variables.

Though imperfect, we believe that the picture density is probably the best proxy available for the relative importance of urban amenities at a certain location because it captures both the heterogeneity in aesthetic quality of buildings and residents' perceived quality of a certain location. Nevertheless, we test the robustness of our results using a completely different, hedonic, amenity index in the spirit of Lee and Lin (2018) (see Appendix B.3 for more details). The hedonic LQI aggregates the average impact of several proxies of amenities, such as the locations of historic buildings, proximity to open space and water bodies, by testing their joint impact on house prices.

For our identification strategy, to be discussed later on, we also construct historic instruments. Knol et al. (2004) have scanned and digitized maps of the land use in 1900 into 50 by 50 meter grids and classified each grid into 10 categories, including built-up areas, water, sand, and forest. We aggregate these 10 categories into 3 categories: built-up areas, open space, and water bodies and calculate the share of the area used for each type in each neighborhood. We further gather data from the 1909 census on occupations and employment in each municipality. Those ones were much smaller than current ones and about 4 times the size of the current neighborhoods.

For each occupation we obtain the required skill level. This enables us to calculate the share of households who are medium and high-skilled. We gather additional data on the railway network in 1900 and the stations which by then existed (see Appendix B.4 for more information), enabling us to calculate employment accessibility in 1909.

Figure 1A provides a map of the Netherlands, the studied area, where we indicate the most important cities. The conurbation formed by the four largest cities, i.e., Amsterdam, Rotterdam, The Hague, and Utrecht is known as the Randstad, which has a population of about 7.1 million. Figure 1B displays the commuting pattern across neighborhoods and shows that the Dutch urban structure is really polycentric as many commuting flows occur between different cities. This underlines the need for a model that allows for location choices in the whole country. Figure 1C is a map of the most important roads and railways that form the transportation network in the Netherlands.

[Figure 1 about here]

Further descriptive statistics are shown in Appendix B.5 


\subsection{Econometric framework and identification}

Assume that labor time is given by $t_{i}(x) \equiv w_{i}(x)\left[\tau_{i}(x)\right]^{-\theta}$, where $\tau_{i}(x)$ is the commuting time between $x$ and $i, \theta>0$ is the elasticity of labor time with respect to commuting time, and $w_{i}(x)$ is the given number of working hours per year of a household working in $i^{13}$

In this case, the LQI becomes:

$$
\Delta(x)=b(x)\left[w_{i}(x)\right]^{1-\mu}\left[\tau_{i}(x)\right]^{-\theta(1-\mu)} .
$$

It then follows from (22) that the income mapping is given by the following expression:

$$
\omega^{*}(x)=\Upsilon\left[\frac{b(x)\left[w_{i}(x)\right]^{1-\mu}\left[\tau_{i}(x)\right]^{-\theta(1-\mu)}}{\Psi}\right]^{\psi / v} .
$$

We observe income conditional on labor supply in the data. For example, if someone has a longer commute and therefore supplies less labor, we observe a lower income net of commuting costs. Hence, let $\tilde{\omega}(x)$ be the gross income, net of commuting costs, of a household $k$ living at $x$ and working in $i$ observed in the data:

$$
\tilde{\omega}_{k i}(x)=\omega^{*}(x) t_{i}(x) \xi_{k i}(x),
$$

where the $\xi_{k i}(x)$ are hourly labor income shocks that are independently and identically distributed according to some given distribution defined on $[0, \infty)$. Taking the log of $(24)$, we obtain:

$$
\log \tilde{\omega}_{k i}(x)=\alpha_{0}+\alpha_{1} \log b(x)+\alpha_{2} \log \tau_{i}(x)+\alpha_{3} \log w_{i}(x)+\tilde{\xi}_{k i}(x),
$$

where $\alpha_{0} \equiv \log \left(\Upsilon / \Psi^{\psi / v}\right), \alpha_{1} \equiv \psi / v, \alpha_{2} \equiv-\theta(1+(1-\mu) \psi / v)$, and $\tilde{\xi}(x) \equiv \log \xi(x)$. Note that we refrain from interpreting $\alpha_{3}$ as being equal to $1+(1-\mu) \psi / v$ because the number of working hours may have a direct effect on income, e.g., by working hard in order to get a wage raise (Bell and Freeman, 2001). At the same time, changes in wages may affect labor supply.

We consider the income mapping, which plays a key role in our model, and first of all provide reduced-form evidence that the picture density is related to observed proxies for amenities and, in turn, we show that sorting by incomes is indeed related to our proxy for amenities and commuting time - the variables that constitute the LQI (see (23)). In line with (25), set

$$
\log \tilde{\omega}_{k i}(x)=\alpha_{1} \log b(x)+\alpha_{2} \log \tau_{i}(x)+\alpha_{4} C_{k}+\zeta_{\mathcal{A}}(x)+\eta_{i}+\xi_{k i}(x),
$$

\footnotetext{
${ }^{13}$ We introduce here the number of working hours $w_{i}(x)$. Hence, $\omega$ captures the gross income per hour. This implies that in our theoretical set-up $t(0)$ is normalized to 1 . We are agnostic about the reasons that explain why $w_{i}(x)$ varies with $x$. According to Rosenthal and Strange (2008), professionals work is longer in denser areas, while Black et al. (2014) observe that married women work more when commutes are shorter.
} 
where $\tilde{\omega}_{k i}(x)$ is the observed income of household $k$ living at $x$ and working in $i, b(x)$ is the density of geocoded pictures, $\tau_{i}(x)$ is the observed commuting time to workplace $i, C_{k}$ are household characteristics, $\zeta_{\mathcal{A}}(x)$ are travel-to-work-area $\mathcal{A}$ fixed effects, $\eta_{i}$ are workplace fixed effects, and $\xi_{k i}(x)$ is an error term. The parameters $\alpha_{1}, \alpha_{2}, \alpha_{3}, \zeta_{\mathcal{A}}(x)$ and $\eta_{i}$ are estimated. ${ }^{14}$

In an ideal setting we compare otherwise identical households, but with differences in incomes. We then test to what extent differences in amenities and commuting time can explain the spatial differences in income. There are several issues when using (26) to identify the causal impact of $b(x)$ and $\tau_{i}(x)$ on income sorting. First, regarding commuting time $\tau_{i}(x)$, unconditional correlations between incomes and commuting times are generally positive rather than negative (see Susilo and Maat, 2007 for the Netherlands). There are several reasons for that. Higher income and educated people are more specialized and, therefore, operate in 'thinner' labor markets. Given that there is a strong idiosyncratic component to residential location choices (people are strongly attached to a location and usually dislike moving), this will imply that people with higher incomes live further away from their workplace (see, e.g., Manning, 2003). Another reason for a bias is that labor markets may not be fully competitive as households may bargain over to get an income compensation for living further away. Hence, observed incomes $\tilde{\omega}_{k i}(x)$ may be higher when people live further away. Note that about $15 \%$ of the costs of a longer commute is paid by the employer (Mulalic et al., 2013).

Second, a more general concern about $\alpha_{1}$ and $\alpha_{2}$ as measures of the impacts of amenities and commuting time on the spatial income distribution is that there is an omitted variable bias due to heterogeneity in preferences for housing quality, agglomeration economies at the workplace, and unobserved spatial features. More specifically, households may not only sort on the basis of income, but also on the basis of other household characteristics. Households with children, for example, may aim to locate in neighborhoods with a large amount of green space. If households with children have higher incomes, we may wrongly conclude that amenities attract the rich, while they in fact attract households with children. The variables $b(x)$ and $\tau_{i}(x)$ could also be correlated with unobserved housing attributes because households with different incomes may have different preferences for housing quality, such as the age of the housing stock (Brueckner and Rosenthal, 2009). For example, a large share of the housing stock in the city center of Amsterdam takes the form of apartments. This may imply that the affluent are not willing to locate there because they eschew apartment living (Glaeser et al., 2008).

Third, there may be reverse causality between $\tilde{\omega}_{k i}(x)$ and $b(x)$ and between $\tilde{\omega}_{k i}(x)$ and $\tau_{i}(x)$. For example, the provision of amenities may be a direct result of the presence of high-income

\footnotetext{
${ }^{14}$ One may argue that we should not control for house size, as the income mapping is a result of the trade-off between amenities, commuting time, and land. We can show that our results are virtually the same if we do not control for house size. The results are available upon request.
} 
households. Indeed, anecdotal evidence suggests that cultural and leisure services are often abundantly available in upscale neighborhoods (Glaeser et al., 2001). Similarly, high income neighborhoods may attract employers that are in need of specialized and highly educated labor. Last, since we do not observe the 'exact' amenity level, there may be a measurement error in $b(x)$, which may lead to a downward bias of $\alpha_{1}$ when the error is random. ${ }^{15}$

The first step to mitigate the biases associated with these concerns is first to 'purge' income from household, job and housing characteristics, $C_{k}$. For example, $C_{k}$ captures the members of the households who work full-time or part-time, the size of the household and the age of the adults, while housing attributes are, for example, housing type and construction year. This approach reduces the likelihood that we measure sorting on the basis of household characteristics other than incomes. We also control for travel-to-work-area fixed effects (at the home place) to address the concern of aggregate sorting effects between urban areas, as well as differences in spatial policies that are often spatially autocorrelated. More specifically, travel-to-workarea fixed effects imply that we measure sorting of rich and poor within commuting zones. Furthermore, but importantly, by including workplace fixed effects $\eta_{i}$ (at the neighborhood level) we control for wage differences between workplaces (e.g., due to agglomeration economies and sectoral composition of an area).

Working with an endless string of controls will not fully address the endogeneity concerns raised above. Unfortunately, our data do not allow us to exploit quasi-experimental or temporal variation in $b(x)$ and $\tau_{i}(x)$. Therefore, to investigate the importance of the omitted variable bias we analyze coefficient movements after including controls. Oster (2019) shows that coefficient movements together with changes in the $R^{2}$ can be used to estimate biased-corrected coefficients. We outline this procedure and discuss the results in detail in Appendix C.2.

Omitted variable bias is not the only endogeneity issue. Our proxies may also suffer from measurement error and reverse causality. We will, therefore, rely on instrumental variables. We exploit the fact that $b(x)$ and $\tau_{i}(x)$ are autocorrelated. First, land use in 1900 is used as an instrument. Clearly, land use in 1900 cannot be affected by today's income distribution, but we expect aesthetic amenities to be positively correlated to the share of built-up area in 1900. For example, the historic city center of Amsterdam has many buildings that have been built before 1900, which are now listed buildings. Furthermore, we also expect water bodies available in 1900 to be correlated to current water bodies, which are often considered as an amenity. As an

\footnotetext{
${ }^{15}$ As suggested by the literature on local public goods, there might be reverse causality, meaning that the location of local public goods is determined by the spatial income distribution. To a large extent, this is because the institutional context that prevails in the U.S. implies that the quality of schools and other neighborhood characteristics are often determined by the average income in the neighborhood (see, e.g., Bayer et al., 2007). This is to be contrasted with what we observe in many other countries where local public goods such as schools are provided by centralized bodies.
} 
instrument for commuting time, we count the total number of workers $a_{1909}(x)$ in 1909 within commuting distance using the railway network in 1900:

$$
a_{1909}(x)=\sum_{i=1}^{n} F\left(\tau_{i}(x)\right) E_{i, 1909},
$$

where $\tau_{i}(x)$ is the commuting time between $x$ and employment location $i=1, \ldots, n, E_{i, 1909}$ are the number of workers at $i$ in 1909, while $F\left(\tau_{i}(x)\right)$ is the share of people who commute at most $\tau$ minutes in the sample (see Appendix B.1). Hence, $F\left(\tau_{i}(x)\right)$ represents the aggregate cumulative distribution of commuting times. Because of temporal autocorrelation, we expect that a better employment accessibility in 1909 also implies a better employment accessibility today and, therefore, a lower commuting time.

Historic instruments can be criticized because of the (strong) identifying assumption that past unobserved locational features are uncorrelated to current unobserved locational endowments. However, these instruments are more likely to be valid in the context of income sorting because the patterns of income sorting within each city have considerably changed throughout the last century. Around 1900, open water and densely built-up areas were not necessarily considered as amenities. For example, the canals in Amsterdam were essentially open sewers (Geels, 2006). Therefore, locations near a canal often repelled high-income households who located in lush areas just outside the city. It was also before cars became the dominant mode of transport. People around 1900 often walked to their working place so that commuting distances were short. However, the rich could afford to live outside the city and take the train to their workplace. The cities in 1900 were not yet influenced by (endogenous) planning regulations, as the first comprehensive city plans date from the 1930s.

Still, one may be concerned that the measure of amenities is itself determined by the wealth of individuals who locate there. The reason is that unobservables that determine the concentration of wealthy individuals in the past also determine the locations of landmarks today, and thus determine where pictures are taken. Moreover, one may argue that historic employment accessibility, which is correlated to current commuting times, makes it easier to find jobs for all household members, and thus increases household income due to better matching, rather than shorter commutes. We address these concerns in several ways.

(i) We estimate specifications where we control for the current share of built-up areas and population density. Locations that were attractive in the past attracted people and consequently have a high share of built-up area in 1900. The share of built-up areas in 1900 is likely to be correlated to the current population density and to shares of built-up areas nowadays. By controlling for the current share of built-up areas and population density we mitigate the issue that our proxy for amenity just captures contemporary population density, rather than a higher amenity level because of the historic buildings. 
(ii) We gather data from the 1909 census on occupations and skills in each municipality. We then control in various ways for the average skill level of households in 1909 as a proxy for the income in the past. Controlling for the skill level should also address the issue that employment density in 1909 may be correlated to better matching opportunities. Since this proxy may be imperfect, we also use the share of Protestants in 1899 at the municipality level as another proxy for income/skill. Indeed, at that time Protestants had a higher education level and were wealthier.

(iii) We also consider another instrument for commuting time. From the 1899 census, we gather data on the share of locally born people (i.e., within the same municipality). If the (lack of) mobility of households is correlated over time, the share of locally born people should be correlated positively to current commuting times because immobile households have to commute on average longer to their jobs.

(iv) Finally, we estimate specifications where we exclusively focus on areas of reclaimed land since 1900. These are areas that are reclaimed from the sea (about $5 \%$ of the land) just before and after World War II. As these reclaimed locations are otherwise identical, and as no one was living in those locations at that time, we address reverse causality, and strongly mitigate any remaining omitted variable bias.

\subsection{Results}

Baseline results. We first check that picture density is a good proxy for amenity endowments. The results in Appendix B.3 show the expected signs: there is a higher picture density areas where there are many historic buildings, in built-up areas, and in areas with more water bodies (e.g., the Amsterdam canal district). The same holds if we control for sorting on other household characteristics (e.g., sorting based on household composition) and commuting time.

Table 1 reports the baseline reduced-form results for the income mapping. Column (1) shows a simple regression of log income on log amenities and $\log$ commuting times, while we only control for demographic characteristics and year fixed effects. This shows that more amenities are associated with higher incomes. Doubling amenities implies an increase in neighborhood income of $(\log 2-\log 1) \times 0.0387=2.7 \%$. However, doubling of commuting time seems to attract households whose incomes are $4.6 \%$ higher - contrary to the expectations. In column (2), we add a wide array of controls related to housing quality and add travel-to-work-area fixed effects to address spatial heterogeneity. Although the $R^{2}$ increases by about $30 \%$, the coefficients related to amenities and commuting time are hardly affected. This suggests that amenities and commuting time are not so much correlated to building quality and aggregate 
characteristics of the urban area.

[Table 1 about here]

In column (3) we further aim to address potential measurement error in the picture density and address reverse causality issues by instrumenting amenities and commuting time with historic variables. The instruments are the number of households within commuting distance in 1909 using the railway network in 1900, the shares of water bodies and of built-up area in 1900 within a neighborhood, as well as within $500 \mathrm{~m}$ and between 500 and $1000 \mathrm{~m}$ of a neighborhood's border. ${ }^{16}$ In Appendix C.1, we report the corresponding first-stage results. The share of built-up area, the share of water bodies in 1900 are strongly and positively correlated to the current amenity level, while employment accessibility in 1909 is negatively related to current commuting time. Overall, the Kleibergen-Paap $F$-statistic is above the rule-of-thumb value of 10 in all specifications, suggesting that the instruments are sufficiently strong.

Going back to Table 1, the coefficient of amenities is now somewhat higher: doubling amenities attracts households whose incomes are $2.6 \%$ higher; doubling commuting time implies an effect of $-15 \%$. Column (4) is the most comprehensive specification where we include job characteristics and workplace fixed effects. We consider this as the preferred specification. Doubling amenities attracts households whose incomes are $1.6 \%$ higher. Doubling commuting time leads to households whose incomes are $14 \%$ lower. Hence, the impact of commuting time seems to be somewhat stronger than the impact of amenities.

Despite the inclusion of controls, travel-to-work-area and workplace fixed effects, one may argue that we do not convincingly address the omitted variable bias. We deal with this issue by estimating bias-corrected regressions following Oster (2019) in Appendix C.2. We show that when we choose the appropriate maximum attainable $R^{2}$ (as only part of the variation in incomes can be explained by variables varying at the neighborhood level), the estimates are very close to the preferred IV estimates (so a positive amenity elasticity of around 0.025 and a commuting time elasticity between -0.05 and -0.45$)$. This strongly suggests that the historic instruments address omitted variable bias.

To sum up, the results unequivocally indicate that the impact of amenities on income sorting is positive and highly significant. As for the commuting time, its effect on income sorting is negative and strong. To compare the effects of commuting and amenities, it is informative to look at a standard deviation of a log change in commuting time or amenities. In the preferred specification, a standard deviation increase in log amenities attracts households whose incomes

\footnotetext{
${ }^{16}$ Since we have more instruments than endogenous variables, one might object that two-stage least squares estimates are biased (Angrist and Pischke, 2009). Hence, we also have experimented with other estimators that are (approximately) median unbiased, such as LIML or GMM estimators. The results are virtually identical. For this reason, we do not report them in the paper.
} 
are about $1.656 \times 0.023=3.7 \%$ higher. On the other hand, a standard deviation increase in log commuting time attracts households whose incomes are $0.645 \times 0.207=13.3 \%$ lower. Hence, commuting time seems to be a more important driver of income sorting than amenities. However, the impact of amenities is far from negligible. For example, if we compare an area with the lowest amenity level (some rural area in the north) with the area with the highest amenity level (the center of Amsterdam), the predicted income difference is $28.6 \%$, which is clearly non-negligible.

Alternative proxies for amenities. One may worry that our results hinge on the particular choice of the amenity index. We therefore consider an alternative proxy for amenity endowments. Following Lee and Lin (2018), we construct an aggregate hedonic amenity index that describes the amenity provision at every location using house prices. The procedure is described in Appendix B.3. We report the results in Table 2, which replicates the specifications in Table 1 but replaces picture density by the log of the hedonic amenity index.

[Table 2 about here]

The effect of commuting time is very much comparable to the results reported in Table 1. Regarding the hedonic amenity index, once we control for housing, location, job characteristics, as well as workplace fixed effects in column (2), we find an elasticity of 0.8 , implying that a $100 \%$ increase in the hedonic amenity index leads to an increase in income of $55 \%$. We find a somewhat lower amenity elasticity in column (4) when we include control variables, workplace and travel-to-work-area fixed effects, and instrument for amenities and commuting time with historic variables. Doubling the amenity level is then associated with an increase in incomes of $36 \%$.

To make the results comparable, we rescale the hedonic amenity index in such a way that the standard deviation of the log of the hedonic amenity index is the same as that of the log of the picture density. The estimated elasticity of the rescaled hedonic amenity index then varies between $1.6 \%$ and $2.4 \%$, which is very much comparable to the impact of picture density.

Effects on land prices. We also investigate the reduced-form impacts of amenities and commuting times on land prices, so we estimate a reduced-form version of (20). In our setup the signs of the effects of amenities and commuting time on land prices and incomes are the same (although magnitudes may differ). Therefore, we now estimate the effects of amenities and commuting time on land prices. The results are reported in Table 3.

[Table 3 about here] 
We start in column (1), Table 3, with a simple OLS specification including amenities and commuting time, while controlling for demographic characteristics. This implies a strong positive effect of amenities on land prices: doubling amenities leads to an increase in land price of $(\log 2-\log 1) \times 0.1874=13 \%$, while doubling commuting time leads to land prices that are $2.5 \%$ lower. Column (2) adds job controls and workplace fixed effects, leading to a coefficient that is $50 \%$ lower.

When we instrument for commuting time with accessibility of employment in 1909, the preferred specification in column (4) with job controls and workplace characteristics indicates that doubling amenities leads to an increase in land prices of $13 \%$, which is sizable. The impact of commuting is somewhat imprecisely estimated, but the coefficient is negative. The point estimate indicates that a $100 \%$ increase in commuting time is associated with a decrease in land prices of $27 \%$. Hence, the reduced-form effects on land prices do indeed have the same signs as the effects on income, but are stronger in magnitude. For example, if we compare the land price differential between the location with the lowest and the highest amenity level, it is $238 \%$, which is considerable.

Other sensitivity checks. We consider various additional robustness analyses in Table 4 . First, we show that our results are similar once we focus solely on urban areas. In column (1) we only include observations in the Randstad. This reduces the total number of observations by more than $50 \%$. However, our results are very similar.

[Table 4 about here]

In column (2), Table 4, we include municipality fixed effects. This implies that we identify commuting and amenity effects within municipalities. Municipality fixed effects absorb any effects related to municipal policies and tax differentials. We find very similar coefficients.

Column (3) controls for the current share of built-up areas and population density to make sure that our amenity proxy is not just capturing population density or built-up land. We find very similar effects for amenities, but the effect of commuting time is now stronger. This may be because we have weak instruments, with a Kleibergen-Paap $F$-statistic that is barely 10 .

Another concern is that clusters of high-income households are autocorrelated so that our instruments are correlated to the concentrations of high-income households in 1909. To investigate whether this is an issue, we calculate the share of medium and high-skilled households in 1909. Municipalities then were much smaller so this is a rather fine-grained measure of skill sorting across space. We also gather data on the share of Protestants in each municipality in 1899 and control for population accessibility in 1900. Including those measures in column (4) does not materially impact our coefficients. Note that the share of high-skilled and medium-skilled households in 1909 is negatively correlated to current incomes, which suggests 
that the determinants of residential choices in the two periods are fairly different. In addition, conditional on commuting time, population accessibility in 1900 does not influence the current income distribution.

In column (5) in Table 4 we further study the sensitivity of our results by choosing another instrument for commuting time. We use the share of the population in 1909 born in the same municipality. If mobility of households is correlated over time, the share of locally born people should be positively correlated to current commuting time, as the areas that host a high number of jobs (so have a low commuting time) are expected to attract workers from other places and in turn have a lower share of locally born people. Indeed, we find that the share of locally born people in 1909 is positively associated with current commuting time. The Kleibergen-Paap Fstatistic again indicates that these are strong instruments. We find a similar coefficient related to commuting time.

To the extent one is still concerned that household income sorting is autocorrelated, in column (6) we only include neighborhoods on reclaimed land. The Netherlands is well known for its large-scale projects that reclaim land from the sea. We consider the three main projects (Wieringermeer, Noordoostpolder, Oostelijk, and Zuidelijk Flevoland) that occurred between 1930 and 1968, but permission by the government to reclaim those areas was already given in 1930. Most of the land was intended for agriculture, but a few small settlements were planned on the newly reclaimed land. Moreover, Lelystad was planned to be the largest city in the area, but nowadays Almere is by far the largest one. Hence, the plans differ considerably from the current spatial distribution of activities. Since only a small share of the population lives in those areas, we only keep about $2.5 \%$ of the observations. The latter approach should address any remaining concerns related to reverse causality as no one was living in those locations at that time, and thus income was zero.

We then instrument for amenities and commuting time with the share of planned built-up and green areas and planned accessibility in column (6). The instruments are unfortunately very weak, leading to imprecise coefficients. Still, the point estimates are again similar to the baseline estimates. Instrumenting either amenities or commuting time leads to similar outcomes, but with somewhat lower standard errors.

Appendix C.3 further shows that our results still hold for a wide range of alternative robustness checks and sample selections. We aim to minimize measurement error regarding commuting time and workplace productivity, by running specifications where we only keep households (i) with a single job, (ii) with a single job in a single-plant firm, and (iii) with a company car who are more likely to use the car for commuting. We further test whether our results change when using the share of highly educated adults in the household, which is a measure that is very much correlated to income, but arguably is measured with little error. We find very similar 
effects, both in terms of sign and magnitude, which confirms that looking at income or skill levels is more or less equivalent. We also use commuting time by rail instead of commuting time over the road and focus on areas close to city centers of large cities. Overall, the impact of amenities and commuting time on income sorting choice is robust.

\subsection{Structural parameters}

Estimating structural parameters We think it is instructive if the reduced-form estimates are interpreted through the lens of the structural parameters. Recall that $\alpha_{1} \equiv \psi / v$ and $\alpha_{2} \equiv-\theta(1+(1-\mu) \psi / v)$, where $\psi$ and $v$ are the shape parameters of the Fréchet distributions regarding the LQI and incomes respectively, $\mu$ is the preference for land, and $\theta$ is the commuting time elasticity. To identify all the necessary parameters we take three steps.

First, to determine $\mu$, we use information on land prices $R(x)$ and lot sizes $h(x)$ for a subset of the sample. Rewriting (14) yields:

$$
R(x)=\frac{\mu \tilde{\omega}(x)}{h(x)-(1-\mu) \bar{h}} .
$$

We use nonlinear least squares to obtain an estimate for $\mu$, given a discount rate (to calculate yearly payments to land) and a minimum lot size $\bar{h}$. We set $\bar{h}=25 \mathrm{~m}^{2}$, which corresponds to the minimum lot size in the sample, and we use a discount rate of $3.5 \%$ to go from land prices to land rents (see Koster and Pinchbeck, 2021). ${ }^{17}$

Second, we estimate the reduced-form income mapping (26) to obtain $\hat{\alpha}_{1}$ and $\hat{\alpha}_{2}$. Then, we have:

$$
\hat{\theta}=\frac{\hat{\alpha}_{2}}{(\hat{\mu}-1) \hat{\alpha}_{1}-1} .
$$

Third, we calculate the LQI, given by equation (23), and then fit a Fréchet distribution through the estimated $\hat{\Delta}(x)$ using Maximum Likelihood to obtain an estimate for $\hat{\psi}$. Hence, $v=\hat{\psi} / \hat{\alpha}_{1}$. Table 5 reports the results.

[Table 5 about here]

We first find $\hat{\mu}=0.0955$, which confirms that richer households spend less of their income on land (Albouy et al., 2016). One may be concerned that $\hat{\mu}$ may seem low compared to the existing literature, but we only include payments to land, not to housing itself. We further show that the commuting time elasticity $\hat{\theta}=0.2024$. This elasticity seems reasonable: doubling the

\footnotetext{
${ }^{17}$ In Appendix C.4 we consider some robustness checks with respect to different values of the minimum lot size and the discount rate. This hardly affects the estimate for $\mu$.
} 
commuting time decreases gross income by $6 \% .{ }^{18}$ Last, we find that there is considerably more heterogeneity in the LQI as compared to incomes, as $\hat{\psi} \ll \hat{v}$. To put it differently, locations are much more differentiated (in terms of amenities and commuting time) than households (in terms of incomes).

Determining the LQI and the income mapping. Using the estimated structural parameters and (23), we can calculate the LQI for each household living at different locations. We show a histogram of the LQI in Figure 2.

[Figure 2 about here]

This shows that the LQI is well approximated by a Fréchet distribution, which is flexible enough to capture the positively skewed distribution of the LQI.

We can further use the estimated parameters to calculate the income mapping $\hat{\omega}^{*}(x)$ throughout the Netherlands. Note that this mapping is identified up to a multiplicative constant. We display the results in Figure 3 where we focus on the most urbanized part of the Netherlands: the Randstad. We observe that the highest income households locate in city centers of Amsterdam, Utrecht, Rotterdam and the Hague, where amenity levels are high and commuting times relatively short.

[Figure 3 about here]

\section{Concluding remarks}

We have used a new setup in which location are differentiated by two attributes, i.e., amenity endowments and commuting costs. The bid-rent function of urban economics may be used to show that the uneven distribution of amenity endowments is sufficient to break down the perfect sorting of households across the city space. Under Stone-Geary, quasi-linear or a generalized CES preferences, there exists a LQI that blends amenities and commuting costs into a single aggregate whose behavior drives households's residential choices. Studying this LQI has allowed us to gain insights about how governments and urban planners could design policies whose aim is to redraw the social map of cities. For example, our analysis suggests that promoting equal access to amenities across individuals is likely to favor residential segregation, whereas a multi-modal provision of amenities across the city fosters income mixing. The relevance of local amenity endowments and commuting costs to explain the residential choices of heterogeneous

\footnotetext{
${ }^{18}$ Using a gravity model of commuting flows, Ahlfeldt et al. (2015) find a commuting time semi-elasticity of about 0.1. Although not directly comparable to our estimate (because we estimate an elasticity), they show that utility decreases by about $7 \%$ when commuting time increases from 5 to 10 minutes; and by $14 \%$ when commuting time increases from 10 to 20 minutes. Hence, our estimate is in the same ballpark.
} 
consumers is confirmed by the empirical analysis where both effects are found to be economically and statistically significant.

\section{References}

[1] Ahlfeldt, G.M. 2013. Urbanity. London School of Economics, memo.

[2] Ahlfeldt, G.M., Redding, S.J., Sturm, D., Wolf, K. 2015. The economics of density: Evidence from the Berlin Wall. Econom. 83(6), 2127-89.

[3] Albouy, D. 2016. What are cities worth? Land rents, local productivity, and the total value of amenities. Rev. Econ. Stat. 98(3), 477-87.

[4] Albouy, D., Ehrlich, G., Liu, Y. 2016. Housing demand, costs-of-living inequality, and the affordability crisis. NBER Working Paper 22816.

[5] Allen, T., Arkolakis, C. 2014. Trade and the topography of the spatial economy. Q. J. Econ. 129(3), 1085-140.

[6] Altonji, J.G., Elder, T.E., Taber, C.R. 2005. An evaluation of instrumental variables strategies for estimating effects of Catholic schooling. J. Hum. Resources 40(4), 791-821.

[7] Bayer, P., Ferreira, F., McMillan, R. 2007. A unified framework for measuring preferences for schools and neighborhoods. J. Polit. Econ. 115(4), 588-638.

[8] Beckmann, M.J. 1969. On the distribution of urban rent and residential density. J. Econ. Theory 1(1), 60-7.

[9] Behrens, K., Kichko, S., Thisse, J.-F. 2021. Working from home: Too much of a good thing? CESifo Working Paper 8831.

[10] Boppart T. 2014. Structural change and the Kaldor facts in a growth model with relative price effects and non-Gorman preferences. Econom. 82(6): 2167-96.

[11] Brueckner, J., Rosenthal, S.S. 2009. Gentrification and neighbourhood cycles: Will America's future downtowns be rich? Rev. Econ. Stat. 91(4): 725-43.

[12] Brueckner, J., Thisse, J.-F., Zenou, Y. 1999. Why is Central Paris rich and Downtown Detroit poor? An amenity-based theory. Eur. Econ. Rev. 43(1), 91-107.

[13] Carlino, G.A., Saiz, A. 2019. Beautiful city: Leisure amenities and urban growth. J. Reg. Sci. 59(3), 369-408. 
[14] Chiappori, P.-A. 2017. Matching with transfers. The economics of love and marriage. Princeton: Princeton University Press.

[15] Combes, P.P., Duranton, G., Gobillon, L. 2008. Spatial wage disparities: Sorting matters! J. Urban Econ. 63(2), 723-42.

[16] Couture, V. 2016. Valuing the consumption benefits of urban density. University of California, Berkeley, memo.

[17] Couture, V., Gaubert, C., Handbury, J., Hurst, E. 2019. Income growth and the distributional effects of urban spatial sorting. NBER WP 26142.

[18] Cuberes, D., Roberts, J., Sechel, C. 2019. Household location in English cities. Reg. Sci. Urban Econ. 75, 120-35.

[19] de Palma, A., Papageorgiou, Y.Y., Thisse, J.-F., Ushchev, Ph. 2019. About the origin of cities. J. Urban Econ. 111, 1-13.

[20] Department of Transport, Communications and Public Works. 2010. Mobiliteitsbalans 2010. The Hague: Kennisinstituut voor Mobiliteit.

[21] Diamond, R. 2016. The determinants and welfare implications of US workers diverging location choices by skill: 1980-2000. Am. Econ. Re. 106(3), 479-524.

[22] Duranton, G., Puga, D. 2015. Urban land use. In: G. Duranton, V. Henderson and W. Strange (eds). Handbook of Regional and Urban Economics, Volume 5. Amsterdam: Elsevier, 2063-117.

[23] Epple, D., Gordon, B., Sieg, H. 2010. Drs. Muth and Mills meet Dr. Tiebout: Integrating location-specific amenities into multi-community equilibrium models. J. Reg. Sci. 50(1), 381-400.

[24] Epple, D., Nechyba, T. 2004. Fiscal decentralization. In: V. Henderson and J.-F. Thisse (eds). Handbook of Regional and Urban Economics. Volume 4. Amsterdam: Elsevier, 561624 .

[25] Fujita, M. 1989. Urban Economic Theory. Cambridge: Cambridge University Press.

[26] Gaigné, C., Koster, H., Moizeau, F., Thisse, J.-F. 2020. Income sorting across space: The role of amenities and commuting costs. VU Amsterdam, memo.

[27] Geels, F. W. 2006. The hygienic transition from cesspools to sewer systems (1840-1930): The dynamics of regime transformation. Research Policy 35(7), 1069-82. 
[28] Glaeser, E.L., Kahn, M., Rappaport, J. 2008. Why do the poor live in cities? J. Urban Econ. 63(1), 1-24.

[29] Glaeser, E.L., Kolko, J. and Saiz, A. 2001. Consumer city. J. Econ. Geogr. 1(1), 27-50.

[30] Gravel, N., Oddou, R. 2014. The segregative properties of endogenous jurisdiction formation with a land market. J. Pub. Econ. 117, 15-27.

[31] Hartwick, J.M., Schweizer, U., Varaiya, P.V. 1976. Comparative statics of a residential economy with several classes. J. Econ. Theory 13(3), 396-413.

[32] Hoelzlein, M. 2020. Two-sided sorting and spatial inequality in cities. UC Berkeley, memo.

[33] Knol, W. C., H. Kramer and H. Gijsbertse (2004) Historisch grondgebruik Nederland: Een landelijke reconstructie van het grondgebruik rond 1900. Wageningen: Alterra.

[34] Koomen, E., Dekkers, J., Van Dijk, T. 2008. Open-space preservation in the Netherlands: Planning, practice and prospects. Land Use Policy 25(3), 361-77.

[35] Koopmans, C., Rietveld, P., Huijg, A. 2012. An accessibility approach to railways and municipal population growth, 1840-1930. J. Transp. Geogr. 25, 98-104.

[36] Koster, P.R., Koster, H.R.A. 2015. Commuters' preferences for fast and reliable travel: A semiparametric estimation approach. Trans. Res. Part B: Methodological 81, 289-301.

[37] Koster, H.R.A., Pinchbeck, T. 2021. How do households value the future? Evidence from property taxes. Am. Econ. J: Econ. Policy, in Press.

[38] Koster, H.R.A., Rouwendal, J. 2017. Historic amenities and housing externalities. Evidence from the Netherlands. Econ. J. 127(605), F396-F420.

[39] Kuratowski, K. 1968. Topology. Academic Press.

[40] Lee, S., Lin, J. 2018. Natural amenities, neighborhood dynamics, and persistence in the spatial distribution of income. Rev. Econ. Stud. 85(1), 663-94.

[41] Lucas Jr., R.E., Rossi-Hansberg, E. 2002. On the internal structure of cities. Econometrica 70(4): $1445-76$.

[42] Manning, A. 2003. The real thin theory: Monopsony in modern labour markets. Labour Econ. 10(2), 105-31.

[43] Monte, F., Redding, S.J., Rossi-Hansberg, E. 2018. Commuting, migration, and local employment elasticities. Am. Econ. Rev. 108(12): 3855-90. 
[44] Montesano, A. 1972. A restatement of Beckmann's model of distribution of urban rent and residential density. J. Econ. Theory 4(2), 329-54.

[45] Mukerji, V. 1963. A generalized S.M.A.C. function with constant ratios of elasticity of substitution. R. Econ. Stud. 30(3), 233-36.

[46] Mulalic, I., van Ommeren, J.N., Pilegaard, N. 2013. Wages and commuting: Quasi-natural experiments' evidence from firms that relocate. Econ. J. 124(579), 1086-105.

[47] Oster, E. 2019. Unobservable selection and coefficient stability: Theory and evidence. J. Bus. Econ. Stat. 37(2), 187-204.

[48] Ritzen, J.M.M., van Dommelen, J., de Vijlder, F.J. 1997. School finance and school choice in the Netherlands. Econ. Education Rev. 16(3), 329-35.

[49] Rosenthal, S.S., Ross, S.L. 2015. Change and persistence in the economic status of neighborhoods and cities. In: G. Duranton, V. Henderson and W. Strange (eds). Handbook of Regional and Urban Economics, Volume 5. Amsterdam: Elsevier Publisher, 1047-1120.

[50] Rossi-Hansberg, E., Sarte, P.D., Owens III, R. 2010. Housing externalities. J. Polit. Econ. 118(3), 485-535.

[51] Saiz, A., Salazar, A., Bernard, J. 2018. Crowdsourcing architectural beauty: Online photo frequency predicts building aesthetic ratings. PLOS One 13: e0194369.

[52] Schmidheiny, K. 2006. Income segregation from local income taxation when households differ in both preferences and incomes. Reg. Sci. Urban Econ. 36, 270-99.

[53] Thisse, J.-F., Turner, M., Ushchev, P. (2021) A unified theory of cities. NBER Working Paper 29078.

[54] Tsivanidis, N. 2019. The aggregate and distributional effects of urban transit infrastructure: Evidence from Bogotá's TransMilenio. UC Berkeley, memo. 


\section{Tables}

TABle 1 - BASELINE REGRESSION RESUlTS

(Dependent variable: the log of household gross income)

\begin{tabular}{|c|c|c|c|c|}
\hline & \multirow[b]{2}{*}{$\begin{array}{l}(1) \\
\text { OLS }\end{array}$} & \multirow{2}{*}{$\begin{array}{c}\frac{+ \text { Job controls }}{(2)} \\
\text { OLS }\end{array}$} & \multicolumn{2}{|c|}{ Historic instruments } \\
\hline & & & $\begin{array}{c}(3) \\
2 \mathrm{SLS}\end{array}$ & $\begin{array}{c}(4) \\
\text { 2SLS }\end{array}$ \\
\hline Pictures per ha (log) & $\begin{array}{c}0.0387^{* * *} \\
(0.0017)\end{array}$ & $\begin{array}{c}0.0294^{* * * *} \\
(0.0013)\end{array}$ & $\begin{array}{c}0.0368^{* * *} \\
(0.0075)\end{array}$ & $\begin{array}{c}0.0226^{* * *} \\
(0.0065)\end{array}$ \\
\hline Commuting time (log) & $\begin{array}{c}0.0670^{* * * *} \\
(0.0013)\end{array}$ & $\begin{array}{c}0.0694^{* * * *} \\
(0.0011)\end{array}$ & $\begin{array}{c}-0.2179^{* *} \\
(0.0895)\end{array}$ & $\begin{array}{c}-0.2065^{* * *} \\
(0.0657)\end{array}$ \\
\hline Household controls & Yes & Yes & Yes & Yes \\
\hline Housing controls & No & Yes & Yes & Yes \\
\hline Job controls & No & No & No & Yes \\
\hline Year fixed effects & Yes & Yes & Yes & Yes \\
\hline Travel-to-work-area fixed effects & No & Yes & Yes & Yes \\
\hline Workplace fixed effects & No & No & No & Yes \\
\hline Number of observations & $10,213,540$ & $10,213,540$ & $10,213,540$ & $10,213,540$ \\
\hline$R^{2}$ & 0.1996 & 0.2594 & & \\
\hline Kleibergen-Paap $F$-statistic & & & 14.29 & 17.81 \\
\hline \multicolumn{5}{|c|}{$\begin{array}{l}\text { Notes: Bold indicates instrumented. Household controls include household size, mean age of } \\
\text { adults, mean gender, household type (couple, single, kids), the share of the household that is } \\
\text { foreign-born. Job controls are the total hours worked, whether the household has a company car, } \\
\text { the share of full-time contracts, the share of permanent contracts. Housing controls include house } \\
\text { type, height of the building, construction year dummies and whether a building is listed. Standard } \\
\text { errors are clustered at the neighborhood level and in parentheses. }{ }^{* * *} p<0.01,{ }^{* *} p<0.05 \text {, * } \\
p<0.10\end{array}$} \\
\hline
\end{tabular}


TABLE 2 - A HEDONIC AMENITY INDEX

(Dependent variable: the log of household gross income)

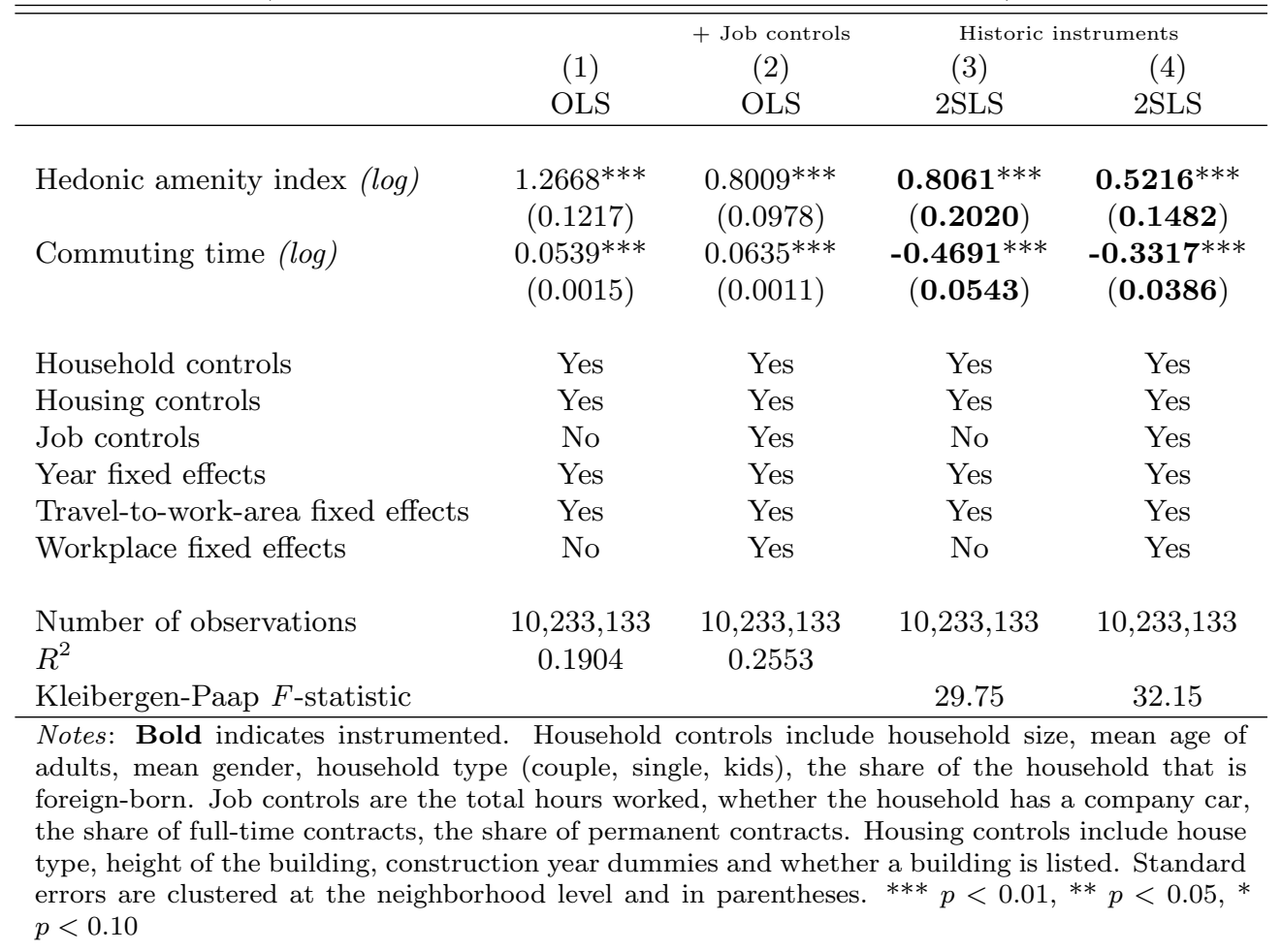

TABLE 3 - EFFECTS ON LAND PRICES

(Dependent variable: the log of land price)

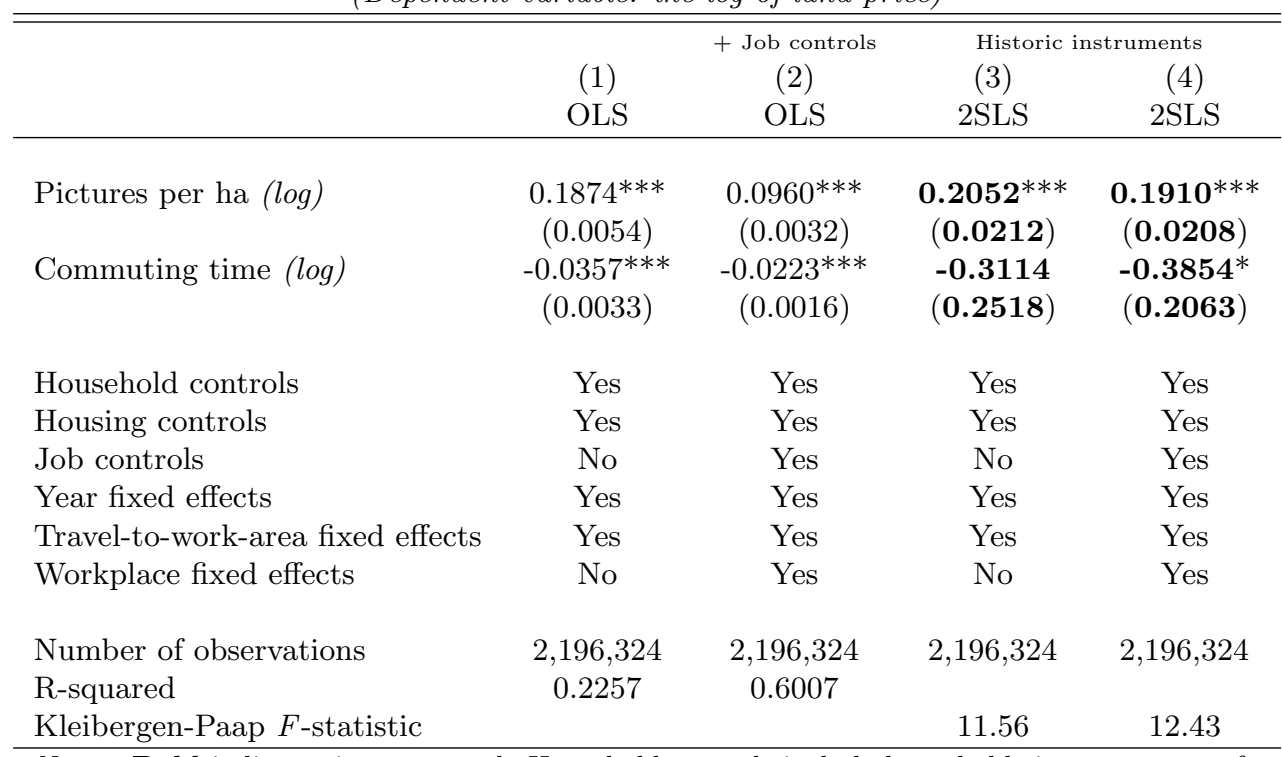

Notes: Bold indicates instrumented. Household controls include household size, mean age of adults, mean gender, household type (couple, single, kids), the share of the household that is foreign-born. Job controls are the total hours worked, whether the household has a company car, the share of full-time contracts, the share of permanent contracts. Housing controls include house type, height of the building, construction year dummies and whether a building is listed. Standard errors are clustered at the neighborhood level and in parentheses. ${ }^{* * *} p<0.01,{ }^{* *}$ $p<0.05, * p<0.10$ 
TABLE 4 - IDENTIFICATION REVISITED

(Dependent variable: the log of household gross income)

\begin{tabular}{|c|c|c|c|c|c|c|}
\hline & $\begin{array}{c}\text { Only } \\
\text { Randstad }\end{array}$ & $\begin{array}{c}+ \text { Municipality } \\
\text { fixed effects }\end{array}$ & $\begin{array}{c}\text { Control for } \\
\text { current land use }\end{array}$ & $\begin{array}{l}1909 \\
\text { skills }\end{array}$ & $\begin{array}{c}\text { Other } \\
\text { instruments }\end{array}$ & $\begin{array}{c}\text { Reclaimed } \\
\text { land }\end{array}$ \\
\hline & $\begin{array}{c}(1) \\
2 \text { SLS }\end{array}$ & $\begin{array}{c}(2) \\
\text { 2SLS }\end{array}$ & $\begin{array}{c}(3) \\
\text { 2SLS }\end{array}$ & $\begin{array}{c}(4) \\
\text { 2SLS }\end{array}$ & $\begin{array}{c}(5) \\
2 \mathrm{SLS}\end{array}$ & $\begin{array}{c}(6) \\
\text { 2SLS }\end{array}$ \\
\hline Pictures per ha $(\log )$ & $\begin{array}{c}0.0300^{* * *} \\
(0.0102)\end{array}$ & $\begin{array}{c}\mathbf{0 . 0 2 4 0} * * * \\
(0.0072)\end{array}$ & $\begin{array}{c}0.0206^{* *} \\
(0.0080)\end{array}$ & $\begin{array}{c}0.0229 * * * \\
(0.0069)\end{array}$ & $\begin{array}{c}0.0305^{* * *} \\
(0.0070)\end{array}$ & $\begin{array}{c}0.0191 \\
(0.0143)\end{array}$ \\
\hline Commuting time $(\log )$ & $\begin{array}{c}-0.2427^{* *} \\
(0.1146)\end{array}$ & $\begin{array}{c}-0.2230^{* * *} \\
(0.0861)\end{array}$ & $\begin{array}{c}-0.5618^{* * *} \\
(0.1121)\end{array}$ & $\begin{array}{c}-0.2962^{* * *} \\
(0.0865)\end{array}$ & $\begin{array}{c}-0.1647^{* *} \\
(0.0790)\end{array}$ & $\begin{array}{l}-0.0561 \\
(0.1077)\end{array}$ \\
\hline Share built-up land & & & $\begin{array}{c}-0.1632^{* * *} \\
(0.0238)\end{array}$ & & & \\
\hline Population per ha (log) & & & $\begin{array}{c}-0.0234^{* * *} \\
(0.0041)\end{array}$ & & & \\
\hline Share of medium-skilled workers in 1909 & & & & $\begin{array}{c}-0.2068^{* * *} \\
(0.0287)\end{array}$ & $\begin{array}{c}-0.1747^{* * *} \\
(0.0265)\end{array}$ & \\
\hline Share of high-skilled workers in 1909 & & & & $\begin{array}{l}-0.1187 \\
(0.0990)\end{array}$ & $\begin{array}{l}-0.0822 \\
(0.0956)\end{array}$ & \\
\hline Share protestants in 1899 & & & & $\begin{array}{l}-0.0008 \\
(0.0113)\end{array}$ & $\begin{array}{l}-0.0072 \\
(0.0102)\end{array}$ & \\
\hline Population accessibility in 1900 (log) & & & & $\begin{array}{l}-0.0053 \\
(0.0056)\end{array}$ & $\begin{array}{c}0.0002 \\
(0.0051)\end{array}$ & \\
\hline Household controls & Yes & Yes & Yes & Yes & Yes & Yes \\
\hline Housing controls & Yes & Yes & Yes & Yes & Yes & Yes \\
\hline Job controls & Yes & Yes & Yes & Yes & No & Yes \\
\hline Year fixed effects & Yes & Yes & Yes & Yes & Yes & Yes \\
\hline Travel-to-work-area fixed effects & Yes & Yes & Yes & Yes & Yes & Yes \\
\hline Municipality fixed effects & No & Yes & No & No & No & No \\
\hline Workplace fixed effects & Yes & Yes & Yes & Yes & Yes & Yes \\
\hline Number of observations & $4,340,639$ & $10,213,540$ & $10,213,540$ & $10,213,540$ & $10,213,540$ & 270,106 \\
\hline Kleibergen-Paap $F$-statistic & 7.500 & 18.18 & 10.05 & 16.08 & 21.49 & 0.264 \\
\hline
\end{tabular}

Notes: Bold indicates instrumented. Household controls include household size, mean age of adults, mean gender, household type (couple, single, kids), the share of the household that is foreign-born. Job controls are the total hours worked, whether the household has a company car, the share of full-time contracts, the share of permanent contracts. Housing controls include house type, height of the building, construction year dummies and whether a building is listed. Standard errors are clustered at the neighborhood level and in parentheses. $* * * p<0.01, * * p<0.05,{ }^{*} p<0.10$

TABLE 5 - StRUCTURAL PARAMETERS

\begin{tabular}{lcc}
\hline \hline & & $(1)$ \\
\hline & $\hat{\mu}$ & $0.0955^{* * *}$ \\
& & $(0.0003)$ \\
& & $0.2024^{* * *}$ \\
Comm preferences & $(0.0683)$ \\
& & $0.6011^{* * *}$ \\
Shape parameter of $\Delta(x)$ & $\hat{\psi}$ & $(0.0072)$ \\
& & $103.5325^{* * *}$ \\
Scale parameter of $\Delta(x)$ & $\hat{\Psi}$ & $(20.4708)$ \\
& & $26.9049^{* * *}$ \\
Shape parameter of $\omega^{*}(x)$ & $\hat{v}$ & $(11.1553)$ \\
& & $10,213,524$ \\
& & \\
Number of observations & &
\end{tabular}




\section{Figures}
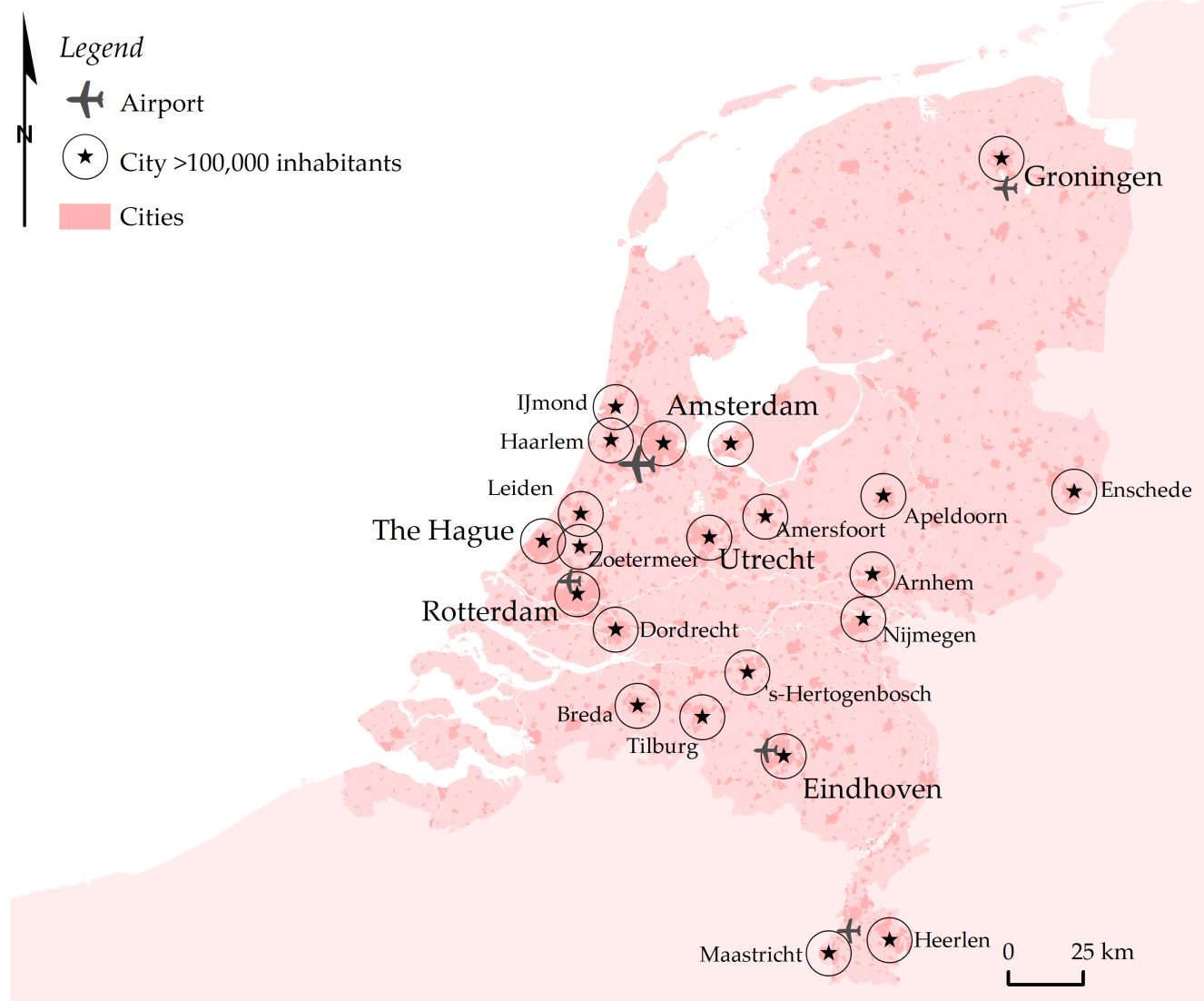

(a) Overview map

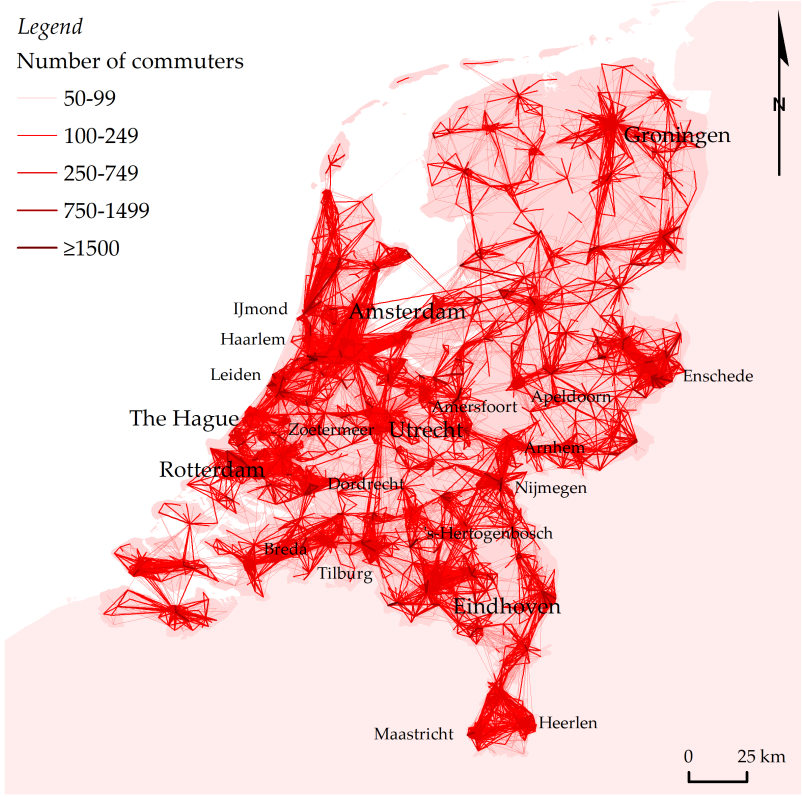

(B) Commuting Networks

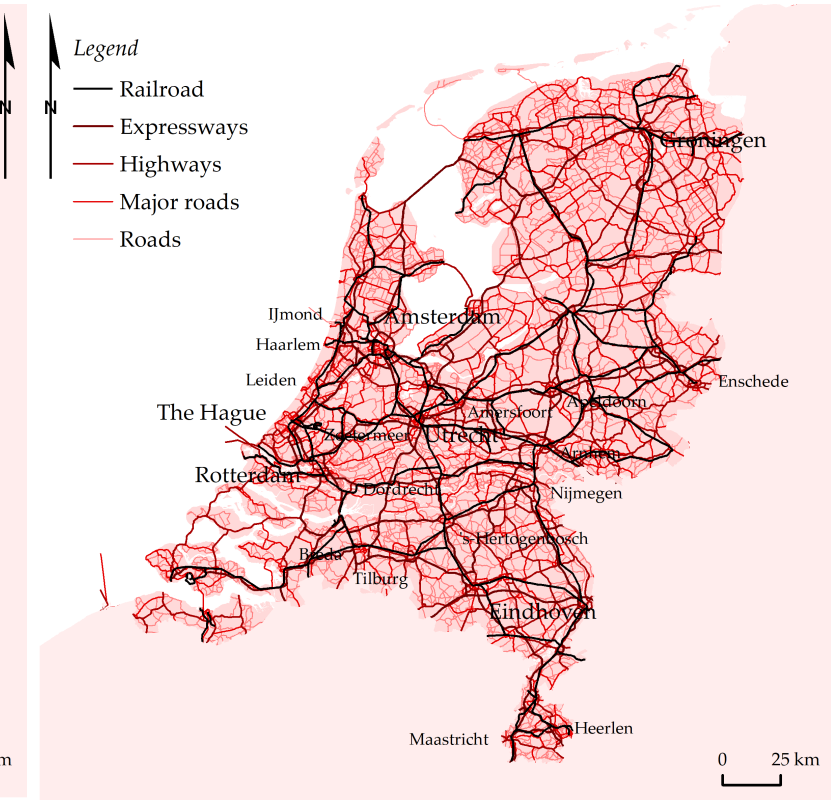

(c) Transport Network

Figure 1 - The Netherlands 


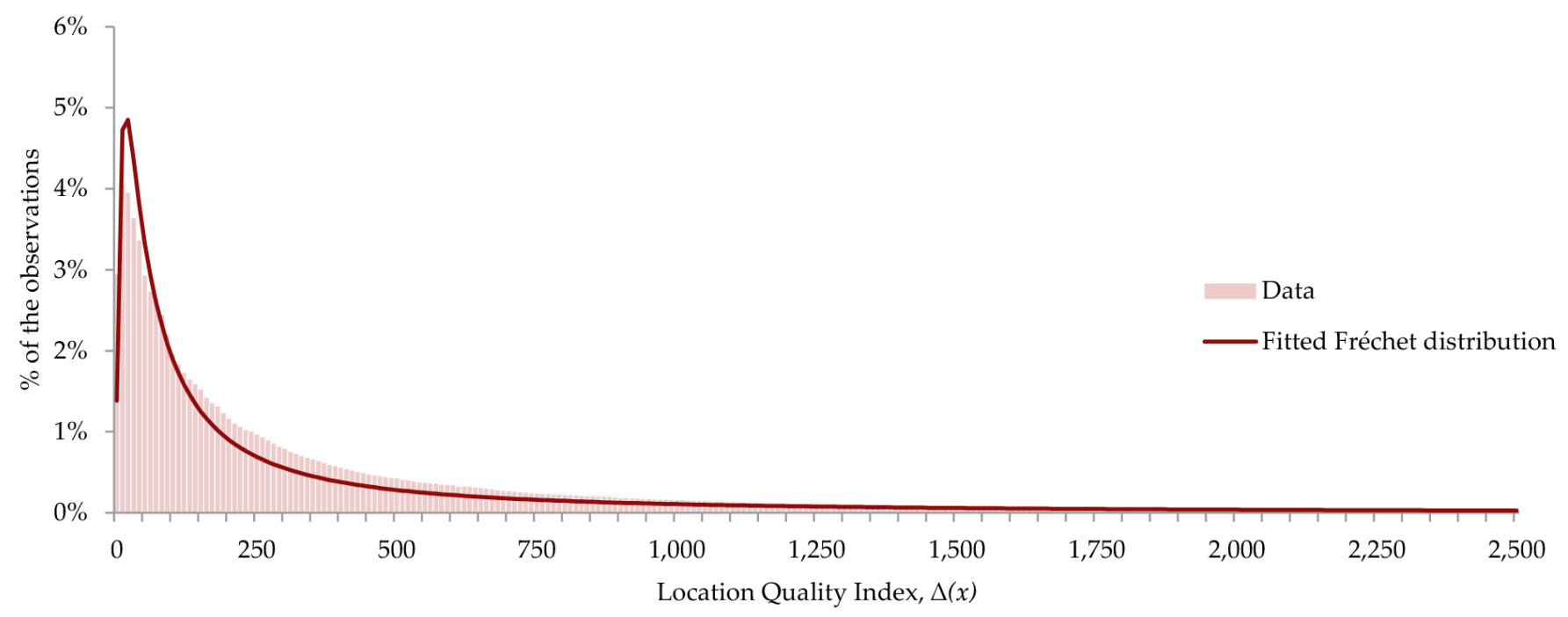

Figure 2 - The LOCATION QUALity INDEX

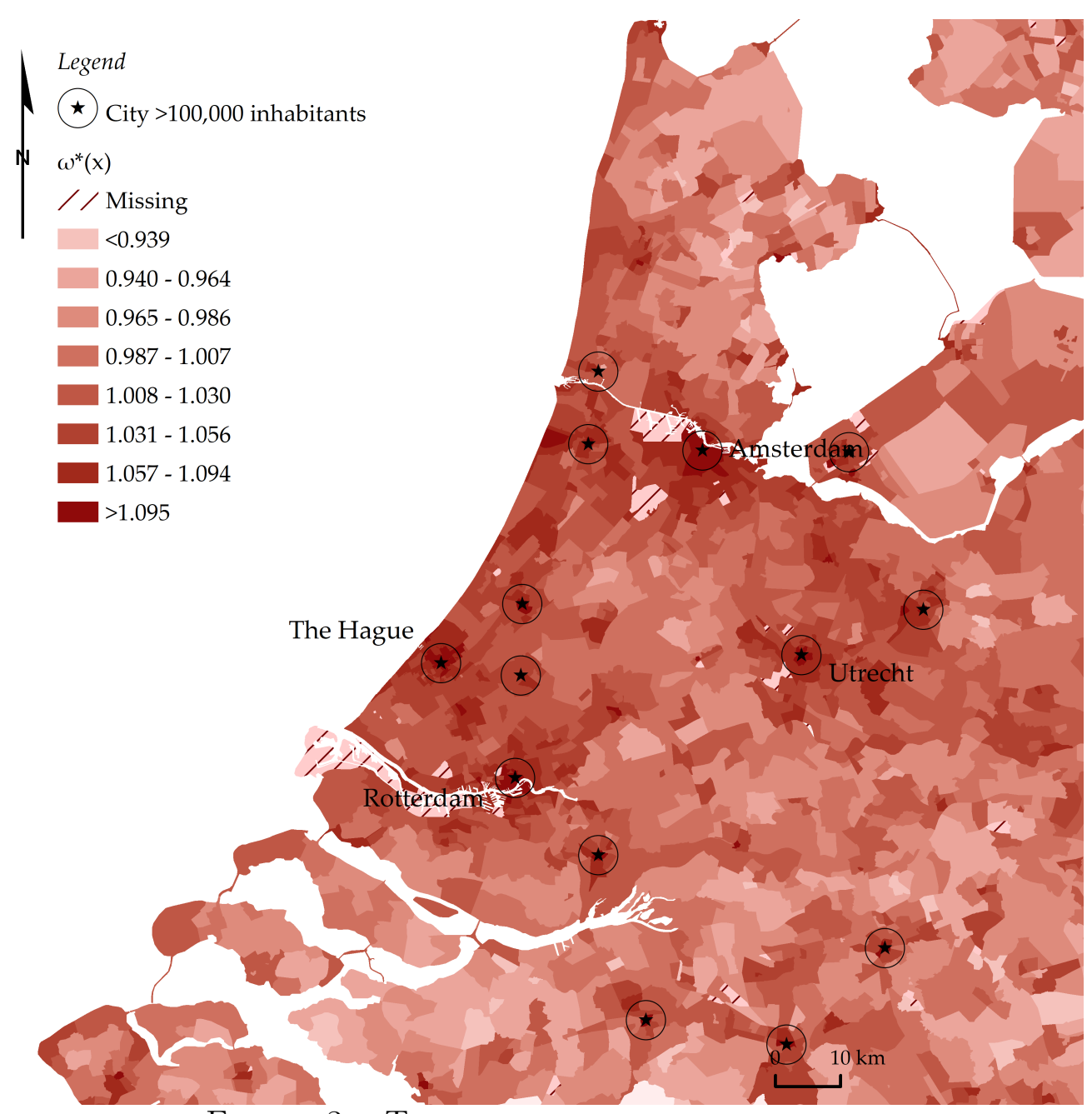

Figure 3 - The PREDICTED INCOME MAPPING 


\section{Appendix A. Theory}

\section{A.1 Proof of Proposition 1}

Differentiating (8) with respect to $x$ and using (7), we obtain:

$$
\Phi_{x}\left(x, \omega, U^{*}(\omega)\right)=\frac{\omega t}{H}\left(\frac{t_{x}}{t}-\frac{Q_{b}}{\omega t} b_{x}\right)
$$

Differentiating (A.1) with respect to $\omega$ and rearranging terms yields the following expression:

$$
\begin{aligned}
\Phi_{x \omega}\left(x, \omega, U^{*}(\omega)\right)= & \frac{t}{H}\left\{\frac{t_{x}}{t}\left[1-\frac{\omega}{H}\left(H_{\omega}+H_{U} U_{\omega}^{*}\right)\right]\right. \\
& \left.+\frac{b_{x}}{t}\left[\frac{H_{\omega}+H_{U} U_{\omega}^{*}}{H} Q_{b}-\left(Q_{b H}\left(H_{\omega}+H_{U} U_{\omega}^{*}\right)+Q_{b U} U_{\omega}^{*}\right)\right]\right\} .
\end{aligned}
$$

Since $Q$ is the solution to the equation $u(q, h)=U / b(x)$, the following expressions must hold:

$$
\begin{aligned}
Q_{b} & =-\frac{U}{b^{2} u_{q}} \\
Q_{b U} & =-\frac{1}{b^{2} u_{q}}+\frac{U}{b^{2} u_{q}^{2}} u_{q q} Q_{U} \\
Q_{b H} & =\frac{U}{b^{2} u_{q}^{2}}\left(u_{q q} Q_{H}+u_{q h}\right) .
\end{aligned}
$$

Assume that the $\omega$-households are located at $x$. Differentiating $u=U^{*}(\omega) / b$ with respect to $\omega$ and using the budget constraint $Q=\omega t(x)-H \Phi$ and (9), we obtain:

$$
\left[t-\left(H_{\omega}+H_{U} U_{\omega}^{*}\right) \Phi\right] u_{q}+\left(H_{\omega}+H_{U} U_{\omega}^{*}\right) u_{h}=\frac{U_{\omega}^{*}}{b} .
$$

Since

$$
-u_{q} \Phi+u_{h}=0
$$

at the residential equilibrium, we have:

$$
t=\frac{U_{\omega}^{*}}{b u_{q}} .
$$

Plugging this expression, $Q_{b}, Q_{b U}$ and $Q_{b H}$ in (A.2), we get

$$
\begin{aligned}
\Phi_{x \omega}\left(x, \omega, U^{*}(\omega)\right)= & \frac{t}{H}\left\{\frac{t_{x}}{t}\left[1-\frac{\omega}{H}\left(H_{\omega}+H_{U} U_{\omega}^{*}\right)\right]\right. \\
& -\frac{b_{x}}{U_{\omega}^{*}} b u_{q} \frac{H_{\omega}+H_{U} U_{\omega}^{*}}{H} \frac{U^{*}}{b^{2} u_{q}} \\
& \left.-\frac{b_{x}}{U_{\omega}^{*}} b u_{q}\left[\frac{U}{b^{2} u_{q}^{2}}\left(u_{q q} Q_{H}+u_{q h}\right)\left(H_{\omega}+H_{U} U_{\omega}^{*}\right)-\frac{U_{\omega}}{b^{2} u_{q}}+\frac{U}{b^{2} u_{q}^{2}} u_{q q} Q_{U} U_{\omega}^{*}\right]\right\},
\end{aligned}
$$


which is equivalent to

$$
\begin{aligned}
\Phi_{x \omega}\left(x, \omega, U^{*}(\omega)\right)= & \frac{t}{H}\left\{-T(x)\left[1-\frac{\omega}{H}\left(H_{\omega}+H_{U} U_{\omega}^{*}\right)\right]\right. \\
& \left.+B(x)\left[1-\frac{H_{\omega}+H_{U} U_{\omega}^{*}}{\omega H} \frac{\omega U}{U_{\omega}^{*}}-\frac{\omega U}{u_{q} \omega U_{\omega}^{*}}\left(u_{q q} Q_{H}+u_{q h}\right)\left(H_{\omega}+H_{U} U_{\omega}^{*}\right)-\frac{U}{u_{q}^{*}} u_{q q} Q_{U}\right]\right\} .
\end{aligned}
$$

Using

$$
\frac{\mathrm{d} u_{q}}{\mathrm{~d} \omega}=u_{q q} Q_{H}\left(H_{\omega}+H_{U} U_{\omega}^{*}\right)+u_{q q} Q_{U} U_{\omega}^{*}+u_{q h}\left(H_{\omega}+H_{U} U_{\omega}^{*}\right),
$$

we can rewrite $\Phi_{x \omega}$ as follows:

$$
\Phi_{x \omega}\left(x, \omega, U^{*}(\omega)\right)=\frac{t}{H}\left[\left(1-\frac{\mathcal{E}_{H, \omega}+\mathcal{E}_{u_{q}, \omega}}{\mathcal{E}_{U, \omega}}\right) B-\left(1-\mathcal{E}_{H, \omega}\right) T\right],
$$

which proves Proposition 1.

Income-independent commuting costs If commuting costs are given by $\omega \tau(x)+c(x)$, the bid rent function $\Phi\left(x, \omega, U^{*}(\omega)\right)$ is given by

$$
\Phi\left(x, \omega, U^{*}(\omega)\right) \equiv \max _{h} \frac{\omega t(x)-c(x)-Q(h, U / a(x))}{h} .
$$

Consequently,

$$
\Phi_{x}\left(x, \omega, U^{*}(\omega)\right)=\frac{1}{H}\left(\omega t_{x}-c_{x}+\frac{b_{x}}{b} \frac{u}{u_{q}}\right)
$$

and

$$
\Phi_{x \omega}\left(x, \omega, U^{*}(\omega)\right)=\frac{t_{x}}{H}\left(1-\mathcal{E}_{H, \omega}\right)+\frac{b_{x}}{b H} \frac{u}{\omega u_{q}}\left(\mathcal{E}_{U, \omega}-\mathcal{E}_{H, \omega}-\mathcal{E}_{u_{q}, \omega}\right)+\frac{\mathcal{E}_{H, \omega}}{H} \frac{c_{x}}{\omega} .
$$

Using (11) and (A.1), one can rearrange the above expression:

$$
\Phi_{x \omega}\left(x, \omega, U^{*}(\omega)\right)=\frac{t}{H}\left[B(x)\left(1-\frac{\mathcal{E}_{H, \omega}+\mathcal{E}_{u_{q}, \omega}}{\mathcal{E}_{U, \omega}}\right)-T(x)\left(1-\mathcal{E}_{H, \omega}\right)+\frac{c_{x}}{\omega t} \mathcal{E}_{H, \omega}\right] .
$$

When $t(x)$ is constant, $T(x)=0$. Therefore, when $B(x)=0$, we obtain

$$
\Phi_{x \omega}\left(x, \omega, U^{*}(\omega)\right)=\frac{c_{x}}{\omega t} \mathcal{E}_{H, \omega}>0 .
$$

\section{A.2 Homothetic preferences}

Assume that the utility $u(q, h)$ is homothetic, that is, homogeneous linear. Then, it must be that $\mathcal{E}_{h, \omega}=\mathcal{E}_{q, \omega}=1$. The first-order condition for utility maximization implies

$$
u_{h}=R u_{q}
$$

It follows from Euler's theorem that

$$
\begin{aligned}
h u_{h}+q u_{q} & =u \\
& \Leftrightarrow h \frac{u_{h}}{u}+q \frac{u_{q}}{u}=1,
\end{aligned}
$$


that is,

$$
\mathcal{E}_{U, h}+\mathcal{E}_{U, q}=1
$$

Since the income elasticity of utility is given by

$$
\mathcal{E}_{U, \omega}=\mathcal{E}_{U, h} \cdot \mathcal{E}_{h, \omega}+\mathcal{E}_{U, q} \cdot \mathcal{E}_{q, \omega}
$$

we get

$$
\mathcal{E}_{U, \omega}=1
$$

It remains to determine $\partial u_{q} / \partial \omega$. Using the first-order condition $u_{h}=R u_{q}$, the budget constraint $R h+q=\omega t$ and Euler's theorem, we obtain:

$$
u_{q}=\frac{u}{\omega t} .
$$

Taking the total derivative of this expression with respect to $\omega$ yields:

$$
\frac{d u_{q}}{d \omega}=\frac{1}{t} \frac{(d u / d \omega) \omega-u}{\omega^{2}}=\frac{u}{\omega^{2} t}\left(\mathcal{E}_{U, \omega}-1\right)=\frac{u_{q}}{\omega}\left(\mathcal{E}_{U, \omega}-1\right)
$$

so that $\mathcal{E}_{u_{q}, \omega}=0$.

To sum up, we have $\mathcal{E}_{U, \omega}=1, \mathcal{E}_{H, \omega}=\mathcal{E}_{h, \omega}=1$ and $\mathcal{E}_{u_{q}, \omega}=0$.

\section{A.3 Stone-Geary preferences}

It is readily verified from (12) that

$$
Q(h, U / b(x))=\left[\frac{1}{(h-\bar{h})^{\mu}} \frac{U}{b}\right]^{\frac{1}{1-\mu}} .
$$

It follows from this expression that

$$
\begin{aligned}
Q_{U} & =\frac{1}{1-\mu} U^{\frac{1}{1-\mu}-1}\left[\frac{1}{b(h-\bar{h})^{\mu}}\right]^{\frac{1}{1-\mu}}=\frac{1}{(1-\mu)} \frac{Q}{U}, \\
Q_{U b} & =-\frac{Q_{U}}{(1-\mu) b}, \\
Q_{b} & =-\frac{U}{b} Q_{U}, \\
Q_{h} & =-\frac{\mu}{1-\mu}\left[\frac{1}{(h-\bar{h})} \frac{U}{b}\right]^{\frac{1}{1-\mu}} \\
Q_{b H} & =\frac{U}{b} \frac{\mu}{1-\mu}(h-\bar{h})^{-1} Q_{U} .
\end{aligned}
$$

Given (7), the expression (8) boils down to

$$
\Phi(x, \omega, U)=-Q_{H}(H, U / b(x)) .
$$


Using $Q_{H}$ defined above, we obtain the bid rent under Stone-Geary preferences:

$$
\Phi(x, \omega, U)=\frac{\mu}{1-\mu}(H-\bar{h})^{\frac{-1}{1-\mu}}\left(\frac{U}{b}\right)^{\frac{1}{1-\mu}} .
$$

Plugging $Q_{b}, Q_{b H}$ and $Q_{b U}$ into (A.2) and rearranging terms leads to

$$
\begin{aligned}
\Phi_{x \omega}\left(x, \omega, U^{*}(\omega)\right)= & \frac{t}{H}\left\{\frac{t_{x}}{t}\left[1-\frac{\omega}{H}\left(H_{\omega}+H_{U} U_{\omega}^{*}\right)\right]\right. \\
& +\frac{b_{x}}{b}\left[\frac{H_{\omega}+H_{U} U_{\omega}^{*}}{H}\left(-\frac{U}{t} Q_{U}\right)\left(\frac{h-(1-\mu) \bar{h}}{(1-\mu)(h-\bar{h})}\right)\right. \\
& \left.\left.+\frac{Q_{U}}{(1-\mu) t} U_{\omega}^{*}\right]\right\} .
\end{aligned}
$$

Plugging $Q_{h}$ and $Q$ in (7) and solving the corresponding equation yields

$$
\frac{h-(1-\mu) \bar{h}}{(1-\mu)(h-\bar{h})}=\omega t\left[\frac{b}{U}(h-\bar{h})^{\mu}\right]^{\frac{1}{1-\mu}} .
$$

Given the expression of $Q_{U}$, it turns out that

$$
\left(-\frac{U}{t} Q_{U}\right)\left[\frac{h-(1-\mu) \bar{h}}{(1-\mu)(h-\bar{h})}\right]=-\frac{\omega}{1-\mu} .
$$

Differentiating (8) with respect to $\omega$ and using (7), we obtain:

$$
\Phi_{\omega}\left(x, \omega, U^{*}(\omega)\right)=\frac{t}{H}\left(1-\frac{Q_{U}}{t} U_{\omega}^{*}\right)
$$

which is equal to 0 if

$$
U_{\omega}^{*}=\frac{t}{Q_{U}}
$$

Using (A.7) and (A.9), (A.5) can be rewritten as follows

$$
\Phi_{x \omega}\left(x, \omega, U^{*}(\omega)\right)=\frac{t}{H} \cdot\left[1-\frac{\omega}{H}\left(H_{\omega}+H_{U} U_{\omega}^{*}\right)\right] \cdot \frac{1}{1-\mu} \cdot\left[(1-\mu) \frac{t_{x}}{t}+\frac{b_{x}}{b}\right] .
$$

Applying the implicit function theorem to (A.6) yields

$$
H_{U}=\frac{(h-(1-\mu) \bar{h})(h-\bar{h})}{U \mu h}
$$

and

$$
H_{\omega}=-\frac{t(1-\mu)^{2}}{\mu h} U^{-\frac{1}{1-\mu}} b^{\frac{1}{1-\mu}}(h-\bar{h})^{1+\frac{1}{1-\mu}} .
$$

Given $Q_{U}$, (A.9) can be expressed as the following differential equation:

$$
U_{\omega}^{*}=t \cdot(1-\mu)\left[b \cdot(h-\bar{h})^{\mu}\right]^{\frac{1}{1-\mu}}\left(U^{*}(\omega)\right)^{-\frac{\mu}{1-\mu}} .
$$


We thus obtain

$$
H_{\omega}+H_{U} U_{\omega}^{*}=t \cdot(1-\mu)(h-\bar{h})\left[\frac{b}{U}(h-\bar{h})^{\mu}\right]^{\frac{1}{1-\mu}}
$$

Therefore, by implication of (A.6), we have:

$$
1-\frac{\omega}{H}\left(H_{\omega}+H_{U} U_{\omega}^{*}\right)=\frac{(1-\mu) \bar{h}}{h} .
$$

Substituting this expression into (A.10) yields:

$$
\Phi_{x \omega}\left(x, \omega, U^{*}(\omega)\right)=\frac{t}{H} \cdot \frac{\bar{h}}{H} \cdot[B-(1-\mu) T] .
$$

\section{A.4 Proof of Proposition 2}

The proof involves four steps.

(i) The bid-max lot size. From the definition of the LQI given by (16), i.e. $\Delta(x) \equiv$ $b(x)[t(x)]^{1-\mu},($ A.6) can be rewritten as follows:

$$
\frac{H-\bar{h}+\mu \bar{h}}{(1-\mu)(H-\bar{h})}=\omega \Delta^{\frac{1}{1-\mu}}\left[\frac{(H-\bar{h})^{\mu}}{U}\right]^{\frac{1}{1-\mu}} .
$$

The LHS of this expression is decreasing and tends to $\infty$ when $H \rightarrow \bar{h}$ and to $1 /(1-\mu)>0$ when $H \rightarrow \infty$. The RHS is increasing in $H$, tends to 0 when $H \rightarrow \bar{h}$ and to $\infty$ when $H \rightarrow \infty$. Therefore, (A.12), or equivalently (7), has a single solution $H(\omega t(x), U / b(x))$. In other words, the bid-max lot size is uniquely determined. It also follows from (A.12) that the bid-max lot size $H(\cdot)$ depends on $b(x)$ and $t(x)$ only through the LQI $\Delta(x)$, that is, $H(\omega t(x), U / b(x)) \equiv$ $H(\Delta(x), \omega, U)$.

Applying the implicit function theorem to (A.12) yields

$$
\frac{\partial H}{\partial \Delta}=-\left[U^{\frac{1}{1-\mu}}(H-\bar{h})^{-\frac{1}{1-\mu}-1} \frac{\mu H}{1-\mu}\right]^{-1} \omega \Delta^{\frac{\mu}{1-\mu}}<0 .
$$

(ii) Equilibrium utility level. Using the definition of the LQI, (A.11) implies that the equilibrium utility level is a solution to the following differential equation in $U^{*}$ :

$$
U_{\omega}^{*}=\Delta^{\frac{1}{1-\mu}}(1-\mu)(H-\bar{h})^{\frac{\mu}{1-\mu}}\left(U^{*}(\omega)\right)^{-\frac{\mu}{1-\mu}},
$$

so that $U^{*}(\omega)$ depends on $\Delta$ only. 
(iii) Supermodularity of the equilibrium utility level. Differentiating (A.14) w.r.t. $\Delta$, we obtain:

$$
\frac{\partial}{\partial \Delta} \frac{\mathrm{d} U^{*}}{\mathrm{~d} \omega}=\Delta^{\frac{\mu}{1-\mu}}(H-\bar{h})^{\frac{\mu}{1-\mu}}\left(U^{*}(\omega)\right)^{-\frac{\mu}{1-\mu}} \cdot\left[1+\mu \Delta(H-\bar{h})^{-1} \frac{\partial H}{\partial \Delta}\right] .
$$

Plugging (A.13) into this expression yields:

$$
\frac{\partial}{\partial \Delta} \frac{\mathrm{d} U^{*}}{\mathrm{~d} \omega}=\Delta^{\frac{\mu}{1-\mu}}(H-\bar{h})^{\frac{\mu}{1-\mu}}\left(U^{*}(\omega)\right)^{-\frac{\mu}{1-\mu}} \cdot\left[1-(H-\bar{h})^{\frac{1}{1-\mu}} \frac{(1-\mu) \omega \Delta^{\frac{1}{1-\mu}}}{\left(U^{*}(\omega)\right)^{\frac{1}{1-\mu}} H}\right] .
$$

It follows from (A.12) that the bracketed term of this expression is equivalent to

$$
1-(H-\bar{h})^{\frac{1}{1-\mu}} \frac{(1-\mu) \omega \Delta^{\frac{1}{1-\mu}}}{\left(U^{*}(\omega)\right)^{\frac{1}{1-\mu}} H}=(1-\mu) \frac{\bar{h}}{h}>0 .
$$

Therefore,

$$
\frac{\partial}{\partial \Delta} \frac{\mathrm{d} U^{*}}{\mathrm{~d} \omega}>0
$$

The Spence-Mirrlees condition thus holds, which implies the existence of a unique positive assortative matching between incomes and the values of the LQI. In other words, there is a unique one-to-one and increasing relationship between $\omega$ and $\Delta$ (Chiappori, 2017). Since a single value of $\Delta$ is associated with $x$, a unique value of $\omega$ must be associated with $x$. Hence, in equilibrium the households who reside at $x$ must have the same income, so that $\omega^{*}(x)$ is a mapping. Furthermore, there exists a unique residential equilibrium because $H\left(\Delta(x), \omega^{*}(x), U^{*}\left(\omega^{*}\right)\right)$ is univocally defined.

Note that the supermodularity of $U^{*}(\omega)$ is equivalent to the inequality $\Phi_{\omega \Delta}>0$. Indeed, differentiating (A.8) w.r.t. $\Delta$ and using (A.9) yield:

$$
\left.\Phi_{\omega \Delta}\left(x, \omega t(x), U^{*}(\omega)\right)\right|_{\Phi_{\omega}=0}=\frac{t}{H}\left[\frac{\partial\left(t / Q_{U}\right) / \partial \Delta}{U_{\omega}^{*}}\right]=\frac{t}{H} \frac{\partial U_{\omega}^{*} / \partial \Delta}{U_{\omega}^{*}}>0 .
$$

(iv) The equilibrium shares. Assume that there are $n \geq 2$ points $x_{1} \neq x_{2} \ldots \neq x_{n}$ exist such that $\Delta\left(x_{1}\right)=\Delta\left(x_{j}\right)$ for $j=2, \ldots, n$. Since $h^{*}\left(x, \omega^{*}(x)\right)=H\left[\Delta(x), \omega^{*}(x), U^{*}\left(\omega^{*}(x)\right)\right]$, the condition (4) may be rewritten as follows:

$$
s\left(x, \omega^{*}(x)\right) f\left(\omega^{*}(x)\right) H\left[\Delta(x), \omega^{*}(x), U^{*}\left(\omega^{*}(x)\right)\right]|\mathrm{d} \omega|=|\mathrm{d} x|, \quad \text { a.e. }
$$

Using (18), we get

$$
s\left(x, \omega^{*}(x)\right) H\left[\Delta(x), \omega^{*}(x), U^{*}\left(\omega^{*}(x)\right)\right] g(\Delta(x))\left|\frac{\mathrm{d} \Delta(x)}{\mathrm{d} x}\right|=1 \quad \text { a.e. }
$$

If $\omega^{*}\left(x_{1}\right)=\omega^{*}\left(x_{j}\right)$ for $j=2, \ldots, m$, then

$$
H\left[\Delta\left(x_{1}\right), \omega^{*}\left(x_{1}\right), U^{*}\left(\omega^{*}\left(x_{1}\right)\right)\right]=H\left[\Delta\left(x_{j}\right), \omega^{*}\left(x_{j}\right), U^{*}\left(\omega^{*}\left(x_{j}\right)\right)\right], \quad j=2, \ldots, n .
$$


Dividing the relationships (A.15) between themselves leads to

$$
\frac{s\left(x_{1}, \omega^{*}\left(x_{1}\right)\right)}{s\left(x_{k}, \omega^{*}\left(x_{k}\right)\right)}=\frac{\left|\mathrm{d} \Delta\left(x_{k}\right) / \mathrm{d} x_{k}\right|}{\left|\mathrm{d} \Delta\left(x_{1}\right) / \mathrm{d} x_{1}\right|}, \quad k=2, \ldots, n .
$$

Since $\sum_{j=1}^{m} s\left(x_{j}, \omega\right)=1$, the above system of equations has a unique solution given by

$$
s^{*}\left(x_{j}, \omega\right)=\frac{1}{\left[\sum_{k=1}^{n} \frac{1}{\mathrm{~d} \Delta\left(x_{k}\right) / \mathrm{d} x_{k} \mid}\right]} \cdot \frac{1}{\left|\mathrm{~d} \Delta\left(x_{j}\right) / \mathrm{d} x_{j}\right|}, \quad j=1, \ldots, n .
$$

\section{A.5 The land gradient}

Plugging $Q_{b}$ into (A.1) leads to

$$
\Phi_{x}\left(x, \omega, U^{*}(\omega)\right)=\frac{\omega t}{H}\left[\frac{U Q_{U}}{\omega t} B(x)-T(x)\right] .
$$

Substituting $t$ as given by (A.9), we obtain:

$$
R_{x}^{*}(x)=\Phi_{x}\left[x, \omega^{*}(x), U\left(\omega^{*}(x)\right)\right]=\frac{\omega^{*}(x) t}{H}\left[\frac{1}{\mathcal{E}_{U, \omega}} B(x)-T(x)\right], \quad \text { a.e. }
$$

Using (A.11) and (13), we have $\mathcal{E}_{U, \omega}(x)=\omega^{*}(x) t(x) /\left(\omega^{*}(x) t(x)-\bar{h} R^{*}(x)\right)>1$. Plugging this expression into $R_{x}^{*}(x)$ leads to

$$
R_{x}^{*}(x)=\frac{\omega^{*}(x) t}{H}\left[\left(1-\frac{\bar{h} R^{*}(x)}{\omega^{*}(x) t(x)}\right) B(x)-T(x)\right], \quad \text { a.e. }
$$

Given $(20)$ and $h^{*}\left(x, \omega^{*}(x)\right)=1 /\left[s\left(x, \omega^{*}(x)\right) g(\Delta(x))|\mathrm{d} \Delta / \mathrm{d} x|\right]$, we get

$$
R_{x}^{*}(x)=s\left(x, \omega^{*}(x)\right) g(\Delta(x))|\mathrm{d} \Delta / \mathrm{d} x| \omega^{*}(x) t(x)\left[\frac{1-s\left(x, \omega^{*}(x)\right) g(\Delta(x))|\mathrm{d} \Delta / \mathrm{d} x| \bar{h}}{1-(1-\mu) s\left(x, \omega^{*}(x)\right) g(\Delta(x))|\mathrm{d} \Delta / \mathrm{d} x| \bar{h}} B(x)-T(x)\right] \text {, a.e. }
$$

\section{Appendix B. Data}

In this appendix, we detail the construction of the various datasets. In Appendix B.1 we elaborate on how we calculate network distances and show the relationship with Euclidian distance. Appendix B.2 continues by explaining how we measure land prices and lot sizes for all locations. This is followed in Appendix B.3 by more information on our proxies for amenities: the picture density and the construction of the hedonic amenity index. In Appendix B.4 we introduce the historical data based on 1900 land use maps. Appendix B.5 reports distributions of the variables of interest. 


\section{B.1 Commuting and travel times}

To estimate the commuting time for each household, we use the tax register information, which provides information on individual jobs and the number of hours worked in each firm for each year. From the ABR Regio dataset, we get information on all firms which provide information on each establishment in the Netherlands, such as its exact location, the industrial sector, and the estimated number of employees in each establishment. Since we do not know the exact establishment, only the firm people work for, we assume that they work at the nearest establishment of the firm. This assumption may be problematic for firms having a large number of establishments (e.g., supermarkets or large banks). Therefore, we keep only firms with a maximum of 15 establishments throughout the Netherlands. As many such firms have establishments in different cities, it is reasonable to assume that people work in the nearest establishment. ${ }^{19}$ Overall, we are left with $95 \%$ of firms. To avoid miscoding and to exclude employment agencies (where people do not actually work), we consider establishments with no more than 10 thousand employees, which correspond to $0.1 \%$ of the total number of establishments and $1 \%$ of total employment. Hence, excluding those establishments is unlikely to affect our results.

We first calculate the commuting time from each home location $x$ to each job location $i$ for each year. Then, we determine the commuting time of each household by computing the average commuting time of each adult household member weighted by the number of hours (s)he worked. To calculate the travel time (as well as the time to travel to amenities) we obtain information on the street network from SpinLab, which provides information on average freeflow speeds per short road segment (the median length of a segment is $96 \mathrm{~m}$ ), which are usually lower than the speed limit.

The dataset from SpinLab provides information on free-flow driving speeds for every major street in the Netherlands. The actual speeds are usually well below the free-flow driving speeds, due to traffic lights, roundabouts and intersections. For each neighborhood we calculate the straight-line distance to the nearest access points on the network and then calculate the network distance. The median distance from an observation in the dataset to the nearest access point of the network is $195 \mathrm{~m}$ (the average is $326 \mathrm{~m}$ ). We assume that the average speed to get to the nearest access points is $10 \mathrm{~km} / \mathrm{h}$. This is the speed based on the Euclidian distance. In reality, the distance to get to the network will be higher because streets are usually curved. Hence, the assumption of $10 \mathrm{~km} / \mathrm{h}$ seems reasonable as the minimum speed on roads in the network is $20 \mathrm{~km} / \mathrm{h}$. Furthermore, because of the dominance of the bicycle, this would be close to the

\footnotetext{
${ }^{19}$ Alternatively, we could consider a distance-decay average of distances to the firm's establishments. Instead, we test robustness by keeping households that have only one working-member who works during the whole year in a single-establishment firm. This leads to nearly identical results.
} 
average cycling speed. Using these information, we calculate the total driving time, which is the sum of the driving time to access the network, the network driving time and the time it takes from the network to arrive at the destination. Alternatively, we calculate for each location pair the Euclidian distance and assume again an average speed of $10 \mathrm{~km} / \mathrm{h}$.

We also calculate the travel time using the train, using a similar approach. The median distance of each centroid to the nearest station is $5.25 \mathrm{~km}$. We then choose the minimum of the travel time over the road, using the train or taking the Euclidian travel time.

[Figure B.1 about here]

The correlation between travel time and Euclidian distance is modest $(\rho=0.643)$. For short distances $(<10 \mathrm{~km})$ the correlation is, however, much higher $(\rho=0.862)$. We plot the relationship between distance and travel time in Figure B.1A. This relationship is monotonic. Figure B.1B shows the share of commuting people who travel at most $\tau$ minutes, which we use to calculate employment accessibility in 1900.

\section{B.2 Land prices and lot sizes}

Information on land values and lot sizes is not directly available but may be inferred from data on home sales. We use information on home sales from NVM (The Dutch Association of Realtors), which comprises the large majority (about 75\%) of owner-occupied house transactions between 2003 and 2017. We know the transaction price, the lot size, inside floor space size (both in $\mathrm{m}^{2}$ ), the exact address, and a wide range of housing attributes such as house type, number of rooms, construction year, garden, state of maintenance, and whether a house is equipped with central heating. We make some selections to make sure that our results are not driven by outliers. First, we exclude transactions with prices that are above $€ 1$ million or below $€ 25,000$ and have a price per square meter which is above $€ 5,000$ or below $€ 500$. We also leave out transactions that refer to properties that are larger than $250 \mathrm{~m}^{2}$ or smaller than $25 \mathrm{~m}^{2}$, or have lot sizes above $5000 \mathrm{~m}^{2}$. These selections consist of less than $1 \%$ of the data and do not influence our results. We follow a similar procedure as Rossi-Hansberg et al. (2010), implying that we can only use information on residential properties with land. We are left with 1, 337, 445 housing transactions.

Let $\mathcal{P}(x)$ denote the house price in year $y, H(\tilde{x})$ the observed lot size and $C(\tilde{x})$ the housing characteristics of property $\tilde{x}$. The $\log$ land rent $R(x)$ is equal to the fixed effects at the level of the postcode (about 15-20 addresses), which we denote by $\varsigma(x)$, while $\vartheta(y)$ denote year $y$ fixed effects. We estimate:

$$
\log \frac{\mathcal{P}(\tilde{x}, y)}{H(\tilde{x}, y)}=\eta_{1} C(\tilde{x}, y)+\varsigma(x)+\vartheta(y)+\epsilon(\tilde{x}, y)
$$


where $\epsilon(\tilde{x}, y)$ is an i.i.d. error term that is assumed to be uncorrelated to land rents and housing characteristics, while $\eta_{1}$ are parameters to be estimated. As $\log R_{x}$ are given by the very local fixed effects, we do not impose any structure on how land rents $R_{x}$ vary across locations. For about $80 \%$ of the data we do not observe land prices directly, because either there were no multiple sales in our study period or because there is no owner-occupied housing in the respective postcode. We therefore also estimate the above equation with neighborhood fixed effects instead.

[Tables B.1 and B.2 about here]

Descriptive statistics for the housing sample are reported in Table B.1. Coefficients $\eta_{1}$ related to the housing attributes are reported in Table B.2. It appears that the house price per square meter of land is generally a bit lower when the property is larger. However, the house price per square meter of land of properties that are (semi-)detached is generally higher. Furthermore, when the maintenance state of a property is good, prices are about 502/1269= $40 \%$ higher. When a property has central heating, the price per square meter is about $5.1 \%$ higher. The dummies related to the construction decades show the expected signs. Properties constructed after World War II until 1970 generally have lower prices because this is a period associated with a lower building quality. Lot sizes are inversely related to pattern of land prices $(\rho=-0.245)$. In other words, more expensive locations generally have smaller lots, which makes sense.

\section{B.3 Amenities}

Picture density. Here we investigate whether there is a meaningful correlation between picture density and observed proxies for amenities. We gather data on the share of a neighborhood in a historic district, the density of listed buildings, as well as the share of the neighborhood occupied by buildings or water. We use similar specifications as reported in Table 2, but take the picture density as dependent variable. Table B.3 reports the results.

[Table B.3 about here]

In column (1) we regress picture density on our proxies for amenities. We find that a standard deviation increase in listed building density is associated with an increase in picture density of $8 \%$. When the share of the area in a historic district increases by 10 percentage points, this is associated with an increase in the picture density of $30 \%$. Hence, the impact of historic amenities on the revealed amenity level is large. The share of built-up land and water bodies in the neighborhood are also positively related to the picture density: a 10 percentage point increase in the share of built-up land or water bodies is associated with an increase in 
the picture density of about 33\%. In column (2) we include commuting time, demographic characteristics, housing attributes and travel-to-work-area fixed effects, leading to very similar estimates.

In column (3) we instrument for commuting time. We observe that commuting time does not seem to be statistically significantly correlated to the amenity level in a certain location. However, once we include job characteristics and workplace fixed effects, we find a weak relationship between commuting time and amenity level: a shorter commuting time is generally associated with a higher picture density. We think this makes sense as the most central locations generally provide a high amenity level and a somewhat better accessibility of jobs. However, we reiterate that this relationship is not statistically strong.

A hedonic amenity index. We test whether our results are robust to using an alternative hedonic amenity index, rather than relying on geocoded pictures. Following Lee and Lin (2018), we construct an aggregate amenity index that describes the amenity level in every neighborhood $x .{ }^{20}$ We will make a distinction between historic amenities and natural amenities.

Let $\mathcal{A}(\tilde{x})$ be a set of variables that describe amenities of property $\tilde{x}$ (so the location is more detailed than the neighborhood $x$ ). For example, we calculate the share of historic districts, the number of listed buildings, water bodies and open space within $500 \mathrm{~m}$ of each property. Let $\mathcal{P}(\tilde{x}, y)$ the house price, while $C(\tilde{x}, y)$ are housing characteristics of property $\tilde{x}$, and $\vartheta(y)$ are year $y$ fixed effects. We also include neighborhood fixed effects $\varsigma(x)$, and thus we identify the effects of amenities on prices within neighborhoods. Specifically, we estimate the following equation:

$$
\log \mathcal{P}(\tilde{x}, y)=\eta_{0} \mathcal{A}(\tilde{x})+\eta_{1} C(\tilde{x}, y)+\vartheta(y)+\varsigma(x)+\epsilon(\tilde{x}, y)
$$

where $\eta_{0}$ and $\eta_{1}$ are parameters to be estimated and $\epsilon(\tilde{x}, y)$ is an i.i.d. error term. We then use $\widehat{\eta}_{0}$ and $\mathcal{A}(\tilde{x})$ to predict the amenity level in each location $x$ in the Randstad:

$$
\tilde{b}(x)=\frac{1}{N(x)} \sum_{\tilde{x}=1}^{N_{x}} \widehat{\eta}_{0} \mathcal{A}(\tilde{x}),
$$

where $\tilde{b}(x)$ is the (alternative) amenity value at $x$ and $N(x)$ are the number of observations in neighborhood $x$. Hence, we take the mean amenity value of all locations $\tilde{x}$ within neighborhoods $x$.

We use data on the universe of housing transactions in the Netherlands between 2010 and 2015 from the NVM. Additional descriptive statistics of the $N V M$ data are reported in Table

\footnotetext{
${ }^{20}$ Albouy (2016) uses information on wages and housing costs to infer the level of amenities for U.S. cities. However, his approach is not applicable here because we are interested in intra-city variation in amenities and incomes.
} 
B.4. We have 695,709 observations and the average house price is $€ 229$ thousand.

[Tables B.4 and B.5 about here]

In Table B.5 we report the results of the regression of equation (B.3.1). We first investigate the impact of listed buildings. It can be seen that the share of historic districts leads to higher price. A 10 percentage point increase in the share of land designated as historic district increases prices by $1.8 \%$. Listed buildings do have a small additional effect of $0.5 \%$ per listed building. In column (2) we investigate the impact of water bodies and open space. For a 10 percentage point increase in water bodies, prices rise by $3 \%$. Moreover, a 10 percentage point increase in open space implies a price increases of $0.6 \%$, so this effect is considerably smaller. When we put historic amenities and natural amenities together, the coefficients are essentially unaffected. We consider this as our preferred specification.

\section{B.4 Historic data}

To instrument current amenity levels and commuting time we use information on land use, the railway network and amenities in 1900. For the 1900 land use maps, Knol et al. (2004) have scanned and digitized maps into 50 by 50 meter grids and classified these grids into 10 categories, including built-up areas, water, sand, and forest. We aggregate these 10 categories into builtup, open space and water bodies. Knol et al. document large changes in land use across the Netherlands from 1900 to 2000. For example, the total land used for buildings has increased more than fivefold. On the other hand, the amount of open space has decreased by about 10\%. We also use information on municipal population in 1900 from NLGIS. Municipalities were much smaller at that time and about the size of a large neighborhood nowadays. We impute the local population distribution using the location of buildings and assuming that the population per building is the same within each municipality. We further use information on railway stations from Koopmans et al. (2012). We enrich these data by adding missing stations from various sources on the internet and create a network with travel times. To approximate the speed, we fit a regression of the length of (current) railway segments between stations on current travel time on the railway network. Based on historic sources, it appears that the average speed is about $50 \%$ of what it is currently (about $70 \mathrm{~km} / \mathrm{h}$ ).

We show a map of land use and the railway network for the Netherlands in 1900 in Figure B.2. In Panel A it is shown that cities like Amsterdam, Rotterdam, The Hague, and Utrecht were already large in 1900. It can also be seen that some areas that have been reclaimed from the sea (e.g., to the northeast of Amsterdam) did not exist in 1900. The Panel B of Figure B.2 shows the railway network. In particular, places around Amsterdam and Utrecht have a high railway accessibility. The first railway line in the Netherlands was opened in 1839 between 
Amsterdam and Haarlem, soon followed by the openings of many other lines.

[Figure B.2 about here]

\section{B.5 Descriptive statistics}

We report descriptive statistics of the 10,213, 524 households of our sample in Table B.6.

[Table B.6 about here]

The average (median) yearly income is $€ 91,535$ (€86,732). The average land price in the sample is $€ 1,312$, but there are stark spatial differences. For example, in the capital Amsterdam, it is $€ 3,046$, while in the rural province of Friesland it is only $€ 716$. Incomes are approximately Fréchet distributed as shown in Figure B.3, where we report the distributions of the log of income and the log of land price. The distribution of land prices is somewhat positively skewed.

\section{[Figure B.3 about here]}

In Figure B.4 we show maps of income and land price distributions across the Netherlands. As expected, land prices are generally higher in cities. The pattern for incomes is less clear, but generally speaking we find that wealthier households locate close to or in cities.

[Figure B.4 about here]

As expected, the correlation between the estimated land price and lot size is negative ( $\rho=$ $-0.245)$. The average lot size is $364 \mathrm{~m}^{2}$. However, in Amsterdam it is only $253 \mathrm{~m}^{2}$, which corresponds to the higher land values in this city. About $15 \%$ of households occupy apartments and the correlation between occupying an apartment and the land price is positive $(\rho=0.153)$.

The picture density, i.e., the proxy for amenity endowments, range from 0 to 231 pictures per hectare. Only $0.2 \%$ of the households live in neighborhoods that do not have any pictures. We will disregard those households. The average picture density in Amsterdam (22.7) is much higher than in Rotterdam (9.63), The Hague (6.17), and Utrecht (7.66). Recall that we only use pictures outside a building taken by residents in determining the amenity index. It appears that $80 \%$ of the pictures are taken outside a building while about $60 \%$ of the pictures are taken by local residents. Going back to Table B.6, we see that the average commuting time is 26 minutes, which is very close to statistics provided by other sources (Department of Transport, Communications and Public Works, 2010). The unconditional correlation of picture density with income is close to zero $(\rho=0.0533)$, but this is not very informative as we do not control for household characteristics. The correlation of picture density with land prices is substantially higher $(\rho=0.431)$. Finally, households that have a short commute do not seem to live in 
high amenity locations as the correlation between picture density and commuting time is low $(\rho=-0.0454)$.

In Table B.7 we provide descriptives for all instruments. The average share of built-up area in 1900 was $4.3 \%$.

[Table B.7 about here] 


\section{Appendix C. Other empirical results and sensitivity}

This appendix reports various additional econometric results. First, we show first-stage results in Appendix C.1. Then we report bias-corrected estimates using Oster's (2019) methodology in Appendix C.2. We undertake additional robustness checks in Appendices C.3 and C.4.

\section{C.1 Pictures and amenities: the first-stage results}

We report first-stage estimates in Table C.1 related to the baseline results reported in Table 2 .

In columns (1) and (2) we focus on the impact on picture density. We find strong positive impact of share of built-up land in 1900 and share water in 1900 on current picture density. For example, when we include workplace and travel-to-work-area fixed effects in column (2), increasing the share of built-up land in 1900 by 10 percentage points in the neighborhood is associated with an increase in the picture density of $42 \%$. This makes sense: locations with many historic buildings are often locations which were already developed around 1900. The impact of water bodies is also positively correlated to the picture density, although the impact is somewhat smaller in magnitude: a 10 percentage point increase in the share of water in 1900 leads to an increase in the picture density of $9.9 \%$.

[Table C.1 about here]

In columns (3)-(4), Table C.1 we take commuting time as a dependent variable. The instruments for commuting time are relevant. We find a strong positive effect of the share of built-up land in 1900 between 500 and 1000m on accessibility. Likewise, employment accessibility in 1909 has a strong negative effect on current commuting time. More specifically, in column (4), doubling employment accessibility in 1909 is associated with an decrease in commuting times of $3.5 \%$.

\section{C.2 Bias-corrected estimates}

Many non-experimental papers use coefficient movements after the inclusion of control variables to investigate whether omitted variable bias is important. Oster (2019) argues that coefficient movements alone are not a sufficient statistic to calculate the bias. Instead, she argues that whether omitted variable bias is a concern depends on the variance of the added control variables, as well as coefficient movements. In other words, changes in the coefficient(s) of interest after adding controls should be scaled by the change in the $R^{2}$. Oster (2019) then derives an estimator to correct estimates for omitted variable bias under the assumption that the relationship between the variables of interest and unobservables can be recovered from the 
relationship between the variables of interest and observable control variables. In our context, this assumption makes sense as control variables that are added bear some potential relationship to unobservables. To be precise, we add many housing, demographic and job controls, as well as workplace and travel-to-work-area fixed effects, which are likely to be correlated to unobservables.

Oster (2019) then derives a GMM estimator to derive bias-corrected estimates of the impact of amenities and commuting time on incomes. There are two key input parameters that have to be determined. First, a parameter must be chosen that determines the relative degree of selection on observed and unobserved variables, which we denote by $\delta$. Although this parameter is fundamentally unknown, Altonji et al. (2005) and Oster (2019) show that $\delta=1$ is a reasonable (upper-bound) value. Second, there is the maximum $R^{2}$ from a hypothetical regression of income on amenities, commuting time and controls, which we denote as $R_{\max }^{2}$. Because of measurement error and random variation in incomes, $R_{\max }^{2}$ is usually well below 1 . Oster (2019) considers to set $R_{\text {max }}^{2}=\Pi \hat{R}^{2}$, where $\hat{R}^{2}$ is the $R^{2}$ obtained from the regression of log income on the variables of interest and all controls and fixed effects. She provides some evidence based on experimental studies that $\Pi \approx 1.3$. To be on the safe side, we consider $\Pi=1.5$ and $\Pi=2$. We report results in Table C.2

\section{[Table C.2 about here]}

In column (1) we consider $\Pi=1.5$. We find that the bias-corrected $\alpha_{1}=0.026$, which is virtually identical to the preferred estimate with historic instruments. The bias-adjusted impact of commuting time is now negative $\left(\alpha_{1}=-0.058\right)$, in line with instrumented estimates reported in Table 2. However, the magnitude is somewhat smaller: doubling commuting time attracts households whose incomes are $4 \%$ lower. However, when the hypothetical $R_{\max }^{2}$ is higher, so that it is twice the $R^{2}$ obtained from the regression of log income on the variables of interest and all controls and fixed effects $(\Pi=2)$, we see that the impact of commuting times becomes considerably stronger. The coefficient in column (2) indicates that a $100 \%$ increase in commuting time attracts households whose incomes are $31 \%$ lower, which is very much comparable to the baseline IV results. The impact of amenities with $\Pi=2$ is somewhat stronger: doubling the picture density attracts households whose incomes are $5.9 \%$ higher.

In column (3) of Table C.2 we further investigate whether these bias-adjusted estimates are robust to the inclusion of more detailed fixed effects. More specifically, we further include municipality fixed effects and assume $\Pi=1.5$. The impact of amenities is very similar to the result reported in column (1) (as well as the baseline result). The coefficient regarding commuting time is about twice as strong, but somewhat in between the results reported in columns (1) and (2). Overall, the results are robust.

In other words, although we do not know the 'true' value for $\Pi$, these results strongly 
suggest that the approach using historic instruments addresses omitted variable bias, as the bias-adjusted coefficients lead to very similar outcomes as the 2SLS estimates with historic instruments. We note that Oster's (2019) methodology does not account for measurement error in amenities or commuting time or reverse causality. It may, therefore, still be important to apply our instrumental variables strategy using historic instruments.

\section{C.3 Sensitivity: other checks}

Table C.3 reports the results of additional robustness checks. Our dataset contains observations on households. When calculating the commuting elasticity and when including workplace fixed effects, we calculate average commuting times based on working hours of different jobs of adults in the household. In column (1) we only include households that are associated with one job (location). This does not lead to significant differences in the outcomes.

Recall that we calculate the commuting time to the nearest plant when the firm has multiple establishments. We test whether this introduces error by only including households that are associated with one job in a single plant firm in column (2). In this way we address any measurement error in commuting time. Again, the estimates are very similar, although the number of observations is considerably lower.

[Table C.3 about here]

Our measure of commuting time relies on the minimum travel time by road and rail. However, in almost all cases travel time by car is shorter. To make sure that households actually consider this travel time, we only keep households having a company car in column (3). This does not change the results.

Column (4) replaces the dependent variable income by the share of adults in the household that have a college degree or more. We find very similar effects. For example, when the picture density doubles, this increases the share of highly educated households by 1.1 percentage points. Doubling commuting times decreases the share of highly educated households by 32.3 percentage points.

Column (5) tests whether the results are robust when using commuting time by rail instead of commuting time by road. The results are comparable.

Finally, in column (6), we only keep locations that are within $15 \mathrm{~km}$ of a city center with at least 100,000 inhabitants to make sure that our results are not driven by rural locations. We find that the coefficients are very similar, except that standard errors of the coefficients are considerably higher. Hence, including locations throughout the Netherlands has the benefit that it leads to more precise estimates. 


\section{C.4 Preferences for land}

Table C. 4 below reports the estimated values for $\mu$ given different assumptions on the discount rate and the minimum lot size.

[Table C.4 about here]

We show that with $\bar{h}=10 \mathrm{~m}^{2}$, and a discount rate of $3.5 \%$ (see Koster and Pinchbeck, 2021), $\hat{\mu}=0.1036$, which confirms that richer households spend less of their income on land (Albouy et al., 2016). Note that $\hat{\mu}$ may seem low, but we only include payments to land, not to housing itself. If we set $\bar{h}=25 \mathrm{~m}^{2}, \hat{\mu}=0.0955$, so it is hardly affected. We consider this to be the preferred estimate. When we increase the discount rate to $5 \%$, the estimates of $\hat{\mu}$ slightly increase to about 0.14 . 


\section{Appendix tables}

TAble B. 1 - Descriptives for $N V M$ Dataset

\begin{tabular}{|c|c|c|c|c|}
\hline & $\begin{array}{c}(1) \\
\text { mean }\end{array}$ & $\begin{array}{l}(2) \\
\text { sd }\end{array}$ & $\begin{array}{l}(3) \\
\text { min }\end{array}$ & $\begin{array}{l}(4) \\
\max \end{array}$ \\
\hline House price (in $€$ per $m^{2}$ ) & 1,269 & 927.2 & 25 & 25,000 \\
\hline Lot size $\left(\right.$ in $\left.m^{2}\right)$ & 445.7 & 1,189 & 25 & 25,000 \\
\hline Size of property $\left(\right.$ in $\left.m^{2}\right)$ & 132.4 & 45.16 & 26 & 538 \\
\hline Number of rooms & 4.944 & 1.363 & 0 & 25 \\
\hline Terraced property & 0.417 & 0.493 & 0 & 1 \\
\hline Semi-detached property & 0.370 & 0.483 & 0 & 1 \\
\hline Detached property & 0.189 & 0.392 & 0 & 1 \\
\hline Private parking space & 0.454 & 0.498 & 0 & 1 \\
\hline Garage & 0.394 & 0.489 & 0 & 1 \\
\hline Garden & 0.966 & 0.182 & 0 & 1 \\
\hline Number of bathrooms & 0.929 & 0.483 & 0 & 8 \\
\hline Number of kitchens & 0.677 & 0.484 & 0 & 5 \\
\hline Number of balconies & 0.132 & 0.354 & 0 & 4 \\
\hline Number of roof terraces & 0.0674 & 0.257 & 0 & 3 \\
\hline Number of floors & 2.717 & 0.636 & 1 & 13 \\
\hline Internal office space & 0.00444 & 0.0665 & 0 & 1 \\
\hline Maintenance score of the outside & 0.758 & 0.131 & 0 & 1 \\
\hline Maintenance score of the inside & 0.753 & 0.143 & 0 & 1 \\
\hline Number of types of insulation & 2.381 & 1.831 & 0 & 5 \\
\hline Central heating & 0.920 & 0.271 & 0 & 1 \\
\hline Listed building & 0.00652 & 0.0805 & 0 & 1 \\
\hline Newly built property & 0.0417 & 0.200 & 0 & 1 \\
\hline Construction year & 1,967 & 34.95 & 1,362 & 2,017 \\
\hline Year of observation & 2,011 & 4.389 & 2,004 & 2,017 \\
\hline
\end{tabular}

Notes: The number of observations is $1,337,495$. Because of confidentiality restrictions the minimum and maximum values refer to the $0.01 \%$ and $99.99 \%$ percentile. This implies that we exclude the bottom and top observations 
TABLE B.2 - EstimATING LAND PRICES AND LOT SIZES

(Dependent variable: the log of land price per $m^{2}$

\begin{tabular}{|c|c|}
\hline & $(1)$ \\
\hline Rooms & $\begin{array}{c}-6.1664^{* * *} \\
(0.4506)\end{array}$ \\
\hline Terraced property & $\begin{array}{c}702.4875^{* * *} \\
(6.5087)\end{array}$ \\
\hline Semi-detached property & $\begin{array}{c}510.0447^{* * *} \\
(6.5516)\end{array}$ \\
\hline Detached property & $\begin{array}{c}360.7740 * * * \\
(6.7580)\end{array}$ \\
\hline Private parking space & $\begin{array}{c}-56.3558^{* * *} \\
(1.9988)\end{array}$ \\
\hline Garage & $\begin{array}{c}-42.8166^{* * *} \\
(2.0556)\end{array}$ \\
\hline Garden & $\begin{array}{c}47.5907^{* * *} \\
(2.8356)\end{array}$ \\
\hline Number of bathrooms & $\begin{array}{c}17.3274^{* * *} \\
(0.9885)\end{array}$ \\
\hline Number of kitchens & $\begin{array}{c}-7.2575^{* * *} \\
(1.0818)\end{array}$ \\
\hline Number of balconies & $\begin{array}{c}47.8147^{* * *} \\
(1.5204)\end{array}$ \\
\hline Number of roof terraces & $\begin{array}{c}109.0801^{* * *} \\
(1.8878)\end{array}$ \\
\hline Number of floors & $\begin{array}{c}94.9407^{* * *} \\
(1.0148)\end{array}$ \\
\hline (Internal) office space & $\begin{array}{c}-55.3454^{* * *} \\
(6.3595)\end{array}$ \\
\hline Maintenance score of the outside & $\begin{array}{c}29.5137^{* * *} \\
(6.3366)\end{array}$ \\
\hline Maintenance score of the inside & $\begin{array}{c}501.7345^{* * *} \\
(5.8143)\end{array}$ \\
\hline Number of types of insulation & $\begin{array}{c}8.3945^{* * *} \\
(0.3138)\end{array}$ \\
\hline Central heating & $\begin{array}{c}65.8404^{* * *} \\
(1.7719)\end{array}$ \\
\hline Listed building & $\begin{array}{c}27.9334^{* * *} \\
(6.2691)\end{array}$ \\
\hline Newly built property & $\begin{array}{c}-13.3758^{* * *} \\
(4.3108)\end{array}$ \\
\hline $3^{\text {th }}$-order polynomial of property size & Yes \\
\hline Construction decade dummies & Yes \\
\hline Year fixed effects & Yes \\
\hline Postcode fixed effects & Yes \\
\hline Observations & $1,280,031$ \\
\hline$R^{2}$ & 0.8295 \\
\hline
\end{tabular}


TABle B.3 - Picture Density And Amenities

(Dependent variable: the log of household gross income)

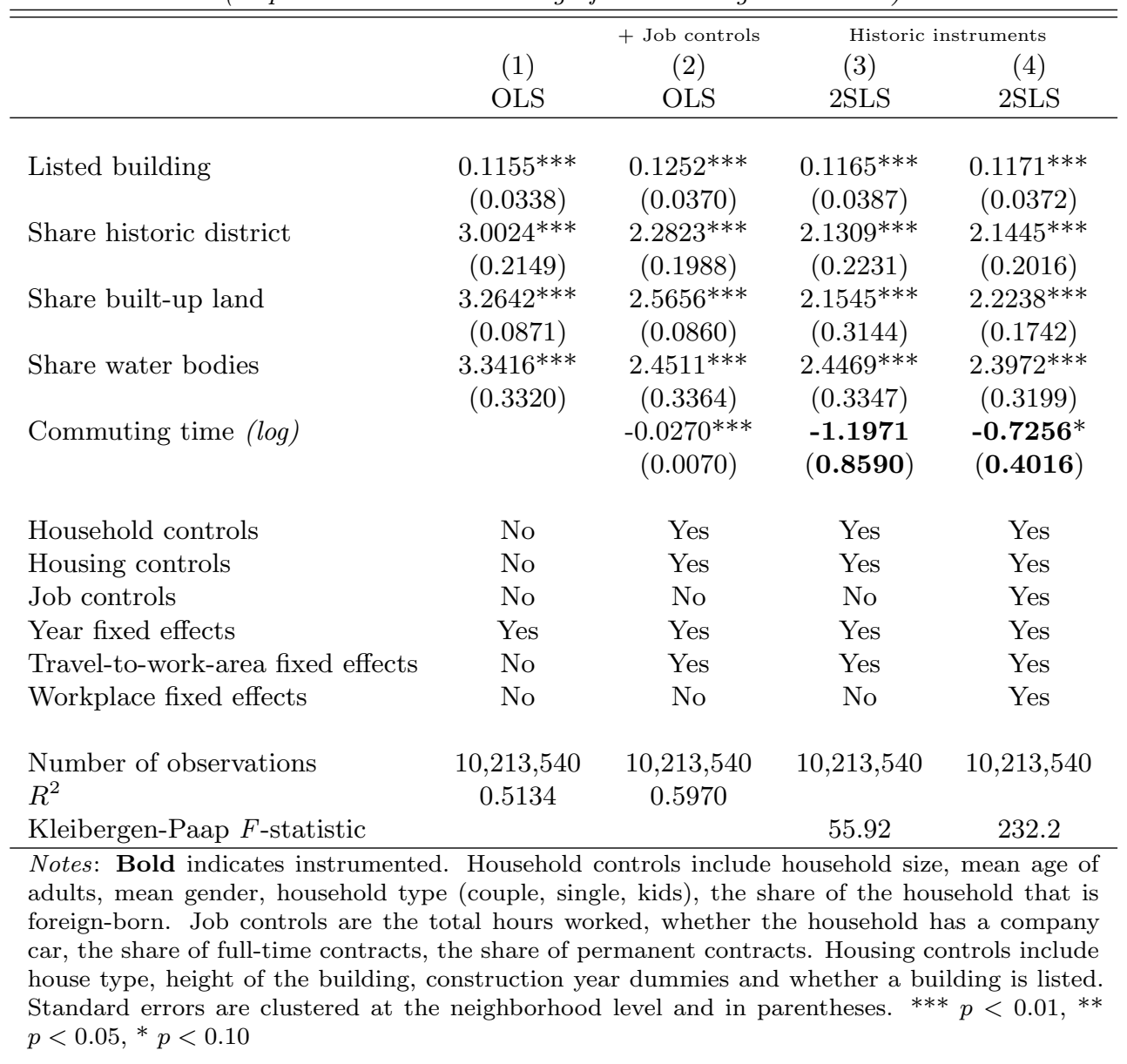

TABle B. 4 - Other DESCRIPTIVE STATistics FOR NVM DATA

\begin{tabular}{lcccc}
\hline \hline & $(1)$ & $(2)$ & $(3)$ & $(4)$ \\
& mean & sd & min & $\max$ \\
\hline & & & & \\
House price $($ in $€$ ) & 229,238 & 116,074 & 25,000 & $1,000,000$ \\
Share land in historic district $<500 \mathrm{~m}$ & 0.0695 & 0.192 & 0 & 1 \\
Listed buildings $<500 \mathrm{~m}$ & 0.179 & 0.894 & 0 & 19.53 \\
Share water bodies $<500 \mathrm{~m}$ & 0.0411 & 0.0713 & 0 & 0.920 \\
Share open space $<500 \mathrm{~m}$ & 0.244 & 0.217 & 0 & 1 \\
Shops, <500m & 0.254 & 0.394 & 0 & 4.711 \\
Hotels, restaurants, cafés $<500 \mathrm{~m}$ & 0.159 & 0.364 & 0 & 7.983 \\
Leisure establishments $<500 \mathrm{~m}$ & 0.0127 & 0.0215 & 0 & 0.318 \\
& & & & \\
\hline
\end{tabular}

Notes: The number of observations is 695,709 . Because of confidentiality restrictions the minimum and maximum values refer to the $0.01 \%$ and $99.99 \%$ percentile. This implies that we exclude the bottom and top 70 observations. 
TABle B.5 - Determining The HeDonic AMEnity IndeX (Dependent variable: the log of house price per $m^{2}$ )

\begin{tabular}{|c|c|c|c|}
\hline & $\begin{array}{l}(1) \\
\text { OLS }\end{array}$ & $\begin{array}{l}(2) \\
\text { OLS }\end{array}$ & $\begin{array}{c}(3) \\
\text { OLS }\end{array}$ \\
\hline Share land in historic district $<500 \mathrm{~m}$ & $\begin{array}{c}0.1796^{* * *} \\
(0.0210)\end{array}$ & & $\begin{array}{c}0.1710^{* * * *} \\
(0.0204)\end{array}$ \\
\hline Listed buildings $<500 \mathrm{~m}$ & $\begin{array}{r}0.0047^{* *} \\
(0.0024)\end{array}$ & & $\begin{array}{c}0.0052^{* *} \\
(0.0024)\end{array}$ \\
\hline Share water bodies $<500 \mathrm{~m}$ & & $\begin{array}{c}0.3014^{* * *} \\
(0.0255)\end{array}$ & $\begin{array}{c}0.2824^{* * * *} \\
(0.0253)\end{array}$ \\
\hline Share open space $<500 \mathrm{~m}$ & & $\begin{array}{c}0.0604^{* * *} \\
(0.0084)\end{array}$ & $\begin{array}{c}0.0636^{* * *} \\
(0.0084)\end{array}$ \\
\hline Housing controls & Yes & Yes & Yes \\
\hline Neighborhood fixed effects & Yes & Yes & Yes \\
\hline Year fixed effects & Yes & Yes & Yes \\
\hline Number of observations & 695,709 & 695,709 & 695,709 \\
\hline$R^{2}$ & 0.8206 & 0.8207 & 0.8217 \\
\hline
\end{tabular}

TABle B.6 - Descriptive StATistics

\begin{tabular}{lcccc}
\hline \hline & $(1)$ & $(2)$ & $(3)$ & $(4)$ \\
& mean & sd & min & max \\
\hline & & & & \\
Gross income $($ in $€)$ & 91,535 & 53,683 & 3,589 & 999,897 \\
Land price $\left(€\right.$ per $\left.m^{2}\right)$ & 1,312 & 752.2 & 0.00753 & 22,418 \\
Lot size $\left(m^{2}\right)$ & 364.3 & 923.8 & 25 & 24,824 \\
Pictures per ha & 2.189 & 8.840 & 0 & 231.9 \\
Commuting time in minutes & 26.39 & 17.18 & 0 & 120.0 \\
Hedonic amenity index & 2.821 & 0.0915 & 2.723 & 3.885 \\
Share historic district & 0.0347 & 0.139 & 0 & 1 \\
Listed building & 0.0941 & 0.699 & 0 & 17.06 \\
Share built-up land & 0.449 & 0.298 & 0.000856 & 1 \\
Share water & 0.0496 & 0.0738 & 0 & 0.813 \\
Total hours worked in household & 2,159 & 913.1 & 416.1 & 6,239 \\
Household has company car & 0.149 & 0.356 & 0 & 1 \\
Works at single-establishment firm & 0.443 & 0.497 & 0 & 1 \\
Number of jobs in household & 1.511 & 0.968 & 1 & 18 \\
Person is male & 0.521 & 0.215 & 0 & 1 \\
Person is foreigner & 0.0718 & 0.217 & 0 & 1 \\
Age of person & 41.99 & 9.008 & 18 & 64 \\
Apartment & 0.153 & 0.360 & 0 & 1 \\
House built <1945 & 0.192 & 0.394 & 0 & 1 \\
& & & & \\
\hline
\end{tabular}

Notes: The number of observations is 10,213,540. For land price and lot size the number of observations is 2,196,280. Because of confidentiality restrictions the minimum and maximum values refer to the $0.01 \%$ and $99.99 \%$ percentile. This implies that we exclude the bottom and top 1,024 observations. 
TABle B.7 - Descriptive STATISTICS FOR HISTORIC DATA

\begin{tabular}{lcccc}
\hline \hline & $(1)$ & $(2)$ & $(3)$ & $(4)$ \\
& mean & sd & min & max \\
\hline & & & & \\
Employment accessibility in 1909 & 38,029 & 23,884 & 1,494 & 163,349 \\
Share of high-skilled workers in 1909 & 0.0298 & 0.0285 & 0 & 0.197 \\
Share of medium-skilled workers in 1909 & 0.216 & 0.128 & 0.00386 & 0.688 \\
Population accessibility in 1900 & 89,184 & 62,641 & 3,008 & 422,544 \\
Share built-up land in 1900 & 0.0432 & 0.103 & 0 & 0.930 \\
Share water in 1900 & 0.0591 & 0.175 & 0 & 1 \\
Share locals in 1899 & 0.643 & 0.102 & 0.217 & 0.950 \\
Share protestants in 1899 & 0.518 & 0.337 & 0 & 0.998
\end{tabular}

Notes: The number of observations is $10,213,540$. Because of confidentiality restrictions the minimum and maximum values refer to the $0.01 \%$ and $99.99 \%$ percentile. This implies that we exclude the bottom and top 1,024 observations

TABle C.1 - PiCtures AND COMMUting time: First-STAGe REgression RESUlts

\begin{tabular}{|c|c|c|c|c|}
\hline & \multicolumn{2}{|c|}{$\begin{array}{c}\text { Dependent variable: } \\
\text { the log of pictures per ha }\end{array}$} & \multicolumn{2}{|c|}{$\begin{array}{c}\text { Dependent variable: } \\
\text { the log of commuting time }\end{array}$} \\
\hline & $\begin{array}{l}(1) \\
\text { OLS }\end{array}$ & $\begin{array}{l}(2) \\
\text { OLS }\end{array}$ & $\begin{array}{l}(3) \\
\text { OLS }\end{array}$ & $\begin{array}{l}(4) \\
\text { OLS }\end{array}$ \\
\hline Share built-up land in 1900 & $\begin{array}{c}4.2960^{* * * *} \\
(0.3192)\end{array}$ & $\begin{array}{c}4.2413 * * * \\
(0.3075)\end{array}$ & $\begin{array}{c}-0.3319^{* * *} \\
(0.0364)\end{array}$ & $\begin{array}{c}-0.3119^{* * *} \\
(0.0348)\end{array}$ \\
\hline Share built-up land in $1900,0-500 \mathrm{~m}$ & $\begin{array}{l}0.6415 \\
(1.2821)\end{array}$ & $\begin{array}{c}0.7537 \\
(1.2279)\end{array}$ & $\begin{array}{c}0.3573^{* *} \\
(0.1483)\end{array}$ & $\begin{array}{c}0.2261 \\
(0.1482)\end{array}$ \\
\hline Share built-up land in $1900,500-1000 \mathrm{~m}$ & $\begin{array}{c}7.2817^{* * * *} \\
(1.4426)\end{array}$ & $\begin{array}{c}6.5271^{* * *} \\
(1.3754)\end{array}$ & $\begin{array}{c}-1.0300^{* * *} \\
(0.1837)\end{array}$ & $\begin{array}{c}-1.1923^{* * *} \\
(0.1869)\end{array}$ \\
\hline Share water in 1900 & $\begin{array}{c}0.8896^{* * * *} \\
(0.3413)\end{array}$ & $\begin{array}{c}0.9869^{* * *} \\
(0.3222)\end{array}$ & $\begin{array}{c}0.1885^{* * *} \\
(0.0452)\end{array}$ & $\begin{array}{c}0.1601 * * * \\
(0.0402)\end{array}$ \\
\hline Employment accessibility in 1909 (log) & $\begin{array}{c}0.1472^{* *} \\
(0.0593)\end{array}$ & $\begin{array}{c}0.1624^{* * *} \\
(0.0569)\end{array}$ & $\begin{array}{c}-0.0353^{* * *} \\
(0.0084)\end{array}$ & $\begin{array}{c}-0.0499^{* * *} \\
(0.0096)\end{array}$ \\
\hline Household controls & Yes & Yes & Yes & Yes \\
\hline Housing controls & Yes & Yes & Yes & Yes \\
\hline Job controls & No & Yes & No & Yes \\
\hline Year fixed effects & Yes & Yes & Yes & Yes \\
\hline Travel-to-work-area fixed effects & Yes & Yes & Yes & Yes \\
\hline Workplace fixed effects & No & Yes & No & Yes \\
\hline Number of observations & $10,213,540$ & $10,213,540$ & $10,213,540$ & $10,213,540$ \\
\hline$R^{2}$ & 0.4907 & 0.5291 & 0.0357 & 0.1496 \\
\hline
\end{tabular}


TABle C. 2 - Bias Corrected estimates (Dependent variable: the log of household gross income)

\begin{tabular}{|c|c|c|c|}
\hline & \multicolumn{2}{|c|}{$\begin{array}{l}\text { Travel-to-work-area } \\
\text { fixed effects }\end{array}$} & \multirow{2}{*}{$\begin{array}{c}\begin{array}{c}\text { Municipality } \\
\text { fixed effects }\end{array} \\
(3) \\
\text { Bias-adj }\end{array}$} \\
\hline & $\begin{array}{c}(1) \\
\text { Bias-adj }\end{array}$ & $\begin{array}{c}(2) \\
\text { Bias-adj }\end{array}$ & \\
\hline Pictures per ha $(\log )$ & $\begin{array}{c}0.0255^{* * *} \\
(0.0026)\end{array}$ & $\begin{array}{l}0.0850^{*} \\
(0.0497)\end{array}$ & $\begin{array}{c}0.0289 * * \\
(0.0111)\end{array}$ \\
\hline Commuting time (log) & $\begin{array}{c}-0.0585^{* * *} \\
(0.0040)\end{array}$ & $\begin{array}{c}-0.445^{* * *} \\
(0.0306)\end{array}$ & $\begin{array}{c}-0.112^{* * *} \\
(0.0068)\end{array}$ \\
\hline Household controls & Yes & Yes & Yes \\
\hline Housing controls & Yes & Yes & Yes \\
\hline Job controls & Yes & Yes & Yes \\
\hline Year fixed effects & Yes & Yes & Yes \\
\hline Travel-to-work-area fixed effects & Yes & Yes & Yes \\
\hline Municipality fixed effects & No & No & Yes \\
\hline Workplace fixed effects & Yes & Yes & Yes \\
\hline$\delta$ & 1.0 & 1.0 & 1.0 \\
\hline$\Pi$ & 1.5 & 2.0 & 1.5 \\
\hline Number of observations & $10,213,540$ & $10,213,540$ & $10,213,540$ \\
\hline \multicolumn{4}{|c|}{$\begin{array}{l}\text { Notes: Household controls include household size, mean age of adults, mean } \\
\text { gender, household type (couple, single, kids), the share of the household that is } \\
\text { foreign-born. Job controls are the total hours worked, whether the household has } \\
\text { a company car, the share of full-time contracts, the share of permanent contracts. } \\
\text { Housing controls include house type, height of the building, construction year } \\
\text { dummies and whether a building is listed. Standard errors are clustered at the } \\
\text { neighborhood level and in parentheses. }{ }^{* * *} p<0.01,{ }^{* *} p<0.05,{ }^{*} p<0.10\end{array}$} \\
\hline
\end{tabular}


TABLE C. 3 - OTher ROBUSTNESS CHECKS

\begin{tabular}{|c|c|c|c|c|c|c|}
\hline & $\begin{array}{c}\text { One job } \\
\text { households }\end{array}$ & $\begin{array}{l}+ \text { Single } \\
\text { plant firm }\end{array}$ & $\begin{array}{c}\text { Company } \\
\text { car }\end{array}$ & $\begin{array}{c}\text { Education } \\
\text { level }\end{array}$ & $\begin{array}{c}\text { Commuting } \\
\text { by rail }\end{array}$ & $\begin{array}{l}\text { City center } \\
<15 \mathrm{~km}\end{array}$ \\
\hline & $\begin{array}{c}(1) \\
2 S L S \\
\end{array}$ & $\begin{array}{c}(2) \\
2 S L S \\
\end{array}$ & $\begin{array}{c}(3) \\
2 S L S \\
\end{array}$ & $\begin{array}{c}(4) \\
2 \text { SLS } \\
\end{array}$ & $\begin{array}{c}(5) \\
2 \text { SLS } \\
\end{array}$ & $\begin{array}{c}(6) \\
2 S L S \\
\end{array}$ \\
\hline Pictures per ha (log) & $\begin{array}{c}0.0239 * * * \\
(0.0065)\end{array}$ & $\begin{array}{c}0.0230^{* * *} \\
(0.0068)\end{array}$ & $\begin{array}{c}0.0207^{* *} \\
(0.0085)\end{array}$ & $\begin{array}{l}0.0165^{*} \\
(0.0090)\end{array}$ & $\begin{array}{c}0.0294^{* * *} \\
(0.0061)\end{array}$ & $\begin{array}{c}0.0229 * \\
(0.0119)\end{array}$ \\
\hline Commuting time (log) & $\begin{array}{c}-0.2127^{* * *} \\
(0.0643)\end{array}$ & $\begin{array}{c}-0.1869^{* * *} \\
(0.0691)\end{array}$ & $\begin{array}{c}-0.2285^{* *} \\
(0.1009)\end{array}$ & $\begin{array}{c}-0.4740^{* * *} \\
(0.0927)\end{array}$ & & $\begin{array}{c}-0.3173^{* *} \\
(0.1440)\end{array}$ \\
\hline Commuting time by rail (log) & & & & & $\begin{array}{c}-0.1045^{* *} \\
(0.0454)\end{array}$ & \\
\hline Household controls & Yes & Yes & Yes & Yes & Yes & Yes \\
\hline Housing controls & Yes & Yes & Yes & Yes & Yes & Yes \\
\hline Job controls & Yes & Yes & Yes & Yes & Yes & Yes \\
\hline Year fixed effects & Yes & Yes & Yes & Yes & Yes & Yes \\
\hline Travel-to-work-area fixed effects & Yes & Yes & Yes & Yes & Yes & Yes \\
\hline Workplace fixed effects & Yes & Yes & Yes & Yes & Yes & Yes \\
\hline Number of observations & $6,706,524$ & $3,532,906$ & $1,523,567$ & $7,626,355$ & $10,213,540$ & $6,023,886$ \\
\hline Kleibergen-Paap $F$-statistic & 17.63 & 14.56 & 7.026 & 17.02 & 10.15 & 5.657 \\
\hline
\end{tabular}

Notes: Bold indicates instrumented. The dependent variable in columns (1)-(3) and (5)-(6) is the log of gross yearly income. In column (4) it is the share of the adults in the household that has a bachelor's degree or higher. Household controls include household size, mean age of adults, mean gender, household type (couple, single, kids), the share of the household that is foreignborn. Job controls are the total hours worked, whether the household has a company car, the share of full-time contracts, the share of permanent contracts. Housing controls include house type, height of the building, construction year dummies and whether a building is listed. Standard errors are clustered at the neighborhood level and in parentheses. ${ }^{* * *} p<0.01,{ }^{* *}$ $p<0.05,{ }^{*} p<0.10$

TABle C.4 - PReferences FOR LAND

(Dependent variable: the log of land price)

\begin{tabular}{|c|c|c|c|c|}
\hline & $\begin{array}{c}(1) \\
\text { NLS }\end{array}$ & $\begin{array}{c}(2) \\
\text { NLS }\end{array}$ & $\begin{array}{c}(3) \\
\text { NLS }\end{array}$ & $\begin{array}{c}(4) \\
\text { NLS }\end{array}$ \\
\hline$\hat{\mu}$ & $\begin{array}{c}0.1036^{* * *} \\
(0.0003)\end{array}$ & $\begin{array}{c}0.0955^{* * *} \\
(0.0003)\end{array}$ & $\begin{array}{c}0.1485^{* * *} \\
(0.0004)\end{array}$ & $\begin{array}{c}0.1375^{* * *} \\
(0.0005)\end{array}$ \\
\hline Discount rate & 0.035 & 0.035 & 0.050 & 0.050 \\
\hline Minimum lot size, $\bar{h}$ & 10 & 25 & 10 & 25 \\
\hline Number of observations & $2,201,524$ & $2,201,524$ & $2,201,524$ & $2,201,524$ \\
\hline
\end{tabular}




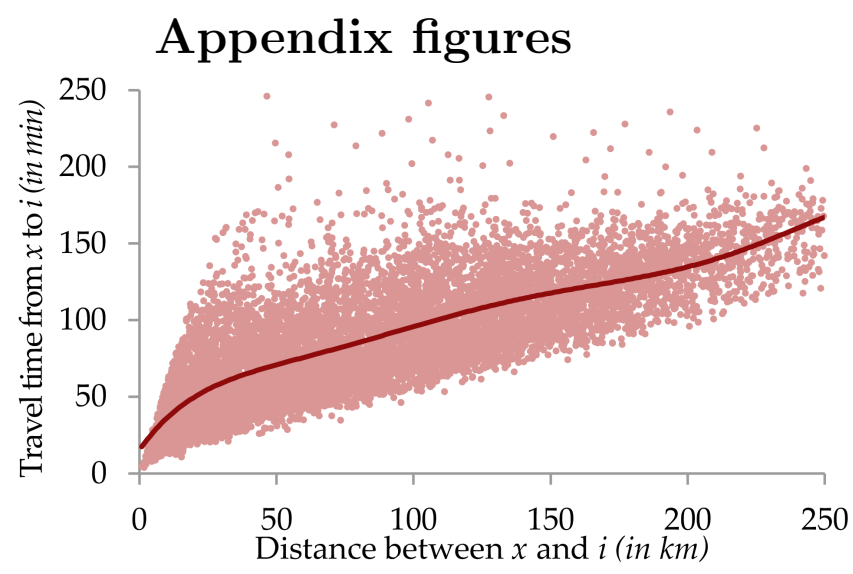

(a) Distance and travel time

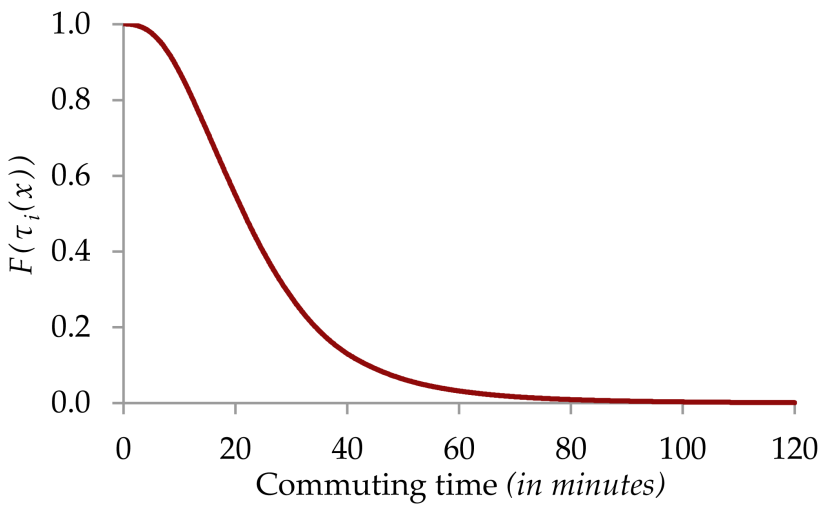

(B) Commuting time Distribution

Figure B.1 - Calculation of travel time AND SPEed

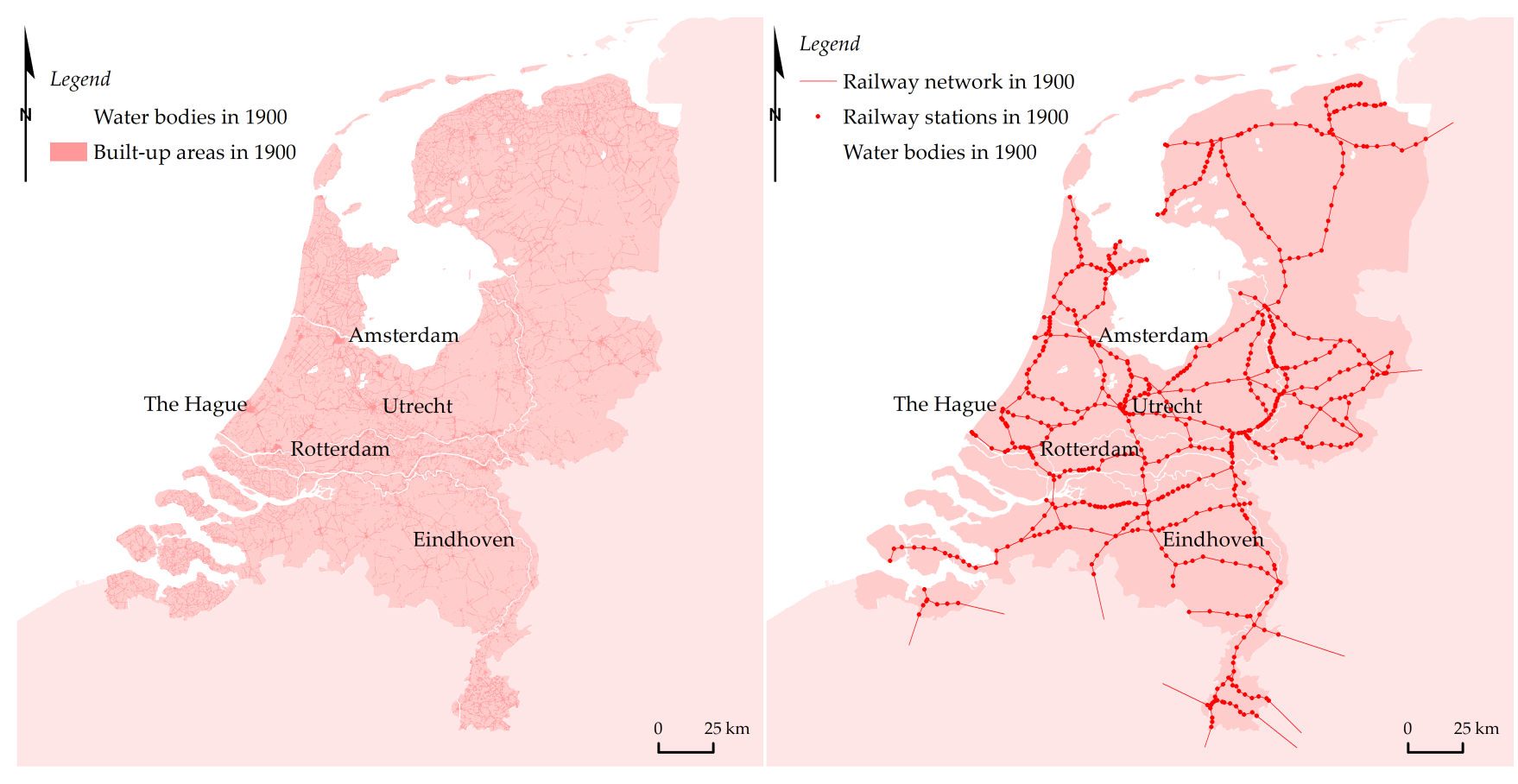

(A) BUILT-UP LAND

(B) The RAILWAY NETWORK AND ACCESSIBILITY

Figure B.2 - Historic DATA From 1900 


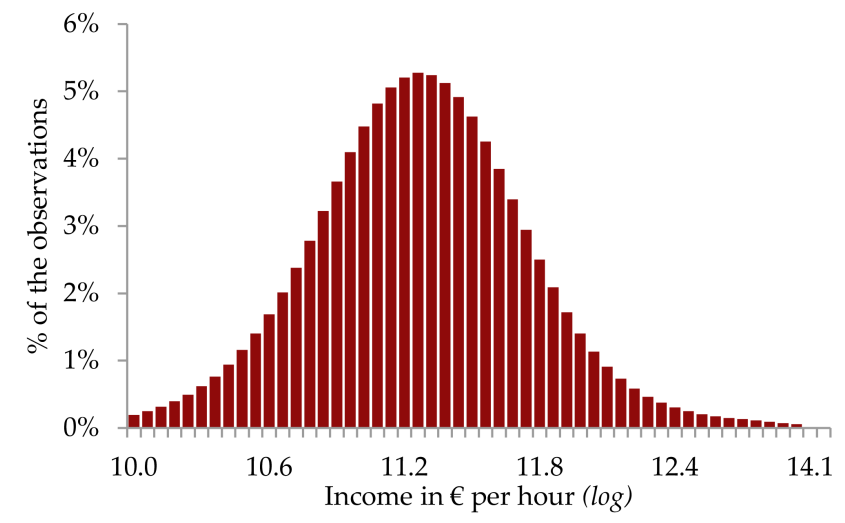

(A) INCOMES

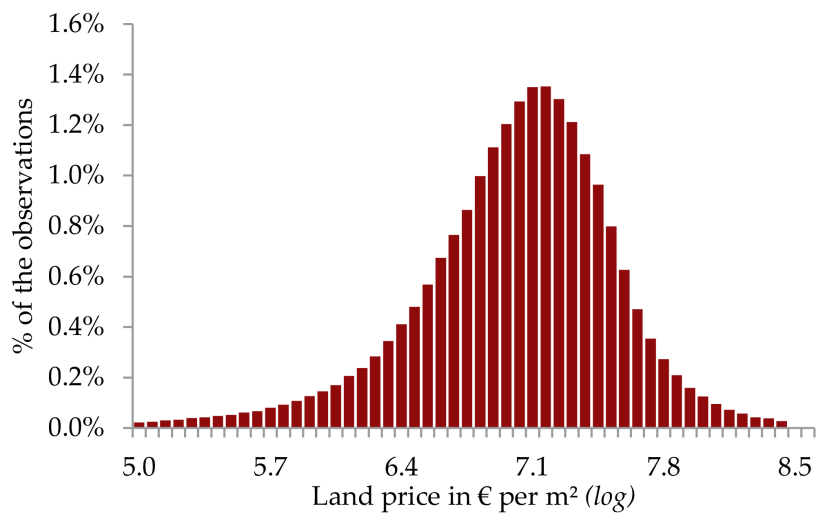

(B) LAND PRICES

Figure B.3 - Histograms FOR the VARIABles OF INTEREST

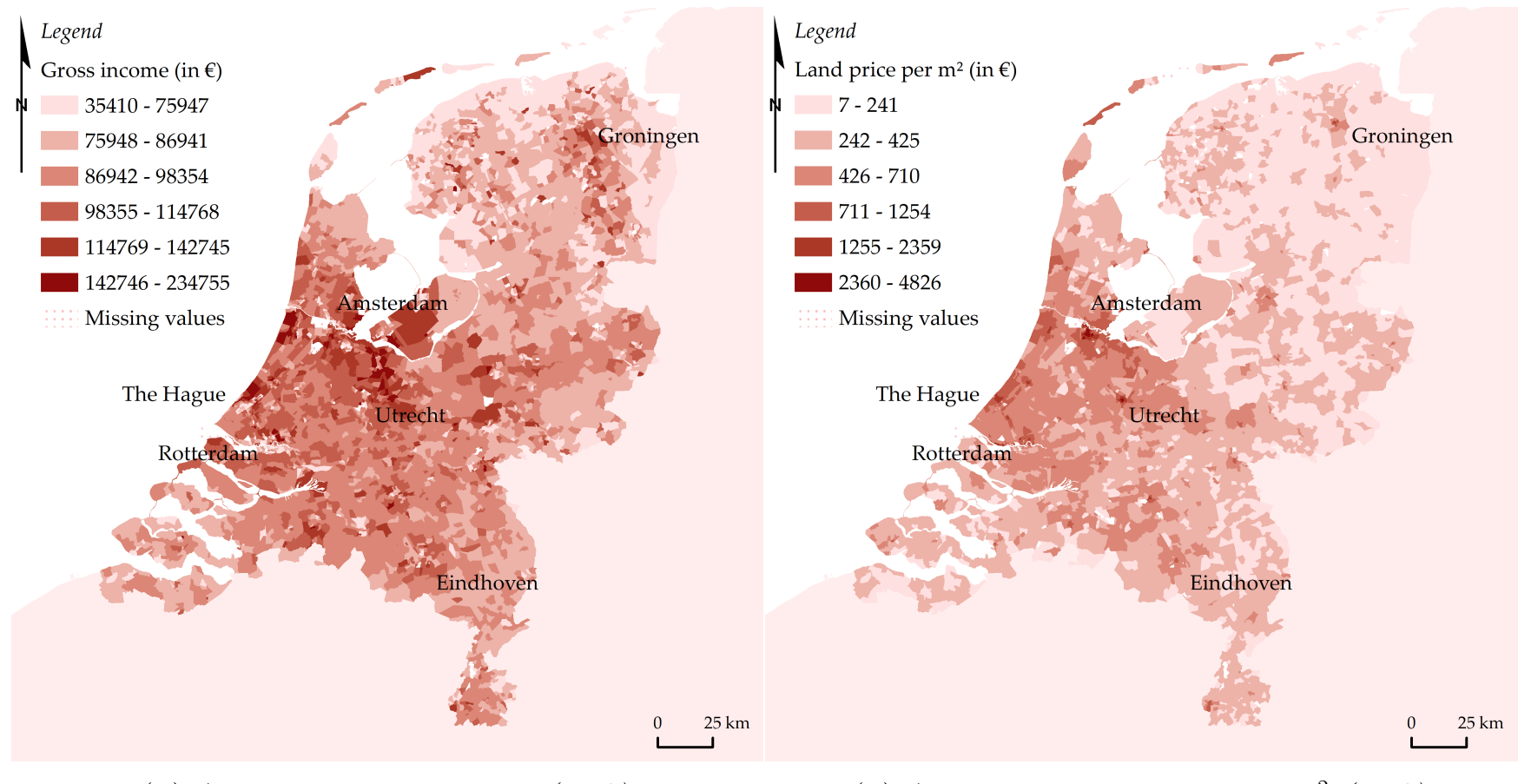

(A) Average gross income (in €)

(B) Average Land PRICES PER $\mathrm{M}^{2}$ (in €) Figure B.4 - Spatial Distribution of VARIABles of INTEREST 